\title{
Parental Perception of Their Child's Weight Status and Food Provision and Consumption Patterns in Appalachia
}

Jill Cochran

West Virginia University

Follow this and additional works at: https://researchrepository.wvu.edu/etd

\section{Recommended Citation}

Cochran, Jill, "Parental Perception of Their Child's Weight Status and Food Provision and Consumption Patterns in Appalachia" (2011). Graduate Theses, Dissertations, and Problem Reports. 4707.

https://researchrepository.wvu.edu/etd/4707

This Dissertation is protected by copyright and/or related rights. It has been brought to you by the The Research Repository @ WVU with permission from the rights-holder(s). You are free to use this Dissertation in any way that is permitted by the copyright and related rights legislation that applies to your use. For other uses you must obtain permission from the rights-holder(s) directly, unless additional rights are indicated by a Creative Commons license in the record and/ or on the work itself. This Dissertation has been accepted for inclusion in WVU Graduate Theses, Dissertations, and Problem Reports collection by an authorized administrator of The Research Repository @ WVU.

For more information, please contact researchrepository@mail.wvu.edu. 
Parental Perception of Their Child's Weight Status and Food Provision and Consumption Patterns in Appalachia

\author{
Jill Cochran \\ Dissertation submitted to the \\ School of Nursing \\ at West Virginia University \\ in partial fulfillment of the requirements \\ for the degree of
}

Doctor of Philosophy in Nursing
Cynthia Armstrong Persily, PhD, RN, Chairperson
Lesley Cottrell, $\mathrm{PhD}$
Stacey Culp, PhD
Alvita Nathaniel, PhD, RN
Heidi Putman, PhD, RN

School of Nursing

Morgantown, West Virginia

2011

Keywords: Parental Perception, Overweight Children, Parental Food Provision and Consumption Patterns 


\section{ABSTRACT \\ Parental Perception of Their Child's Weight Status and Food Provision and Consumption Patterns in Appalachia}

\section{Jill Cochran}

Obesity rates have continued to accelerate in the pediatric population. The accompanying co-morbidities of obesity have been recognized, yet the long term complications are not fully understood. The Health Belief Model is utilized in this study to evaluate parental perception of their child's weight status, related demographic factors, and food provision and consumption patterns associated with parental perception.

The purpose of this cross-sectional descriptive study was to examine the accuracy of parental perception of their child's weight status and to describe characteristics of those who accurately and inaccurately perceive their child's weight status. Chi-square analysis was used to determine relationships between parental perception of their child's weight status and the child's actual weight status. Relationships between parental perception of their child's weight status and demographic factors, as well as parental weight status, were also explored. Binary logistic regression was used to identify demographic predictors of parental accuracy of their child's weight status.

This study utilized data from the CARDIAC project which spanned from 2006-2009. Three cohorts of children from kindergarten $(n=957)$, second grade $(n=608)$, and fifth grade $(n=$ 304) were evaluated from 16 counties in West Virginia. In addition, responses from an accompanying questionnaire were linked to the demographic and anthropometric data.

Parents of children in each cohort had a high level of accuracy in perceiving their child's weight status. Of the cohorts, parents of children in the fifth grade had the lowest accuracy in perceiving their child's weight status. Overall, parents were the least accurate in perceiving their child's weight status when the child was in the obese BMI category. More accurate parental perception was found in females than males in regard to their child's weight status.

Results indicate that parents in this study have a higher level of accurate parental perception of their child's weight status than in previous studies. Modifying factors were not a significant influence on accurate parental perception, nor did it impact the perceived threat of the child's BMI status. Without measurement of perceived threat, accurate parental perception of the child's weight status cannot be considered equivalent to perceived threat of the illness. Therefore, likelihood of action cannot be determined from this study. The Health Belief Model (HBM) was not helpful in this population with this particular problem. Likelihood of change in the food provision and consumption patterns depends on accurate perception of the problem and how the problem impacts their child. Recommendations for future studies include evaluating a broader, more ethnically diverse population. Additional studies should include the impact of perceived threat of illness. 


\section{Acknowledgements}

This work is the product of so many people. I am grateful to my husband, Fred, who gave up so much to help me complete this work and helped me "keep the faith" in myself. I am thankful to my parents who said, "You have to get this done while I'm still able to go to your graduation!' I am grateful to my sons who both completed master's level education while I completed my doctoral studies and for my extended family, brothers and sisters, who would ask, “Are you finished yet?" I am indebted to my colleagues at WVSOM and in the clinic who helped me attain this milestone in my career.

I would like to express my gratitude to Cynthia Armstrong Persily for taking me as a student. She gave me encouragement and confidence to complete this work, and is a role model for me. I am thankful for Alvita Nathaniel, who gave me the courage to keep going. Thank you both for believing in me. My success is a product of your mentoring. I feel so fortunate to have had the expertise of the other members on my committee. Each of you represent an aspect of my passion in this work, and I will always value your input in helping me meet my goals. I will always be grateful to June Lunney for introducing me to the treasures in secondary data and for her help when I needed it most.

The joy in the journey was definitely from my classmates. Sue, Sara, Denise, Jennifer, and Susan, you have been a gift to my life. I will never forget the fun and events that carried us through the program. I admire each of you so much. The friendship that we have created from this program will be a monumental event in my life.

For my obese pediatric patients, I can only say that it is because of you that I started on this journey.

iii 


\section{TABLE OF CONTENTS}

Chapter 1: Introduction of the Problem .......................................................................... 1

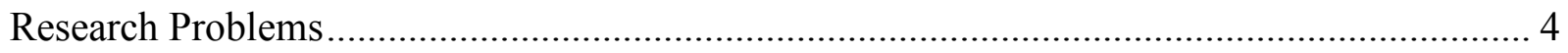

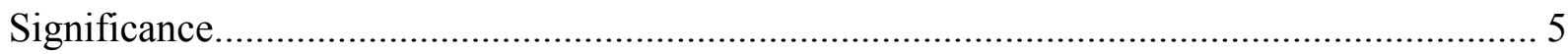

Chapter 2: Review of the Literature.................................................................................. 8

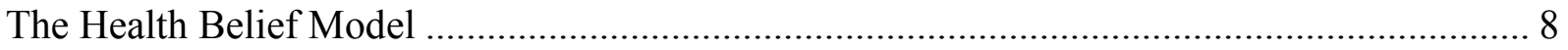

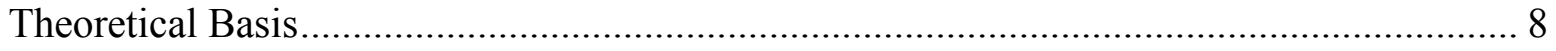

Parental Perception and the Health Belief Model .............................................................. 13

Individual Perceptions, Modifying Factors, and Likelihood of Actions ............................ 13

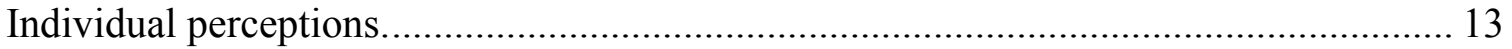

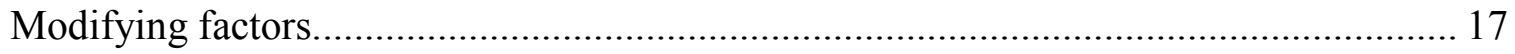

Likelihood of Action ......................................................................................... 21

Parental influence and food provision and consumption patterns .............................. 21

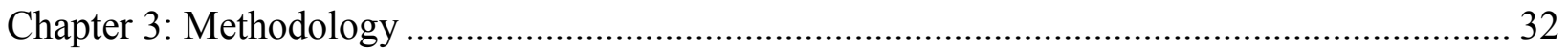

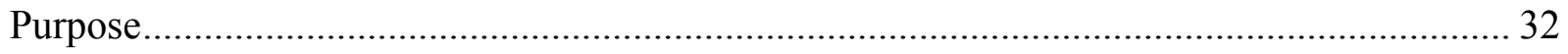

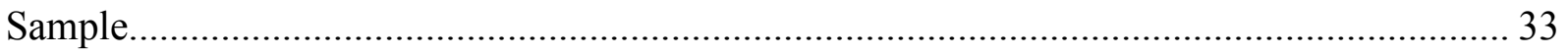

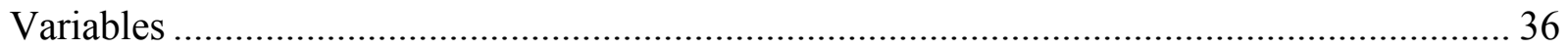

Individual perceptions/parental perception....................................................... 36

Likelihood of change /food provision and consumption patterns................................... 40

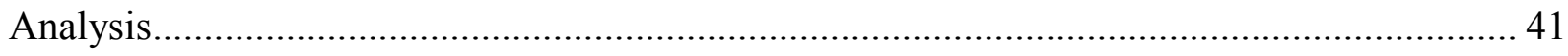

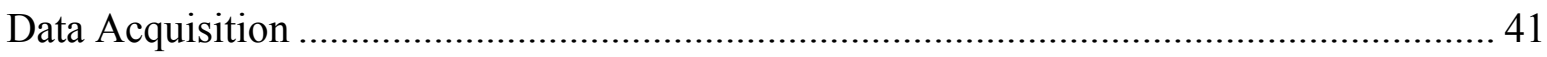

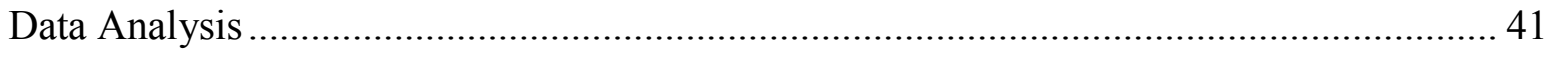

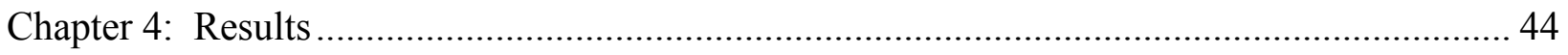

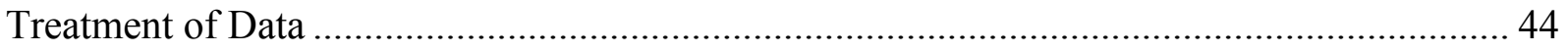




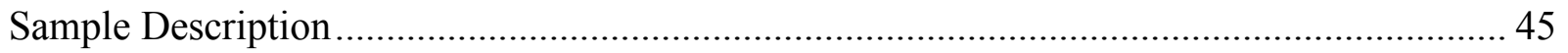

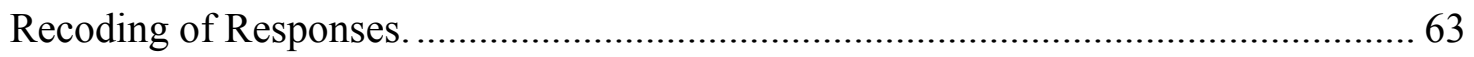

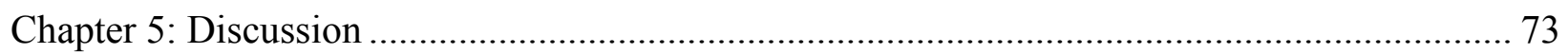

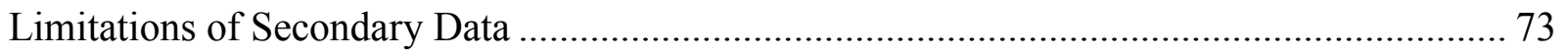

Individual Perceptions/Parental Perception of Child's Weight Status ...................................... 76

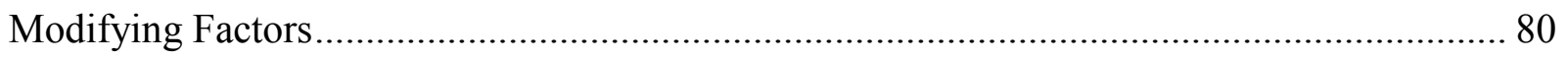

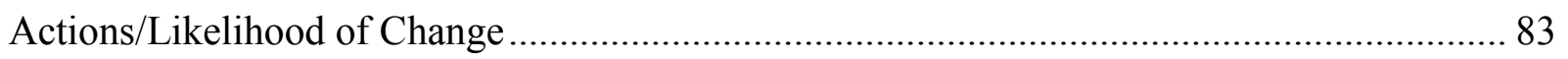

Utility of the Health Belief Model as a Framework for this Study......................................... 85

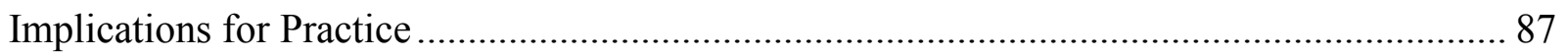

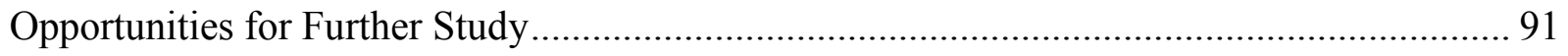

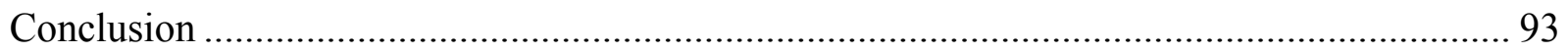

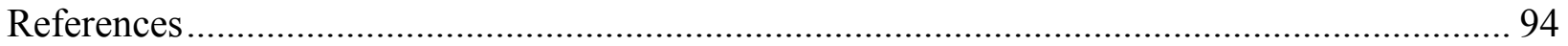




\section{LIST OF TABLES}

Table 1: Kindergarten Cohort: Demographics and Child's BMI Category....................48

Table 2: Second Grade Cohort: Demographics and Child's BMI Category ....................50

Table 3: Fifth Grade Cohort: Demographics Variables and Child's BMI Category............52

Table 4: Parental Perception and Actual BMI Status .................................................55

Table 5: Kindergarten Cohort: Gender as Related to Parental Accuracy.....................57

Table 6: Kindergarten Cohort: Child's BMI Category as Related to Parental Accuracy........57

Table 7: Second Grade Cohort: Race as Related to Parental Accuracy........................58

Table 8: Second Grade Cohort: Child's BMI Category as Related to Parental Accuracy.......59

Table 9: Second Grade Cohort Parents' BMI Category as Related to Parental Accuracy.......59

Table 10: Fifth Grade Cohort: Gender and Child's BMI Category as Related to Parental

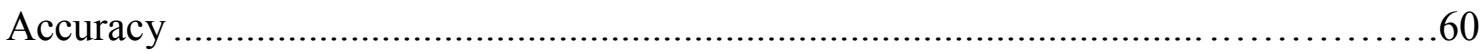

Table 11: Kindergarten Cohort: Parental Accuracy of Their Own BMI Category..............61

Table 12: Second Grade Cohort: Parental Accuracy of their Own BMI Category..............62

Table 13: Fifth Grade Cohort: Parental Accuracy of their Own BMI Category................63

Table 14: Food Provision and Eating Patterns Questions and Responses....................65

Table 15: Second Grade Cohort: Talked to Child About Eating Habits.........................67

Table 16: Second Grade Cohort: Decide What to Eat at Home............................67

Table 17: Accuracy in Weight Status Perception for Parents and Accuracy for Their Child....68

Table 18: Kindergarten Association Between Accurate Prediction of Child's Weight Status and

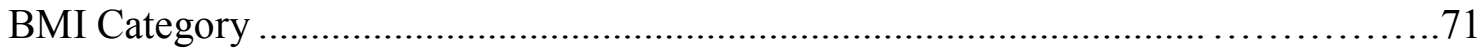


Table 19: Second Grade Association Between Accurate Prediction of Child's Weight Status, Race, and BMI Catego.................................................... 71

Table 20: Fifth Grade Association Between Accurate Prediction of Child's Weight Status and

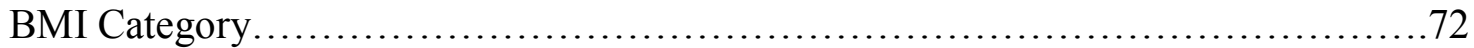

vii 


\section{LIST OF FIGURES}

Figure 1: The Health Belief Mode ...............................................................................11

Figure 2: Health Belief Model and Parental Perception of Their Child's Weight Status .......12

Figure 3: Parental Perception and Perceived Threat.....................................................87

viii 


\section{APPENDICES}

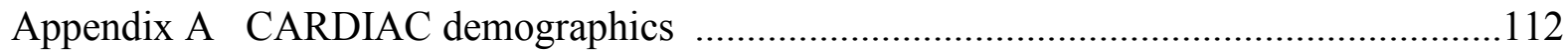

Appendix B CARDIAC questionnaire 2005-2006 ..................................................113

Appendix C CARDIAC questionnaire 2006-2007 ....................................................114

Appendix D CARDIAC questionnaire 2007-2008 ........................................................115

Appendix E Components of CARDIAC questionnaire ............................................116

Appendix F Rural Area Commuting Codes (RUCAs) ...............................................117

Appendix G Health Belief Model permission .......................................................119

Appendix H CARDIAC questionnaire permission................................... 120 


\section{Chapter 1: Introduction of the Problem}

Obesity is a growing health concern for children and adolescents in the United States. The short and long term consequences of obesity impose a massive threat to health and health care, especially in rural areas. Reducing the upward trend in children's obesity requires perception of the problem as well as the severity of obesity related illnesses. Creating or maintaining a healthy nutritional climate often involves factors that change or modify how the problem is perceived. The actions needed to promote change in a family's nutritional patterns must outweigh the barriers of preventing the action. At that point, change will likely occur and the obesity trend will decline.

The rate of obesity has increased in children and adolescents from 13.9\% in 1999 (Ogden, Flegal, Carroll, \& Johnson, 2006; de Ferranti et al., 2004) to 17.1\% in 2003-2004. The reporting period of 2003-2004 finds that $17.1 \%$ of children and adolescents 2-19 years of age were overweight defined as body mass index (BMI) at or above the $95^{\text {th }}$ percentile of the age specific BMI-for-Age Growth Chart (Ogden, Carroll, \& Flegal, 2008). The most recent data from the National Health and Nutrition Examination Survey (NHANES) showed no significant change in the prevalence of overweight children and adolescents between 2003-2004 data and 2005-2006 data. In the years 2003-2006, 16.3\% of children and adolescents aged 2-19 years were at or above the 95th percentile of the 2000 BMI-for-age growth charts defining them as obese (Kuczmarski, Ogden, Grummer-Strawn, Flegal, Guo, Wei, Johnson, 2000; C. L. Ogden et al., 2008). Significantly higher percentages of obese children live in rural areas. The obesity rate in rural areas is $16.5 \%$ compared to an urban rate of $14.8 \%$ (Liu et al., 2007). The clustered southern states of West Virginia, Kentucky, Tennessee, North Carolina, Texas, South Carolina, Mississippi, and Louisiana have the highest rate of obesity in the nation (Liu et al., 2007). The 
majority of these states are in the Appalachian region (Appalachian Regional Commission, 2007).

Obesity is also related to poverty and education level (Center for Disease Control, 2009). In both rural and urban families, higher levels of obesity are associated with populations of lower incomes. In a recent analysis, children from families with a poverty rating of $100 \%$ below the Federal Poverty Level (FPL) had an obesity rate of $21.3 \%$ compared to $10.2 \%$ of children in families at or above 400\% FPL (Liu et al., 2007). Rural areas, and especially Appalachia, have a higher rate of poverty. In Appalachia states the poverty rate is $14.3 \%$ compared to $12.6 \%$ nationally (U.S. Census Bureau, 2007). Rural areas also have a lower educational status. The Appalachian area still lags behind national standards in post-educational rates (Appalachian Regional Commission, 2009).

The consequences of childhood obesity are immediate and long term. The most immediate consequence of overweight, as perceived by children, is social discrimination associated with poor self-esteem and depression (U.S. Department of Health and Human Services, 2009). But, obesity is not just a cosmetic concern. Obesity is accompanied by a host of co-morbid conditions. Problems typically found in obese adults, such as elevated cholesterol and triglycerides, are now seen in younger patients (Demerath et al., 2003). Compared to children with a healthy weight, risk factors for heart disease such as high cholesterol and high blood pressure occur with increased frequency in overweight children and adolescents.

Overweight adolescents have a $70 \%$ chance of becoming overweight or obese adults. This risk increases to $80 \%$ if one or more parents are overweight (U.S. Department of Health and Human Services, 2009). 
The continued rise in obesity has been associated with an increase in type 2 diabetes in children (Rosenbloom, Joe, Young, \& Winter, 1999). In the past, when diabetes was diagnosed in children, it was frequently type 1 or insulin dependent diabetes. However, in the past twenty years, type 2 diabetes, or non-insulin dependent diabetes, has emerged and is increasing among children (National Center for Chronic Disease Prevention and Health Promotion \& Diabetes Public Health Resource, 2005). Researchers at the Center for Disease Control (CDC) estimate that among newly diagnosed cases of diabetes in children, the proportion of those with type 2 diabetes ranges between $8 \%$ and $43 \%$, of the total cases (de Ferranti et al., 2004; National Center for Chronic Disease Prevention and Health Promotion, 2006). The escalating trend of diabetes presents multiple health issues for the future.

Obesity, and the associated health problems of obesity, has a significant impact on the U.S. health care system (U.S. Department of Health and Human Services, 2007). A national study attributed costs associated with being overweight (BMI 25-29.9) or obese (BMI $>30)$ at 9.1\% of total medical expenditures in 1998 (E. A. Finkelstein, Fiebelkorn, \& Wang, 2003). Estimated costs of obesity in 2003 were $\$ 75$ billion with approximately one-half of this cost financed by Medicare and Medicaid (E. A. Finkelstein, Fiebelkorn, \& Wang, 2004).

Environmental factors that encourage overeating and inactivity are learned in childhood and may contribute to the development of obesity (Golan, 2006). Families harbor obesity. If one parent is obese, the child has a 50\% chance of becoming obese. If both parents are obese, the child has an $80 \%$ chance of becoming obese. Obese children have a $70 \%$ chance of being overweight or obese as adults (U.S. Surgeon General, 2001). The eating patterns of the parent are modeled to the child (Birch \& Fisher, 1998). Adjusting parental food provision and consumption patterns requires motivation to change. Unless the parents perceive their child's 
weight status as a health risk, change will not occur. If change is considered, barriers such as limited resources and poverty add to the burden of making healthier choices (Etelson et al., 2003; Myers \& Vargas, 2000; Jain et al., 2001; Baughcum et al., 2000; Baughcum et al., 1998; Hackie \& Bowles, 2007). Increased incidence of obesity in rural areas may limit exposure to other populations with healthier weight status and further impair obesity recognition in the parent and their child (Liu et al., 2007).

Investigation of children's obesity must include parental perception of the problem and identification of the predisposing factors. Factors that modify accurate or inaccurate perception of the problem may relate to certain demographic characteristics. Appalachian areas have a higher rate of poverty and overall lower educational status which may be barriers to making healthier food choices (Liu et al., 2007). Environmental factors, such as media and culture, that encourage overeating and inactivity are learned in childhood and may contribute to the development of obesity (Golan, 2006). Parental obesity is related to children's obesity (U.S. Surgeon General, 2001). Parents create the environment that nurtures the child and directs their child's growth. The child depends on the home environment for survival and learned life-style patterns. Children internalize healthy or unhealthy life-styles by modeling the parent's behavior (Rolls, Engell, \& Birch, 2000). The likelihood of change in how the parents provide food and initiate consumption will not occur if the parent does not perceive their child's weight status as a problem.

\section{Research Problems}

Given the importance of parental involvement in their children's health status, this study proposed the following questions: 
1. Is there a difference between parental perception of their child's weight status and the child's actual weight status as determined by CDC guidelines?

2. Are there differences in selected demographics between parents who accurately perceive their child's weight status and parents who inaccurately perceive their child's weight status?

3. Is there a difference between self-perceived weight status of parents and their actual weight status determined by CDC guidelines?

4. Are there differences in food provision and consumption patterns between parents who accurately perceive their child's weight status as overweight, parents who accurately perceive their child's weight status as under/normal weight, parents who inaccurately perceive their child's weight status as overweight, and parents who inaccurately perceive their child's weight status as under/normal weight?

5. Is there a relationship between accuracy in weight status perception for parents and accuracy for their child?

6. What are the significant predictors of accuracy in parental perception of their child's weight status?

\section{Significance}

The current epidemic of childhood obesity is influenced by factors such as parental food provision and consumption patterns, cultural influences, education, and poverty (Golan et al., 1998; Golan, 2006; Omar et al., 2001; Stolley \& Fitzgibbon, 1997). While parents are not the solitary cause for their child's obesity, they represent the largest influence in prevention, management, and elimination of this health concern. It is crucial that parents recognize obesity in their child as the first step toward taking action. Studies investigating parental perception of their child's weight status overwhelmingly indicate that parents do not see their child as obese 
(Baughcum, Burklow, Deeks, Powers, \& Whitaker, 1998; Baughcum, Chamberlin, Deeks, Powers, \& Whitaker, 2000; Etelson, Brand, Patrick, \& Shirali, 2003; Jain et al., 2001; S. Myers \& Vargas, 2000b; Wake, Salmon, Waters, Wright, \& Hesketh, 2002).

The Health Belief Model (HBM) represents a model that can guide research and practice to impact obesity and the consequences of obesity by integrating clinical processes with family change. Nurses have the opportunity to assist parents in perceiving their child's accurate weight status. If the child's weight status is abnormal, nurses have the unique ability to provide information that parents understand. Once the parent accurately perceives their child as obese, nutritional change must be instituted to produce healthy patterns of nutrition for their child. Nurses are change agents in promoting healthier lifestyles for the child and the family. Changing parental feeding patterns and making lifestyle adaption requires continued support for mothers and families. Empowering parents to change lifelong habits requires nursing interventions aimed at giving the parents tools needed to change. Nurses understand the cultural and economic impact on food choices and can assist families in making healthy modifications. Parents, especially mothers, carry the responsibility of feeding their infant and further providing a food environment as the child grows. Maternal feeding practices are more than nutrition. Maternal bonding occurs during feeding. Feeding is a psychological process for the mother and the child.

The present and future consequences of obesity impose a health care crisis that will demand enormous health care resourses and economic support (E. A. Finkelstein et al., 2003). Obesity is a complex problem that requires multiple solutions. Understanding accurate parental perception of their child's weight status and the relationship of factors that modify parental perception will promote interventions that support parental change in nutritional practices. 
This study added to the body of knowledge that informs nursing care of obese children and families. Use of the HBM can guide clinical practices that promote accurate parental perception of their child's weight status, after determining modifying factors that identify and predict those at risk for inaccurate perception. The study provided support for future tests of cues to actions to determining interventions that are successful in creating parental change. Clinical practices will benefit from a model that guides nursing care to improve healthy behaviors in families. 


\section{Chapter 2: Review of the Literature}

The purpose of this study was to describe parental perceptions of their child's weight status related to their child's actual weight status, and the relationship to food provision and consumption patterns in this population. This chapter will discuss the Health Belief Model and review literature related to parental perception, food provision and consumption patterns, and descriptive factors associated with these concepts. The review will be structured using the concepts of the Health Belief Model.

\section{The Health Belief Model}

\section{Theoretical Basis}

The Health Belief Model (HBM) was initially developed to explain the widespread failure of people to participate in programs designed to detect and prevent disease processes (Hochbaum, 1958; Rosenstock, 1960; Rosenstock, 1974). In the 1950s, a group of social psychologists in the U.S. Public Health Service engaged in understanding non-participating behaviors based on current learning theories derived from Cognitive Theory (Lewin, Dembo, Fester, \& and Sears, 1944; K. Lewin, Adams, Zener, \& Joint Tr, 1935; Tolman, 1932) and Stimulus Response (S-R) Theory (Thorndike, 1998; Watson, 1930).

S-R theorists believe that learning is the result of events which reduce physiological drives, thus impacting behavior. Skinner (1938) formulated the hypothesis that frequency of a behavior is determined by the reinforcements of that behavior. Skinner proposed that the mere association of a behavior and the immediate consequence was enough to affect behavior. According to Skinner, reasoning is not required in behavior change.

Cognitive theorists emphasize the role of subject expectations, or expecting a certain action to result in a particular outcome. Behavior is thought to be a function of a subjective 
value associated with an outcome. Outcome valuing and expectation of that event to occur is the basis of Cognitive theory. Cognitive theory posits that reasoning is required for behavior to occur (K. Lewin et al., 1944; K. Lewin et al., 1935; Tolman, 1932). Behaviorist and Cognitive theorists agree that consequences and behavioral reinforcements are important to behavior. Cognitive theorists suggest influencing expectations of the outcome, while behaviorists seek behavior change based on the reinforcement alone. Components of both theories contributed to the HBM (Glanz, Lewis, \& Rimer, 1990).

The HBM is a value-expectancy theory. The first principle involves valuing wellness and avoiding illness. Next, the person must believe that certain actions will prevent or alleviate the expected illness. Expectancy is further described by how an individual estimates their susceptibility and the potential for illness severity as well as the individual's belief that a proposed action would reduce the risk (Becker, 1974; Kirchhoff, Sylwestrak, Chenelly, \& McLane, 1988).

The HBM was tested in programs developed by the U. S. Public Health Service. One early program involved screening for tuberculosis. Despite the prevalence of the disease, few participated in a free mobile clinic that was easily accessible (Hochbaum, 1958). The authors of the HBM concluded that the mobile clinic was not used because people did not perceive their risk for tuberculosis, or they did not see the screening as a means of reducing or preventing the disease. As the HBM evolved, further studies expanded and clarified the model to extend from screening to preventive action and illness behavior.

The current model contains 6 key concepts: perceived susceptibility, perceived severity, perceived benefits, perceived barriers, cues to action, and self-efficacy. Perceived susceptibility is defined as one's belief regarding the chance of getting a specific condition. The severity of 
illness and the related sequelae of the illness is the perceived severity. Perceived benefits describe one's belief in the efficacy of the advised action to reduce risk or severity of illness impact. The tangible and psychological costs of the advised actions relates to how the individual perceives barriers of that action. Cues to action are triggers that activate one's readiness to action in preventing the disease. Self-efficacy is the confidence one has in his/her ability to actually take action (Hochbaum, 1958; Rosenstock, 1960; Rosenstock, 1974).

The HBM describes a process originating with individuals acknowledging their susceptibility to an illness and realizing the impact or severity of the disease process (see figure 1). The modifying factors of individual perceptions and the likelihood of action are influenced by multiple variants including age, socio-economic status, knowledge, ethnicity, and personality traits. Cues, or interventions that change behaviors relate to education, symptoms, media advertising, self-efficacy and numerous other factors. Likelihood of action is the result of modifying factors on individual perceptions which stated simply is the perceived benefits of the action minus the perceived barriers of the action equals behavior change (Glanz et al., 1990; Hochbaum, 1958; Rosenstock, 1960; Rosenstock, 1974; Becker, Drachman, \& Kirscht, 1974). Although no specific studies have utilized the HBM in parental perception studies, the HBM could be a practical tool in guiding research and interventions in children's obesity. Perceptions of the parents as related to their child's weight status are a starting point in the process. Factors that modify perception include elements that assist the parent in an accurate visualization of their child's weight status. The likelihood of change in food provision and consumption patterns is a result of parents accurately perceiving their child's weight status and the severity of the problem. The long-term outcome of changed food provision and consumption patterns is a child in a normal weight percentile for age and gender. 


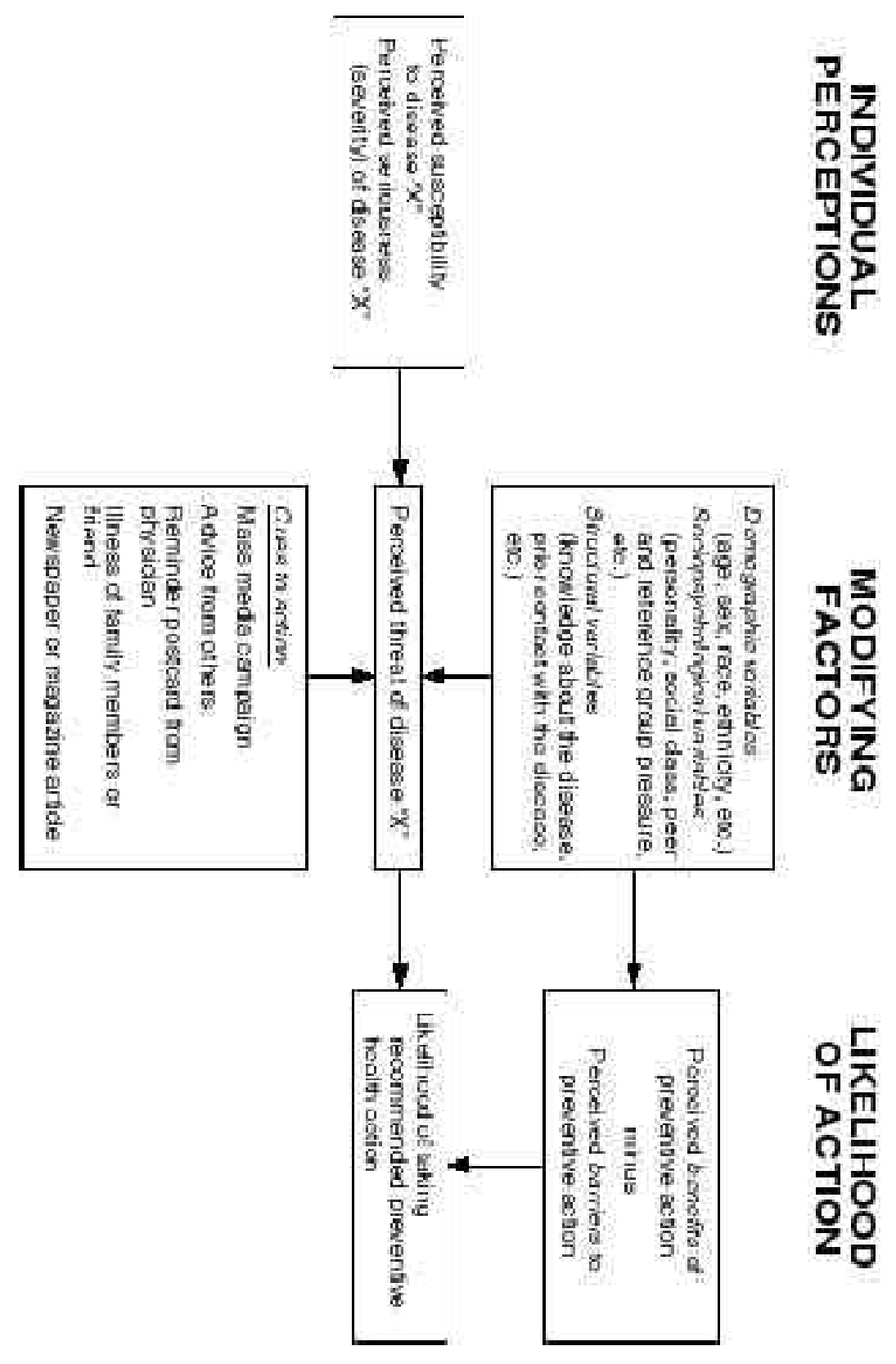

\section{Figure 1: The Health Belief Model}

Becker, M. H., Drachman, R. H., \& Kirscht, J. R. (1974). A new approach to explaining sick-role behavior in low income populations. American Journal of Public Health, 64, 205-216. (Fig 1, p. 206). 
Figure 2: Health Belief Model and Parental Perception of Their Child's Weight Status

\begin{tabular}{|c|c|c|}
\hline $\begin{array}{l}\text { Individual } \\
\text { Perceptions }\end{array}$ & $\begin{array}{l}\text { Modifying } \\
\text { Factors }\end{array}$ & $\begin{array}{l}\text { Likelihood of } \\
\text { Action }\end{array}$ \\
\hline $\begin{array}{l}\text { Parental Perception of } \\
\text { their child's weight } \\
\text { status: } \\
\text { Accurate/Inaccurate }\end{array}$ & $\begin{array}{l}\text { Socio-economic } \\
\text { status } \\
\text { Education } \\
\text { Rurality } \\
\text { Parental Weight } \\
\text { Status } \\
\text { Race/Ethnicity }\end{array}$ & $\begin{array}{l}\text { Likelihood of } \\
\text { Change in Food } \\
\text { Consumption } \\
\text { and Eating } \\
\text { Patterns }\end{array}$ \\
\hline
\end{tabular}

Adapted from Becker, M. H., Drachman, R. H., \& Kirscht, J. R. (1974). A new approach to explaining sick-role behavior in low income populations. American Journal of Public Health, 64, 205-216. (Fig 1, p. 206). 


\section{Parental Perception and the Health Belief Model}

This section will review literature related to the HBM components pertinent to this study. Parental perception based on accurate or inaccurate parental perception of their child's weight status or body image will be explored in varying populations. Modifying factors of accurate and inaccurate parental perceptions of their child's weight status were considered. Likelihood of action, change in parental food provision and consumption patterns, and barriers to change will also be discussed. Future studies will evaluate cues to action and likelihood of change.

\section{Individual Perceptions, Modifying Factors, and Likelihood of Actions}

\section{Individual Perceptions}

Parental perception of their child's weight status involves body image perception projected to their child's body shape and habitus. Body image is a term that encompasses personal and perceptual components of self-reflected body status (Probst, Vandereycken, Vanderlinden, \& Van, 1998; Sands, 2000). Body image studies have previously focused on adolescent populations secondary to eating disorders (Kostanski \& Gullone, 1999; Schur, Sanders, \& Steiner, 2000). Body image is also an aspect of self-esteem (Ben-Tovim \& Walker, 1992; Slade, 1994). Body image and body image dissatisfaction are indicators of pathological eating patterns as well as markers of success (Cash \& Deagle, III, 1997; Ohring, Graber, \& Brooks-Gunn, 2002). Parental perceptions of their child's body image are reflected in multiple studies. The literature clearly reflects inaccurate parental perceptions when their child is designated as overweight.

In a study of 622 mothers of overweight children, $79 \%$ did not perceive their child as overweight (Baughcum et al., 2000). This cross sectional survey of mothers of children aged 
23-60 months was conducted during a nutritional interview. Of the group, 99 mothers had overweight or obese children. The mothers correctly identified themselves as overweight, but not their children. Low educational status of the mother was cited as an associated factor of inaccurate perception. In a similar WIC population of Hispanic mothers (Olvera-Ezzell, Power, $\&$ Cousins, 1990), 38 mothers were assessed for accurate perception of their child's weight status. Sixty-one percent did not recognize their child as overweight.

Parental perception was evaluated before and after a state-wide screening program in Arkansas (West et al., 2008). In this study, $60 \%$ of parents underestimated their child's weight at baseline. Parents of younger children were more likely to underestimate (65\%) than parents of adolescents (51\%). One year after measurement, accurate perception improved to 53\% ( $\mathrm{P}<$ $0.0001)$.

In a largely Hispanic population, Myers and Vargas (2000) questioned 200 parents of overweight children aged 2-5 years with open-ended questions about the size of their child. Using only direct visualization of their child's body, parents answered questions about weight and health concerns. Criteria for inclusion into the study required a weight-for-height ratio above the $90^{\text {th }}$ percentile. Parents did acknowledge health risks, specifically cardiac risks (72\%), however, $35 \%$ of parents did not perceive their child as obese. Nearly $45 \%$ of parents thought their child's weight was fine. Only $7 \%$ of parents saw their child as slightly overweight. A similar study (Etelson et al., 2003) asked 83 parents to assess their 4-5 year old child's weight status by plotting their perception on a ruler with extremely underweight and extremely overweight at each end point of the scale after viewing standard growth cards (National Center for Health Statistics, 2000). Only $10.5 \%$ of the parents accurately identified their child as overweight in the overweight group of children. The non-obese group had 59\% accuracy in 
plotting accurate weights. Not only was inaccurate perception noted in the obese population, but also only $41 \%$ of parents with normal weight children demonstrated accuracy in plotting their child's weight status.

Other studies have documented that parents are not aware of their child's obesity and consequently, do not perceive the association between obesity and health risks. Parent reported child health and well-being was explored with a group of Australian parents. The BMI of their primary school children was used as a weight indicator. Of the 2,863 children, $17 \%$ were overweight and 5.7\% were obese. Data from this two-stage random cluster sample revealed that $42 \%$ of parents of obese children and $81 \%$ of parents with overweight children did not report health or well-being concerns for their children (Wake et al., 2002).

Even when the health risks of obesity are recognized, parents have not been found to recognize obesity in their child. Etelson, Brand, Patrick, and Shirali (2003) evaluated excess weight as a health risk in a group of 83 parents. Parents of normal weight and overweight children did not differ in their concerns of excess weight as a health risk, but the groups did differ in the accuracy of their perceptions of their child's weight. Parents of normal weight children were 59\% accurate in recognizing their child's weight status while parents of overweight children had only $10.5 \%$ accuracy in weight status recognition $(p<0.001)$ when compared to standardized charts.

Standardized measuring tools or charts have not been effective in helping parents accurately perceive the weight status of their child. Jain et al. (2001) interviewed 18 low-income mothers of overweight, obese, and normal weight children. Mothers described their overweight or obese child as "thick" or "solid" and associated inactivity with being overweight or obese. The same mothers did not think that current growth charts defined a healthy weight. 
Inaccurate parental perception of childhood weight status is a global issue. Parents of British children demonstrated inaccurate perception of their child's weight status. Parents of 277 healthy randomly recruited children and their parents were evaluated for accurate perception of weight status. This study defined overweight as a BMI of at least 25 and obesity as a BMI of 30 in parents. Overweight children were described at $\geq 91^{\text {st }}$ percentile and obese as $\geq 98^{\text {th }}$ percentiles. Only $25 \%$ of parents recognized their child as overweight. Even when the child was obese, 33\% of mothers saw their child's weight as "about right" (Carnell, Edwards, Croker, Boniface, \& Wardle, 2005). Among overweight and obese parents, $40 \%$ of the mothers and $45 \%$ of the fathers judged their own weight as "about right". Maternal weight status did not affect mother's perception of their child's weight status. A similar study from England (Carnell et al., 2005) evaluated parental perception in 564 parent-child dyads. Children were aged 3-4 years. Accurate parental perception was found in only $17.1 \%$ of obese children.

In Tiawan, $\mathrm{Wu}, \mathrm{Yu}, \mathrm{Wei}, \&$ Yin (2003) evaluated weight-controlling behaviors in a population of overweight and obese parents and their children. Using a random sample of 287 children, a cross sectional study of weight-controlling behaviors and family factors associated parental perception of overweight and obesity as a positive factor in successful weightcontrolling behaviors. Seven variables significantly influenced weight-controlling behaviors including obesity level, mother's education, family-structure, socioeconomic status of the family, parents' perception of their child's weight, parents' concern, and supervision. Step-wise regression analysis was used to further analyze the variables. Of these seven variables, parental supervision $(p<0.001)$, a higher level of parental education $(p<0.01)$, and the more attention parents paid to the weight problem of the child $(p<0.05)$ had the most positive effects on weightcontrolling behavior. 
Parental perception of their child's weight status has been studied in vulnerable populations including Native-Americans and Appalachians. Three tribes from Wisconsin were assessed for accurate perception of their child's weight status. Participants included 366 parentchild dyads participants from kindergarten through second grade. Twenty-six percent of children were overweight $\left(\geq 95^{\text {th }}\right.$ percentile $)$ and $19 \%$ were at risk for overweight $\left(\geq 85^{\text {th }}\right.$ to $<95^{\text {th }}$ percentile). Caregivers recognized only $15.1 \%$ of overweight children. Factors predictive of accurate perception included the child having a BMI $>99^{\text {th }}$ percentile (Adams, Quinn, \& Prince, 2005). In a similar study, body mass index (BMI) information was collected during the Coronary Artery Risk Detection In Appalachian Communities (CARDIAC) Project. Screening procedures revealed that $37(33.6 \%), 14(22.2 \%)$, and $23(32.4 \%)$ of the kindergarten, fifth graders, and ninth graders were at risk for being overweight or were already overweight. In the group, of at risk for being overweight or overweight, $62.2 \%$ of kindergarteners' parents, $57.1 \%$ of $5^{\text {th }}$ graders' parents, and $43.5 \%$ of $9^{\text {th }}$ graders' parents perceived their children to be of healthy weight (Cottrell et al., 2007).

Modifying factors. Characteristics of parents with inaccurate perceptions of their child's obesity have been reported in the literature. These include low education, poverty, race, age of the child, rurality, and ethnicity, and parental weight status. It is unknown as to whether these factors modify parental perceptions; however they are clearly associated with inaccurate perception of their child's weight status.

Educational status. Baughcum et al. (2000) identified lower educational status of the mother as an associated factor of inaccurate parental perception of their child's weight status. Forty-five percent of mothers who inaccurately perceived their child's weight status had low education, noted in this study as high school degree or less. Obesity (body mass index $\geq$ 
$30 \mathrm{~kg} / \mathrm{m}^{2}$ ) was more common in the lower education group (30\% vs $\left.14 \%\right)$ and children of parents with lower education were more overweight (weight-for height-percentiles $\geq 90^{\text {th }} ; 19 \%$ vs $14 \%$ ). A similar study conducted in Milan, Italy (Genovesi et al., 2005) described an inverse correlation between parental misperception of their child's weight status and maternal education. A group of 569 mother-child couples were evaluated by questionnaire and anthropometric measures. A significant association was noted between the mother's educational level and weight status based on BMI. Both mothers $(p=0.002)$ and children $(p=0.02)$ with a higher prevalence of overweight and obesity were in a lower educational class. Perception of their child's obesity ( $p$ $=0.008)$ was worse in the lower educational class.

Poverty. Poverty is associated with poor parental perception of their child's weight status. Six of the previously reviewed studies (Etelson et al., 2003; Myers \& Vargas, 2000; Jain et al., 2001; Baughcum et al., 2000; Baughcum et al., 1998; Hackie \& Bowles, 2007) have documented inaccurate parental perception of their child's weight status using predominately Women, Infant, and Children (WIC) families. WIC is a federal program. The usual state income eligibility requirements must be between 100 percent of the Federal poverty guidelines (issued each year by the Department of Health and Human Services), but cannot be more than $185 \%$ of the Federal poverty income guidelines (United States Department of Agriculture, 2009). Another study by Jain et al (2001) questioned a group of 18 low-income mothers with obese children. Qualitative questions were answered regarding weight issues of their children. Mothers judged their child's size based on clothing size and physical activity. Even when the child was overweight, the mother considered the child healthy if physical activity was feasible. Comparable studies were not conducted in populations that were designated as predominately higher income brackets. 
Maternal weight status. Maternal weight status (perceived or measured) is not consistently associated with accurate or inaccurate perception. Mother-child dyads were studied using 14 year follow-up data from a population based prospective birth cohort of 2,650 Australian children (52\% males, $48 \%$ females). At age 14, the child's observed and perceived weight status was evaluated. Fifteen percent of mothers of normal weight children misclassified their child as underweight. Forty percent of mothers of overweight children misclassified their child as normal or underweight (Mamun, McDermott, O'Callaghan, Najman, \& Williams, 2008). Predictors of maternal inaccurate perceptions were maternal BMI and having family mealtimes together. A similar study used a population of 112 mothers and their children aged 2-6 years participating in swimming lessons. The overall population contained less obese children (21\%) than normal weight children (78.4\%). Mothers correctly assessed their own obesity (39 out of 40), but only $4.1 \%$ correctly assessed their child as obese (Crouch, O'Dea, \& Battisti, 2007)

Not all studies have found a relationship between maternal obesity and parental perception of their child's weight status. Jeffery et al (2005) noted that only $25 \%$ of parents recognized their child as overweight. In this study, however, maternal weight status did not affect awareness of their child's weight status. Similarly, West et al. (2008) found that overweight parents were no more likely to underestimate their child's weight status.

Race, ethnicity, and culture. Accurate or inaccurate perception has been studied in special populations related to race, ethnicity and culture. One-hundred and eleven African American families were screened during a diabetes prevention study (Intagliata, Ip, Gesell, \& Barkin, 2008). A substantial number of the children were obese (69\%). However, only $44 \%$ of the care givers perceived the child's weight to be a health problem. Parental perception of their child's overweight status has been evaluated in populations that were predominately Latino 
(Intagliata et al., 2008) and Hispanic (Hackie \& Bowles, 2007). Mother-child dyads (n=123) recruited from a Latino community were assessed by questionnaires and anthropometric measurements. Myers and Vargas (2000) reported a low rate of accurate parental perception $(10.5 \%)$ and utilized a population predominately Hispanics. Mothers in West Virginia, which is the only state entirely in the Appalachian area reported inaccurate perception of their child's weight status in the CARDIAC study. Parents, with children in three age groups, reported inaccurate perception of their child's weight status (Cottrell et al., 2007).

Age and gender of child. Parental inaccuracies have been associated with the age of the child. Baughcum et al. (2002), Myers and Vargus (2000), Etelson (2003), Adams et al. (2005), Carnell (2005), and Hackie and Bowles (2007) studied populations of children under the age of 6 years. As previously cited, Baughcum et al. reported an inaccuracy rate of $79 \%$, Myers and Vargus 89.5\%, Eitelson 89.5\%, Adams, et al 84.9\%, Carnell 82.9\%, and Hackie and Bowles $61 \%$.

As children age, accurate perception by parents of the child's weight status improved. Eckstien (2006) noted that parents of children age 6 and older had 56\% accurate perception versus $18 \%$ of children younger than six years of age of overweight children. Maynard et al. (2003) studied a large population of 5500 children ages 2-11. Significant difference improvement in accuracy was noted at 7.8 year of age for both boy and girls. In another study by Wald et al. (2007) accuracy rates of $17 \%$ for parents of children aged 3-5 year and $61.7 \%$ for children aged 6-12 was noted.

Studies of older children and teens demonstrate a better relationship between age and accurate perception. A study of 15,483 teens by Goodman et al. (E. Goodman, Hinden, \& Khandelwal, 2000) demonstrated parental accuracy of 32\% of their teen's weight status. West 
(2008) noted parents of older children more likely to correctly estimate their weight status. Sixty-five percent of parents with children $<13$ years of age reported inaccurate weight status perception compared to $51 \%$ of parents with children $\geq 13$ years of age.

Gender has been studied as a modifying factor in parental perception. Studies by Wake et al. (2002), West (2008) and Goodman, et al. (2004) did not note a significant difference in parental perception related to gender. However, Wald (2007) noted parental perception was more accurate for females at $63 \%$ compared to $46 \%$ for males. Crouch (2007) noted a near significant level $(p=0.056)$ of health concern for parents of females who were overweight. Maynard et al. 2003) noted parents to be more accurate for females at $29 \%$ compared to males at $14.0 \%$

Rurality. Accurate or inaccurate parental perception of their child's weight status has not been studied specifically in populations designated as rural or urban. However, studies comparing rural and urban rates of obesity in children show higher rates in rural areas. In a recent report, urban children had a lower rate of obesity (14.4\%) compared to rural children (16.5\%) (Liu et al., 2007). Parental perception was not measured; however, behaviors related to children's obesity were compared. Fewer rural children (25.4\%) failed to meet physical activity recommendations compared to urban children (29.3\%). Family meal time was also decreased in rural children (21.9\%) compared to urban children $(25.3 \%)$.

\section{Likelihood of Action}

Parental influence and food provision and consumption patterns. One of the first tasks a new mother is given is to feed her infant. She may breast feed on the delivery table or receive the child later for feeding. Feeding promotes bonding and attachment in the early stages of infancy (Satter, 1990). The baby demonstrates contentment when fed and seems peaceful. 
This validates the skill of a mother. As the child develops, other forms of bonding such as reading to the child, playing, and other activities become nurturing. Still, providing nourishment for the child remains a continuous need for the mother (Birch \& Fisher, 1998). The decision to breast or bottle feed is the first impact a mother has on her child's food choices. Availability of food choices are primarily governed by the parent. Food selection is based on likes and dislikes of the parents. The food provision and consumption patterns of the parent is modeled to the child (Birch \& Fisher, 1998). Mothers may not adjust developmental food provision and consumption patterns appropriately in order to assist the child with receiving other feedback and contentment. The mother may inhibit the child's nutritional self-regulation based on her needs to validate her child's contentment (Satter, 1996). Preparing a meal is often timed by the parent's schedule, not the child's feeding needs. The child is expected to eat at the proposed meal times and the meal is the parent's means of providing nutrition for the child.

From the time of birth, parents also have a major influence on foods children prefer (Benton, 2004). The availability of foods in the child's environment adds to reinforcement of food choices. Using food as a reward is a common strategy used by parents; therefore children are rewarded for eating foods that are disliked. This further increases the aversion to that particular food (Birch \& Fisher, 1998). Parents build the association of eating with certain situations and emotions (Koivisto et al., 1994). How parents feed their children is a central theme in both prevention and treatment of obesity. Six studies have been found that analyze parental food provision and consumption patterns (Baldaro et al., 2003; Franzese et al., 1998; Laessle, Uhl, Lindel, \& Muller, 2001; Lissau \& Sorensen, 1994; Olvera-Ezzell, Power, and Cousins, 1990; Trombini et al., 2003). 
Olvera-Ezzell, Power, and Cousins (1990) conducted an observational/descriptive study of food provision and consumption patterns in Mexican-American mothers and their obese children ages 4-8. Thirty-eight mothers participating in a weight loss program were observed in their homes. During the study, family meal time was observed. Mothers were evaluated as to the mealtime interaction and feeding situations with their children. Child eating compliance was more likely to follow a verbal maternal command or a given portion $(p<0.01)$. Mothers commonly used commands, reasoning, threats, and bribes to control eating. None of these strategies demonstrated significant change in the eating patterns of the children. The older the child, the less the mothers used verbal encouragement. In addition, parents with education above the average of 9.7 years served healthier foods $(p<0.05)$.

Trombini and colleagues (2003) studied attachment styles of mothers of obese and normal weight children. Thirty mothers of overweight or obese children and 80 mothers of normal weight children completed questionnaires rating relationship, need for approval, and four attachment styles. Mothers of overweight or obese children had a significant prevalence in insecure attachment styles (66.6\%) as compared to the group of mothers with normal weight children (38.5\%). Mothers of overweight or obese children had an insistent requirement of idealization in their own role as a parent and required frequent reinforcement that their care is sufficient. It is suggested that overfeeding meets this need. The authors suggest that maternal behavior supports the use of psychologic interventions on the parent-child relationship as imperative in weight reduction strategies.

Parental impact on emotional eating was explored by Baldaro (2003). The study compared obese and non-obese children and their parents in accuracy of interpreting emotional situations. A group of 11 girls and 10 boys with obesity and their mothers were compared to a 
control group of parents and non-obese children. A series of 32 brief film sequences interpreted by four actors expressing four emotions (anger, sadness, fear, and happiness) was presented first without sound, second without video, and then with both sound and video. Compared to the control group, obese boys and girls and their mothers showed a significant reduced ability $(p<$ $0.05)$ to decode visual and verbal signs of emotion. The authors conclude that the eating pattern, in this sample, is triggered by emotions, not physiological needs and was used by the parent to soothe their child.

Patterns of emotional eating and psychological issues may also contribute to the onset of obesity. Parental recall of the onset of obesity in their children was explored in a study by Franzese et al. (1998). Parents of 886 obese children were surveyed in order to study factors associated with the origin of obesity. Parents of $46.7 \%$ of the children said obesity had always been present (group A). The remaining 53.3\% (group B) noted an onset of obesity at a mean age of $5.3 \pm 2.6$ years. Group B recalled an event associated with the onset of obesity in 197 cases (health event: 119, psycho-social event: 78).

The effect of emotional support, especially from the family, affects obesity and eating patterns. Eighty obese and non-obese children aged 8-12 were evaluated in a laboratory setting. A controlled repeated measure design was used. The child was observed eating with the mother present and without her presence. The child was observed by a monitor using a cumulative eating curve which measures the amount and time involved in the eating process. Differences in eating patterns between normal weight and overweight children emerged only under the condition when the mother was present. When the mother was present, the overweight children ate faster with greater bite size and showed an acceleration of their eating rate towards the end of the experimental meal. This study suggests that the mother's presence lessens self-control 
leading to a food provision and consumption pattern with greater food intake for the overweight child (Laessle et al., 2001). Age and educational levels of the mothers were not provided.

The power of family support is further amplified when support is not present. Lissau and Sorenson (1994) conducted a longitudinal study investigating the impact of parental neglect on obesity in the young adult. Third grade children from Copenhagen schools were randomly selected for the study. Information from 987 pupils was obtained from a parental questionnaire and from school personnel based on the child's hygiene and family factors. Ten years later, 881 $(86 \%)$ of the children previously considered neglected were reevaluated for BMI. Parental neglect greatly increased the risk of obesity compared to harmonious support with an odds ratio of 7.1 .

Likelihood of change in parental nutritional patterns. Once parents perceive their child as overweight, interventions to modify and change parental food provision and consumption patterns may be considered. The likelihood of parental action is influenced by benefits of change and barriers that impede the change process. The concept of change has been vastly studied in health care and health promotion. The path between perception and likelihood of action involves multiple factors. Parents are key to the process.

Golan et al. (1998) proposed that parental influence alone was enough to change weight status of a child. These researchers compared exclusive parental intervention with child based approaches. Sixty obese children were measured and at least $20 \%$ over ideal weight for age. A one-year longitudinal prospective design was used with random allocation of two groups (parents as change agent and children as change agent). Behavior changes and weight loss were found to be significantly different between groups. The parent only group had greater weight loss in their child than did the child only group $(14.6 \% v s 8.4 \% ; p<0.05)$. Behavior changes involved 
activity level, television viewing, stimulus exposure (snack food exposure), eating related to hunger, eating style, and energy intake. In all of the behavior change categories, the parent-only group scored significantly higher than the child-only group (Golan et al., 1998). Golan et al. (2006) repeated the study using 32 families with obese children. Measurements at 6 and 12 months show significant difference between the groups. The parent-only group noted a significant reduction in the percentage of the child's weight at 6 months $(p=0.02)$ and even more at 12 months $(p<0.05)$.

Mothers are usually seen as the agent of change. Sixty-five African American girls and their mothers participated in a 12 week study of eating habits. Mother-daughter dyads were randomly assigned to a treatment or placebo control group. The groups were tested for dietary fat intake, parental support, and role modeling. After pre-testing, the treatment group was exposed to a culturally specific obesity prevention program focused on adopting a low-fat, low calorie diet and increasing activity. At the end of the program, the groups were again tested for dietary fat intake, parental support and role modeling. The treatment group demonstrated significant improvement from the control group in reducing the fat intake $(p<0.001)$ and parental support and role modeling $(\mathrm{p}<0.01)$. The mothers and daughters were not separated in this program and the mothers scored higher than the daughters in decreasing dietary fat intake (Stolley \& Fitzgibbon, 1997).

Likelihood of change: barriers and benefits. Likelihood of change is directly influenced by the barriers that hamper the change and the benefits that occur because of the change. Identifying the barriers and benefits in changing food provision and consumption patterns has been studied in children and parents. Barriers include family dynamics, knowledge, 
and culture (Glanz et al., 1990; Hochbaum, 1958; Rosenstock, 1960; Rosenstock, 1974; Becker, Drachman, \& Kirscht, 1974) .

Parents as the sole agents of change is the theme in a qualitative study by Omar et al. (2001). Barriers to change in health behavior were identified in a predominately male population. Twenty low-income caregivers of toddlers (11 fathers, 1 boyfriend, 6 mothers, 1 grandmother, and 1 aunt) participated in focus groups discussing barriers to healthy eating. Reported barriers included division of responsibilities, work schedules, cost of food, inadequate food preparation time and combinations of these factors.

Knowledge as a benefit or barrier in changing food provision and consumption patterns has been investigated. Mothers and their young children were studied to determine if greater nutrition knowledge or gains in nutrition knowledge promote more successful weight loss (Klohe-Lehman et al., 2006). A convenience sample of 141 obese mothers and their children were measured for height and weight. Mothers completed questionnaires with demographic and baseline nutritional knowledge. Mothers attended 8 weekly weight-loss classes emphasizing diet, physical exercise, and behavior modification. Mothers that successfully lost weight had higher score on the nutritional pretest $(r=0.31, p<0.001)$ and post-test $(r=0.34, p<0.001)$ than did the participants that did not successfully lose weight. A higher pre-test score may indicate a healthier life-style in general and not truly be a predictor of weight loss.

Determining if the sex of the parent/child is a benefit or barrier to change parental food provision and consumption patterns was further explored by Temple et al. (2006). A two-year family-based program including one overweight parent and an overweight child was conducted $(\mathrm{n}=167)$. The program included anthropometric measurements, individual counseling, education, and physical activity. Children with opposite-sex dyads had greater weight loss $(\mathrm{p}<0.01)$ at 6 
and 12 months compared to children with same dyads. Mother-daughter dyads exhibited poorest results at each measurement while the mother-son dyad had the greater results $(p<0.05)$. Parenting skills and family dynamics play an important role in weight control.

Inaccurate parental perception was a barrier in a qualitative study of 20 randomly selected children attending a weight loss clinic (Murtagh, Dixey, \& Rudolf, 2006). Delayed parental recognition of obesity was identified as one of the psychological barriers to weight loss. Lack of role models, poor social support, and the sacrifices involved in weight control were barriers expressed by the children. Children also cited lack of control in maintaining the behavior change as a problem.

Cultural beliefs may pose barriers to changing parental food provision and consumption patterns. Studies by Baughcum et al $(1998 ; 2000)$ suggested that maternal concern about their infants under eating or being underweight was higher in obese mothers regardless of their child's weight status. This perception by obese mothers may represent one mechanism by which infants with obese mothers are predisposed to obesity later in life (Baughcum et al., 1998; Baughcum et al., 2000). This relates to the misconception identified by parents that heavier is healthier (Baughcum et al., 1998; Baughcum et al., 2000).

Citing family support as a benefit, a similar study interviewed 11 mothers of overweight or obese children. The parents recognized health risks of obesity and saw their child as overweight and obese. They did not see their child's condition as an isolated health risk and instead, viewed the problems as a family issue. Their strategies focused more on the family than the child. Environment, family heritage, culture, and genetics were cited as contributing factors. The family, not the child was noted as an effective change agent in the strategy of changing the weight problem (Jackson et al., 2005). 


\section{Knowledge and Limitations}

The existing literature provides numerous studies related to accurate or inaccurate parental perception of their child's weight status. Studies investigating parental perception overwhelmingly support that parents do not see their child as obese (Adams et al., 2005; Cottrell et al., 2007; West et al., 2008; Jeffery et al., 2005; Wake et al., 2002; Etelson et al., 2003; Myers \& Vargas, 2000; Jain et al., 2001; Baughcum et al., 2000; Baughcum et al., 1998). Five of the studies (Etelson et al., 2003; Myers \& Vargas, 2000; Jain et al., 2001; Baughcum et al., 2000; Baughcum et al., 1998) used predominately WIC families, representing lower socio-economic status than the general population. Lower education as an influence is not consistently defined in the studies. Similar studies have not been conducted in populations with higher educational or higher socio-economic status. Measuring perception of a parent regarding their child's weight status has not been consistent in the literature. Three qualitative studies (Jain et al., 2001; Jackson et al., 2005; Murtagh et al., 2006) used prompting questions to assess perception. Some of these questions were somewhat leading, considering the studies were conducted in health care facilities. Two studies specifically noted inaccurate parental perception using standardized growth charts primarily used in the clinical setting by health care providers (Jain et al., 2001; Etelson et al., 2003). No studies available in the current literature have evaluated factors that influence parents to accurately perceive their child's weight status. The higher incidence of obesity in rural areas and Appalachia suggests similar perception and food provision and consumption patterns associated with the culture. While some studies have looked at specific populations such as Latinos and Hispanics (S. Myers \& Vargas, 2000c), studies have not targeted rural areas or Appalachia as a sole focus of parental perception or parental food provision and consumption patterns related to accurate or inaccurate perception of a child's weight status. 
Education, socio-economic status, race, ethnicity and culture have strong associations with inaccurate parental perception of their child's weight status. Perceived maternal BMI has a noted association with perception; however it varies from accurate to inaccurate (Mamun et al., 2008; West et al., 2008; Jeffery et al., 2005). When compared to urban areas, rural populations have a higher rate of obesity. Accurate or inaccurate perception has not been compared in these populations.

Studies considering age as a factor in accurate parental perception noted that accuracy is lower in children under six years of age (Adams et al., 2005; Baughcum et al., 2000; Etelson et al., 2003; Hackie \& Bowles, 2007; S. Myers \& Vargas, 2000a) than children aged six and older (Eckstein et al., 2006; Maynard et al., 2003; Wald et al., 2007). Tanner staging also distorts perception, however, accuracy in teens was found to be more accurate than children less than six years of age (Goodman et al., 2004; West et al., 2008). Gender, as a factor in accurate parental perception, is not always noted (Goodman et al., 2004; Wake et al., 2002; West et al., 2008), although three studies noted that females were more often perceived as overweight in parents that accurately perceived their child as overweight (Crouch et al., 2007; Maynard et al., 2003; Wald et al., 2007).

Parental influence on food provision and consumption patterns has a strong theoretical and research basis (Satter, 1999; Satter, 1996; Birch \& Fisher, 1998). Studies on maternal attachment (Trombini et al., 2003), emotional eating (Baldaro et al., 2003; Franzese et al., 1998), and emotional support (Lissau \& Sorensen, 1994) demonstrate connections between eating patterns and subsequent weight status. Uniformity does not exist in measuring eating patterns and emotional support in these studies. 
The concept of parents as agents of change is supported by the literature. Recognition of likelihood of change is an important factor and requires concise measurement. Evidence exists for using the parent as the sole agent in a change process (Golan et al., 1998; Golan, 2006; Omar et al., 2001; Stolley \& Fitzgibbon, 1997). Parental intent to change has not been studied jointly with accurate perception. However, parental knowledge prior to weight loss interventions (Klohe-Lehman et al.,2006) is suggested as a predictor to successful weight loss. The importance of family participation in the process of change and incorporating cultural and ethnic factors into the course of action has been discussed, but not measured (Jackson et al., 2005).

The HBM has not been used to guide any of the reviewed studies of children's obesity. However, the model seems to be an excellent framework to guide the study of parental perception of their child's weight status, food provision and consumption patterns, and intent to change. Understanding how accurate or inaccurate perceptions relate to food provision and consumption patterns is a vital step in alleviating the problem of children's obesity. 


\section{Chapter 3: Methodology}

\section{Purpose}

The purpose of this cross-sectional descriptive study was to examine the accuracy of parental perception of their child's weight status and to describe characteristics of those who accurately and inaccurately perceive their child's weight status. The aims of the study were to:

1. Describe accuracy of parental perception of their child's weight status as compared to their child's actual body status determined by CDC guidelines of BMI percentiles (age, gender, height and weight).

RQ1: Is there a difference between parental perception of their child's weight status and the child's actual weight status as determined by CDC guidelines?

2. Describe the relationship of selected demographic variables (rural designation, education, age, gender, and socioeconomic status) to accurate parental perception of their child's weight

RQ2: Are there differences in selected demographics between parents who accurately perceive their child's weight status and parents who inaccurately perceive their child's weight status?

3. Describe accuracy of self-perceived weight status in parents as compared to their own weight status determined by CDC guidelines of BMI.

RQ3: Is there a difference between self-perceived weight status of parents and their actual weight status determined by CDC guidelines?

4. Describe the relationship of food provision and consumption patterns of parents with accurate and inaccurate perceptions of their child's obesity.

RQ4: Are there differences in food provision and consumption patterns between parents who accurately perceive their child's weight status as overweight, 
parents who accurately perceive their child's weight status as under/normal weight, parents who inaccurately perceive their child's weight status as overweight, and parents who inaccurately perceive their child's weight status as under/normal weight?

5. Describe the relationship of parental perception of their child's weight status related to parent's self-perceived weight status.

RQ5: Is there a relationship between accuracy in weight status perception for parents and accuracy for their child?

6. Describe predictors of accurate parental perception of their child's weight status.

RQ6: What are the significant predictors of accuracy in parental perception of their child's weight status?

\section{Sample}

The study used existing data from the Coronary Artery Risk Detection In Appalachian Communities (CARDIAC) study collected during the years of 2005-2009. CARDIAC is a cardiovascular screening project for West Virginia children in kindergarten (CARDIAC-Kinder), second, and fifth grade (CARDIAC-Kid). All $5^{\text {th }}$ graders in West Virginia were eligible to participate in the screening program. All kindergarteners and second graders in select counties were also eligible to participate. Each screening was conducted within the school setting and was free for all participants. The program continues to be supported by the West Virginia Department of Pediatrics at West Virginia University and is funded by the Claude Worthington Benedum Foundation and the West Virginia (WV) Department of Health and Human Services.

Parents or legal guardians of all children who participated in the CARDIAC health screening completed a questionnaire. Data from this questionnaire were used for this study. All 
procedures for the original study were approved by the Institutional Review Board (IRB) for the Protection of Human Subjects at West Virginia University. The request for approval of this secondary analysis was added to the original IRB application as an addendum.

\section{CARDIAC Data Extraction}

The existing CARDIAC data included information from a demographic questionnaire, anthropometric measurement, and a serum lipid profile. An additional questionnaire, "Environmental Determinants of Physical Activity in Children" was added to specific populations during the 2005-2009 collection years. Approximately 300 participants completed the questionnaire during the original study period of 2005-2006. Later years include additional participants. For the proposed study, demographic data, anthropometric measurements, and selected items from the "Environmental Determinants of Physical Activity in Children" were used to answer the research questions.

Anthropometric measures. The method for measuring children in the CARDIAC study is standard and has been used for the duration of the project. A child's weight status was reported as BMI percentiles obtained from measurements taken by CARDIAC project staff members. Height $(\mathrm{cm})$ and weight $(\mathrm{kg})$ were obtained by measuring to the tenth digit using the SECA Road Rod stadiometer $\left(78^{\prime \prime} / 200 \mathrm{~cm}\right)$ and the SECA 840 Personal Digital Scale. Both SECA stadiometer and digital scales have been incorporated in national and international measurement studies of children's obesity for over 5 years (Seca - seca sensa 804.). Standard calculation for each child's BMI was based on the recommended equation from the CDC (weight (kg)/height $(\mathrm{cm})^{2}$ X 10,000) (Hammer, Kraemer, Wilson, Ritter, \& Dornbusch, 1991; Pietrobelli et al., 1998). Weight percentile categories were based on age-and gender-specific growth charts recommended by the CDC. Children's BMI percentiles are categorized into 4 groups (Hammer 
et al., 1991; Pietrobelli et al., 1998) : underweight $\left(<5^{\text {th }}\right.$ percentile), normal weight (from the $5^{\text {th }}$ to the $84.9^{\text {th }}$ percentile), overweight (between the $85^{\text {th }}$ and $94.9^{\text {th }}$ percentiles) and obese $\left(95^{\text {th }_{\%}} \%\right.$ and above). The CARDIAC Project utilizes West Virginia Rural Health Education Partnership (WVRHEP) students to assist with measurements. The WVRHEP students are health science students from schools of medicine, nursing, dentistry, pharmacy, as well as students of physical therapy. CARDIAC staff and local school nurses are trained by WVRHEP students to conduct anthropometrical testing.

\section{Parent Questionnaire}

The parent questionnaire contained standard demographic information given to every participant. The additional questionnaire, "Environmental Determinants of Physical Activity in Children" was also completed by the sample to be analyzed for this study. One parent or legal guardian of each participating child answered a series of questions exploring their child's cardiovascular risk (see Appendices A, B, C, and D for complete questionnaire). Validated questions developed from a previous study (Cottrell et al., 2007) assessed parent health knowledge using a series of questions (Cronbach's $\alpha=0.89$ ) with a yes or no response. Parent health attitudes were assessed using questions developed for this study with a dichotomized (yesno) scale (Cronbach's $\alpha=0.76)$. Parent and child behaviors regarding feeding and activity were assessed using items taken from the National Survey of Early Childhood Health (Blumberg, Halfon, \& Olson, 2004) and incorporated into the questionnaire. Questions were selected that best described the variables related to the HBM (see Appendix E). Instructions to the parent in completing the form were to fill in entire circle of response. 


\section{Variables}

\section{Individual Perceptions/Parental Perception}

Conceptual definition. Perception is defined as a process whereby sensory stimulation becomes translated into an organized experience (Posner, 1977). Perception involves observation and a mental image. Perception is an attitude of an understanding process of airing knowledge about the environment or situation. Parental perception of their child's weight status involves seeing their child's shape or body image by personal and perceptual means (Sands, Tricker, Sherman, Armatas, \& Maschette, 1997; Probst, Vandereycken, Vanderlinden, \& Van, 1998). Perception occurs by various means of progression. The process includes selecting information about their child and organizing the selection in a manner in which it is interpreted in an interpersonal environment by the parent's mind (Perception as a process, 2009).

Operational definition. Parental perception of their child's weight status was evaluated by comparison of the parent's response to question Q 42 "Compared to other children the same age and gender, how would you describe your child's weight (fill in only one): very underweight, slightly underweight, about the right weight, slightly overweight, and very overweight." Accurate perception was defined as: very underweight or slightly underweight as associated with BMI's less than the $5^{\text {th }}$ percentile, about the right weight associated with BMI's at or above the $5^{\text {th }}$ percentile to less than the $85^{\text {th }}$ percentile, slightly overweight associated with BMI's at or above the $85^{\text {th }}$ percentile to less than the $95^{\text {th }}$ percentile, and very overweight associated with BMI's equal to or greater than the $95^{\text {th }}$ percentile (U.S. Department of Health and Human Services, 2006).

Parental perception of their own weight status was determined using Q-24 that asked parents to describe their own weight using one of 5 responses: very underweight, slightly 
underweight, about the right weight, slightly overweight, and very overweight. Accurate responses were: very underweight, slightly underweight associated with BMI's of less than 18.5, about the right weight associated with BMI's of 18.5-24.9, slightly overweight associated with BMI's of 25-29.9, and very overweight associated with BMI's of 30 or greater (Center for Disease Control, 2007). It was compared to Q 25 (self-reported height) and Q 26 (self-reported weight).

\section{Modifying Factors}

\section{Education}

Educational status was assessed using the demographic tool completed by parents. The categories were: $8^{\text {th }}$ grade education or less, some high school, high school graduate or GED, some college or technical training, college graduate, and completed graduate school. The response is given by filling in the corresponding circle next to the given responses. Parents complete the demographic sheet and the tool reflected whether the mother or father is completing the form.

\section{Socioeconomic Status}

The socioeconomic status of the population was determined using the Census Bureau equation of family size and composition (ERS/USDA data - 1990 rural-urban commuting area code). If a family's total income is less than the family's threshold, then that family and each member of the family is considered in poverty. This formula does not differ with geography, but is updated for inflation using Consumer Price Index (CPI-U). The official definition of poverty uses income before taxes and does not include capital gains or noncash benefits such as public housing, Medicaid and food stamps (United States Department of Agriculture, 2009). Poverty is designated into percents of the population of that county that meets the definition of poverty. 
For this study, the socioeconomic status of the participants and families was described using a proxy measure of poverty level in the county of residence. This was determined by the ZIP Codes taken from the CARDIAC data which was categorized into counties. The socioeconomic status of the participants was then determined by the zip code of the participant, compared to the county designation of percent of poverty of that county for children ages 0-17 living in poverty as determined by the Census Bureau (U.S. Census Bureau, 2007). Three categories were designed to describe level of poverty for the county in which the child and family reside: Level 1, poverty level $10 \%-15 \%$ of population designated as living in poverty: Level $2,16 \%-25 \%$ of population designated as living in poverty, and Level 3, 26\% and above of population designated as living in poverty.

\section{Rurality}

The operational definition of rural varies. The U.S. Census Bureau defines rural areas as areas comprising open country and settlements with fewer than 2,500 residents (U.S. Census Bureau, 2001). Urban areas are comprised of larger areas and densely settled areas around them. Urban areas do not necessarily follow municipal boundaries, but are densely settled territory as it might appear from the air. Most counties, whether metropolitan or nonmetropolitan, contain a combination of rural and urban populations.

For this study, rural was defined using Rural-Urban Commuting Area (RUCA) codes. RUCA codes are a detailed and flexible method for determining sub-county level metro and micro areas (see Appendix E). Census codes, rather than counties are used to provide a more detailed classification of the geographic pattern of settlement. Census tracts also are the smallest geographic building block delineating commuting data. The principles of measurement include population density, urbanization, and daily commuting to identify urban cores and surrounding 
territory that has economic ties to the larger core areas. Ten codes are given describing urbanized areas. Code 1 is described as equal to an urbanized area. Codes 2, 5, and 8 refer to a commuting share of $30 \%$ to a metropolitan, micropolitan, or small town. Less than $30 \%$ commuting to a single core area is noted by codes 3,6 , and 9 . Small towns and micropolitan areas are tracts equivalent to urban clusters (codes 4 and 7). Code 10 identifies rural tracts where the primary flow is to another rural tract or local. In general, RUCA primary codes 4-10 are designated as rural (see Appendix F). RUCA codes permit stricter or looser classifications of metropolitan, micropolitan, and small town commuting areas. This classification scheme provides an alternative to county-based systems for situations where more detailed geographic analysis is feasible (ERS/USDA data - rural definitions: Data documentation and methods, 2000).

\section{Race/Ethnicity}

Race/ethnicity was determined based on the self-report of parents from the CARDIAC questionnaire completed by the parent. Categories in this questionnaire included: Black, Hispanic, White, Asian, Bi-racial, and Other. Since the state of West Virginia is entirely in the Appalachian area, all participants were assumed to be members of the Appalachian culture due to their West Virginia residence.

\section{Gender}

Comparison of responses by parents related to the child's gender was determined based on answers from the demographic questionnaire (see Appendices A, B, C, D). The questionnaire places the word "sex" with responses of female or male. The response is given by filling in the corresponding circle next to the given responses. 


\section{Likelihood of Change /Food Provision and Consumption Patterns}

Conceptual definition. For the purpose of this study, food provision and consumption patterns was defined as the methods, timing, environment, emotional climate, and content of nutritional input supplied or administered to the child. Feedings may be administered by the mother through breast or bottle feeding as an infant or supplied for the child to take at given intervals as the child grows. The feeding process begins as a passive dependent process and evolves into an independent function. It is an emotional process (Satter, 1990). Mothers usually bear the initial responsibility for the methods and timing of feeding. As the child progresses developmentally, mothers have less responsibility in the active feeding process. However, in American culture, mothers still bear most of the responsibility for providing the foods and the environment where the food is consumed (Birch \& Fisher, 1998).

Operational definition. Food provision and consumption patterns are operationalized in this study through answers provided by mothers to questions on the questionnaire, "Environmental Determinants of Physical Activity in Children". For the purpose of this study, change was not evaluated, but food provision and consumption patterns of the participants were described. Questions that reflect foods provided for the child and general aspects of nutritional history in the family were identified. Seven questions described present food provision and consumption patterns. Parents were asked to complete the following questions by filling in the circle: Q- 37, subset question 1, 2, and 6: "In the past 2 months, how often have you done the following: 1. Established regular meal times, 2. Required family to eat as a group, and 6 . Talked to your child about his/her eating habits". Possible responses were: "never, rarely, sometimes, most often, and always". Questions describing food selection both inside and outside the home were answered in a similar manner: Q-39. "To what extent can your child 
independently decide": 1. "What to eat while at home", and 2. "What to eat while outside the home". Possible responses include: "never, rarely, sometimes, most often and always. Additional questions describing food provision and consumption patterns such as Q-45, subset question 8 and 9, which asks: 8. "Do you encourage your child to eat healthier?" and 9. "Do you use sweets as a reward?" Possible responses of "Yes" or "No" were also used.

\section{Analysis}

\section{Data Acquisition}

After obtaining IRB approval for additional use of the CARDIAC data, information from the 8 counties that utilized the "Environmental Determinants of Physical Activity in Children" questionnaire was acquired for the three grades surveyed. The responders to this survey were matched with the original CARDIAC demographic and anthropometrical questionnaire they also completed. Data cleaning was done with the oversight of the CARDIAC team. Data acquired was de-identified. Cleaned and prepped data for use in this study were downloaded from the CARDIAC data bank in Excel format.

\section{Data Analysis}

Data was analyzed using the Statistical Package for Social Science (SPSS) Graduate Pack for Windows (2004) computer software program. After data cleaning, and removal of any subjects with impossible values or greater than $10 \%$ of the necessary data elements missing, descriptive statistics were used to describe the sample. Each group of students from kindergarten, fifth grade, and ninth grade students was evaluated. The BMI of every child in the sample was calculated using their correct weight, and height, and comparing to the appropriate CDC guidelines for BMI percentiles in children by age. Analysis strategies for each research question are reviewed below. Parametric testing was used after meeting all assumptions. All 
analyses used a level of $p<0.05$ to designate statistical significance. Because this study uses previously collected data, a post hoc power analysis was completed, considering the actual number of useable cases available from larger data set.

RQ1: Is there a difference between parental perception of their child's weight status and the child's actual weight status as determined by CDC guidelines?

To describe parental perception of their child's weight status and the actual weight status, chi-square analysis was used to determine whether there is a relationship between a child's weight status and his or her parent's perception of that weight status.

RQ2: Are there differences in selected demographics between parents who accurately perceive their child's weight status and parents who inaccurately perceive their child's weight status?

Children were subdivided into groups where parents accurately and inaccurately perceived their weight status. Chi-square analysis was used to compare demographic variables between the groups.

RQ3: Is there a difference between self-perceived weight status of parents and their actual weight status determined by CDC guidelines?

Chi-square analysis was used to determine whether there is a relationship between the parent's actual weight status and his or her perception of that weight status as determined by CDC guidelines of BMI.

RQ4: Are there differences in food provision and consumption patterns between parents who accurately perceive their child's weight status as overweight, parents who accurately perceive their child's weight status as under/normal weight, parents who inaccurately perceive their child's weight status as overweight, and parents who inaccurately perceive their child's weight status as under/normal weight? 
Food provision and consumption patterns between parents who accurately perceive their child's weight status as overweight, parents who accurately perceive their child's weight status as under/normal weight, parents who inaccurately perceive their child's weight status as overweight, and parents who inaccurately perceive their child's weight status as under/normal weight was compared by using chi-square to evaluate responses to seven questions related to food provision and consumption patterns.

RQ5: Is there a relationship between accuracy in weight status perception for parents and accuracy for their child?

To address parental perception of their own weight status, a chi-square test was used to determine whether there was a relationship between parental perception of their own weight status and their perception of their child's weight status.

RQ6: What are the significant predictors of accuracy in parental perception of their child's weight status?

Logistic regression was used to identify significant predictors of accuracy in parental perception. The response variable was the dichotomous perception accuracy variable (accurate/inaccurate). Statistically significant results for the chi-square analysis in the previous questions was identified and selected as variables for inclusion in the regression model. Potential predictors included: parent's educational status, socioeconomic status, rurality, child's weight status, age, gender, parent's weight status, and food provision and consumption patterns.

The HBM was tested through this study by use of selected questions that represent variables which coincide with components of the HBM. Variables representing parental perception, modifying factors, and likelihood of action were identified and evaluated. Results of this study are discussed as related to the HBM. 


\section{Chapter 4: Results}

This chapter contains results of analyses as related to the aims of this study. It is divided into two sections: (1) descriptive analyses of the data, 2) statistical analyses related to the research questions which describe the relationship between accurate and inaccurate parental perception of their child's weight status, the parent's weight status, food provision patterns, and predictors of accurate parental perception of their child's weight status.

\section{Treatment of Data}

After receiving permission from the WVU IRB as a research associate for the protocols of the CARDIAC project, permission was granted for use of CARDIAC data. Data sets were received from the CARDIAC project in three age groups: (1) kindergarten, (2) second grade, and (3) fifth grade. Data sets for the CARDIAC project from the 2006 to 2009 time period were used for this study. Sixteen counties in West Virginia were represented in the data: Barbour, Boone, Braxton, Clay, Calhoun, Clay, Gilmer, Lewis, Lincoln, Marshall, Marion, Mason, Monongalia, Pendleton, Randolph, and Taylor.

The data sets contained two components of the CARDIAC project: 1) anthropometric and demographic data measured and recorded by CARDIAC team members and 2) the questionnaire "Environmental Determinants of Physical Activity in Children" containing selfreported data completed by parents of children participating in the project. Specific data from each component were selected and placed in data sets for three cohorts: kindergarten, second grade, and fifth grade. Anthropometric measurements contained in the data sets had the child's BMI percentile. Further recoding was necessary to categorize the BMI into categories of underweight, normal weight, overweight, and obese. Parents self-reported their height and weight. BMIs were then calculated from the parent's reported height and weight; then BMIs 
were categorized into CDC designations of: underweight, normal weight, overweight and obese. Cardiac team members linked the anthropometric and demographic data for the student and the questionnaire reported by the parent for that child. Data sets were received in an SPSS file and were cleaned, prepped, and de-identified by CARDIAC team members.

\section{Sample Description}

Demographic data from the data sets were analyzed to describe the educational level of the parent, gender of the child, rurality, social economic status and race designation.

Additionally, BMI category was reported from the sample to reflect the BMI percentiles of three cohorts of children. Each cohort contained an adequate sample size; however certain categories did not contain adequate data for analyses. Therefore, demographic data in certain research questions required recoding to meet requirements for chi-square analyses. According to Munro (2005) chi square analyses requires an expected square count that is greater to or equal to 5 to meet the assumptions underlying the parametric techniques. Categorizing or recoding data for this study created variables that were mutually exclusive and followed a theoretical reason for the categories meeting the assumptions underlying chi-square.

\section{Demographics of Children}

Race was originally reported in five categories in all cohorts. However, few responses were given in categories of Black, Asian, Hispanic, Bi-Racial, and other (kindergarten total $n=$ 919, Black, Asian, Hispanic, Bi-Racial, and other $n=53$; second grade total $n=703$ Black, Asian, Hispanic, Bi-Racial, and other $n=133$; fifth grade total $n=297$, Black, Asian, Hispanic, Bi-Racial, and other $n=16$ ). Therefore, two groups were created: a) Caucasian and b) all other races (Black, Asian, Hispanic, Bi-Racial, or other). This met the assumptions for chi-square,

\section{Demographics of Families}


Due to the small numbers of responses for level of education below high school for the mothers in all cohorts (kindergarten $n=32$; second grade $n=20$; fifth grade $n=7$ ), these categories were collapsed for chi square analysis to reflect high school (HS) or less as one category, while other educational categories from the original data set were kept intact. Socioeconomic status was described using county designation of the participant and economic status of that county as given by the U.S. Census Department and the United States Department of Agriculture in three levels: Level 1, 10\%-15\% of population designated as living in poverty; Level 2, 16\%-25\% of population designated as living in poverty; and Level 3, 26\% and above of population designated as living in poverty.

Information regarding who completed the form was given in two cohorts. The kindergarten questionnaire offered responses of "mother, father, or other." In the second grade cohort, "mother, other adult female, father, other adult male" was offered as responses. The fifth grade cohort questionnaire did not provide an opportunity for respondents to report information regarding who completed the form.

\section{Rurality}

Counties of residence were classified using Rural-Urban Commuting Area Codes (RUCA) to distinguish rurality (United States Department of Agriculture, 2009). Based on definitions of rural, (ERS/USDA data - rural definitions: Data documentation and methods) The Economic Research Service of the United States Department of Agriculture (USDA) defines nine methods of operationalzing rural. RUCA codes define rural areas based on the same theoretical principles and information used by the Office of Management and Budget (OMB). RUCA codes allow rural definitions based on metropolitan, micropolitan, and small town commuting areas. RUCA primary codes $4-10$ are designated as rural 
(http://www.ers.usda.gov/data/ruraldefinitions). This designation of rural was used in this study. RUCA codes from the three cohorts were categorized as "rural" (RUCA codes 4-10) and nonrural (RUCA codes 1-3).

\section{Demographics of Kindergarten Cohort}

The kindergarten cohort was the largest sample. Multiple characteristics of that sample were explored. There were 957 participants in this group. In this cohort, $71.7 \%$ of the children were under or normal weight and gender was almost equally distributed $(48.6 \% ; 51.4 \%)$. The majority of kindergarten children were Caucasian (94.3\%). Mothers were the main person completing the form $(93.9 \%)$.

The geography and socio-economic status of the kindergarten cohort was also described. The majority of their families lived in counties designated non-rural (63.1\%) Slightly less than one-half $(47 \%)$ of that population lived in counties with $10 \%-15 \%$ of the populations living in poverty. Most mothers had post-high school education (57.6\%). A detailed description of sample demographics appears in Table 1. 
Table 1: Kindergarten Cohort: Demographics and Child's BMI Category

\begin{tabular}{|c|c|c|c|}
\hline & Characteristic & Frequency & Percent \\
\hline \multirow[t]{2}{*}{ Child's Gender } & Female & 444 & 48.6 \\
\hline & Male & 486 & 51.4 \\
\hline \multirow[t]{2}{*}{ Child's Race } & White & 866 & 94.3 \\
\hline & All other races & 53 & 5.7 \\
\hline \multirow[t]{3}{*}{ Poverty Level } & $\begin{array}{l}\text { Level } 1 \text {, poverty level } 10 \% \text { - } \\
15 \% \text { living in poverty }\end{array}$ & 440 & 47.0 \\
\hline & $\begin{array}{l}\text { Level } 2,16 \%-25 \% \text { of } \\
\text { population designated as living }\end{array}$ & 350 & 37.4 \\
\hline & $\begin{array}{l}\text { Level } 3,26 \% \text { and above of } \\
\text { population designated as living }\end{array}$ & 146 & 15.6 \\
\hline \multirow[t]{2}{*}{ Rural Urban } & Non-Rural & 591 & 63.1 \\
\hline & Rural & 345 & 36.9 \\
\hline \multirow[t]{4}{*}{ Mother's Education } & HS or less & 105 & 24.8 \\
\hline & Some Post HS college or tech & 117 & 27.5 \\
\hline & Undergraduate degree & 128 & 30.1 \\
\hline & Graduate school & 75 & 17.6 \\
\hline \multirow[t]{4}{*}{ Child's BMI Category } & Underweight & 35 & 4.0 \\
\hline & Normal weight & 590 & 67.6 \\
\hline & Overweight & 120 & 13.8 \\
\hline & Obese & 127 & 14.6 \\
\hline Person Completing & Mother & 855 & 93.9 \\
\hline \multirow[t]{2}{*}{ Form } & Father & 39 & 4.2 \\
\hline & Other & 17 & 1.9 \\
\hline
\end{tabular}




\section{Second Grade Cohort}

The demographic characteristics of the second grade cohort were obtained from 608 participants with $54.2 \%$ females and $45.8 \%$ males. More than one-half of the second-grade children were under or normal weight $(66.4 \%)$. Caucasian was the predominant race in this cohort. The majority of the families of the second grade children lived in areas designated as non-rural $(72.2 \%)$. The majority of the mothers reported post high school education. Most of the participants (47.3\%) lived in counties that contained $10 \%-15 \%$ of the population living in poverty. Mothers were the main person completing the form $(92.4 \%)$. See Table 2 for detailed demographic data. 
Table 2: Second Grade Cohort: Demographics and Child's BMI Category

\begin{tabular}{|c|c|c|c|}
\hline & Characteristic & Frequency & Percent \\
\hline \multirow[t]{2}{*}{ Child's Gender } & Female & 329 & 54.2 \\
\hline & Male & 278 & 45.8 \\
\hline \multirow[t]{2}{*}{ Child's Race } & White & 570 & 94.5 \\
\hline & All other race & 133 & 5.5 \\
\hline \multirow[t]{3}{*}{ Poverty Level } & $\begin{array}{l}\text { Level } 1 \text {, poverty level } 10 \% \text { - } \\
15 \% \text { living in poverty }\end{array}$ & 287 & 47.3 \\
\hline & $\begin{array}{l}\text { Level } 2,16 \%-25 \% \text { of } \\
\text { population designated as living } \\
\text { in poverty }\end{array}$ & 212 & 34.9 \\
\hline & $\begin{array}{l}\text { Level } 3,26 \% \text { and above of } \\
\text { population designated as living } \\
\text { in poverty }\end{array}$ & 108 & 17.8 \\
\hline \multirow[t]{2}{*}{ Rural Urban Commuting } & Non-Rural (RUCA codes 1-3) & 411 & 72.2 \\
\hline & Rural (RUCA codes 4-10) & 158 & 27.8 \\
\hline \multirow[t]{4}{*}{ Mother's Education } & HS or less & 117 & 23.9 \\
\hline & Some Post HS college or tech & 135 & 27.6 \\
\hline & Undergrad degree & 153 & 31.3 \\
\hline & Grad school & 84 & 17.2 \\
\hline \multirow[t]{4}{*}{ Child's BMI Category } & Underweight & 17 & 2.8 \\
\hline & Normal weight & 386 & 64.2 \\
\hline & Overweight & 90 & 15.0 \\
\hline & Obese & 108 & 18.0 \\
\hline Person Completing & Mother & 534 & 92.4 \\
\hline \multirow{3}{*}{ Form } & Other Adult Female & 12 & 2.1 \\
\hline & Father & 29 & 5.1 \\
\hline & Other Adult Male & 2 & 0.4 \\
\hline
\end{tabular}

\section{Fifth Grade Cohort}

The demographic patterns of the fifth grade cohort were described with 304 participants;

$54.8 \%$ females and $45.2 \%$ males. In fifth grade children, more than one-half of the participants 
were under or normal weight (56.6\%). Again, Caucasian was the predominant race $(94.6 \%)$. No information was given as to who completed the demographic form in this cohort.

The economic and geographic composition of the fifth grade cohort was varied. The majority of the families lived in areas designated as rural (60.9\%). However, for this group, the percentage living in poverty level $1(10 \%-15 \%$ of the population living in poverty, $41 \%)$, and Poverty level 2, (16\%-25\% of population designated as living in poverty, $42.9 \%)$ were nearly equal. The majority of the mothers reported post high school education. Further detailed data are found in Table 3. 
Table 3: Fifth Grade Cohort: Demographics Variables and Child's BMI Category

\begin{tabular}{|c|c|c|c|}
\hline & Characteristic & Frequency & Percent \\
\hline \multirow[t]{2}{*}{ Child's Gender } & Female & 165 & 54.8 \\
\hline & Male & 136 & 45.2 \\
\hline \multirow[t]{2}{*}{ Child's Race } & White & 281 & 94.6 \\
\hline & All other races & 16 & 5.4 \\
\hline \multirow[t]{3}{*}{ Poverty Level } & $\begin{array}{l}\text { Level } 1 \text {, poverty level } 10 \%-15 \% \text { living in } \\
\text { poverty }\end{array}$ & 116 & 41.1 \\
\hline & $\begin{array}{l}\text { Level } 2,16 \%-25 \% \text { of population designated } \\
\text { as living in poverty }\end{array}$ & 121 & 42.9 \\
\hline & $\begin{array}{l}\text { Level } 3,26 \% \text { and above of population } \\
\text { designated as living in poverty }\end{array}$ & 45 & 16.0 \\
\hline Rural Urban & Metro counties(RUCA codes 1-3) & 119 & 39.1 \\
\hline \multicolumn{4}{|l|}{ Commuting Area } \\
\hline & $\begin{array}{l}\text { Non-metro counties } \\
\text { (RUCA codes } 4-7 \text { ) }\end{array}$ & 185 & 60.9 \\
\hline \multirow[t]{4}{*}{ Mother's Education } & HS or less & 53 & 39.6 \\
\hline & Some Post HS college or tech & 29 & 21.6 \\
\hline & Undergrad degree & 36 & 26.9 \\
\hline & Grad school & 16 & 11.9 \\
\hline Child's BMI & Underweight & 4 & 1.3 \\
\hline \multirow[t]{3}{*}{ Category } & Normal & 163 & 54.9 \\
\hline & Overweight & 54 & 18.2 \\
\hline & Obese & 76 & 25.6 \\
\hline
\end{tabular}




\begin{abstract}
Aims of the Study
The following section presents analysis of each aim of the study. Parental perception of their child's weight status, perception of the parent's weight status, and factors that describe parental accuracy of their child's weight status are described. Factors that predict accurate parental perception of the child's weight status are also analyzed.

RQ1: Is there a relationship between parental perception of their child's weight status and the child's actual weight status as determined by CDC guidelines?

Recoding of Parental Perception Responses

To calculate parental perception of their child's weight status, data were recoded for two categories of perception responses. Too few responses were given in perceived categories of underweight and obese to meet chi-square assumptions. Therefore, responses that were perceived as "underweight" were combined with perceived "normal weight" and responses perceived as "obese" were combined with perceived "overweight".

\section{Recoding Child's BMI Category}

To be consistent with the combined categories of perceived weight status, the child's actual weight status or BMI category was also recoded. Thus, the BMI categories for the child's actual weight were collapsed to reflect under/normal weight as one category and overweight/obese as the second category in the BMI variable. After collapsing the categories, the assumptions for chi-square analysis were met, and chi-square analysis was performed to determine significant relationships between parental perception of their child's weight status and the child's actual BMI category.

\title{
Results of Analysis
}


Each cohort demonstrated a significant relationship between accurate parental perception of the child's weight status and the child's actual weight category (kindergarten $p<0.001$, second grade $p<0.001$, and fifth grade $p=0.002$ ). To determine if accuracy in perception of the child's actual weight status was related to which parent completed the form, a chi square analysis was performed in both the kindergarten and second grade cohort. There was no significant relationship between which parent completed the form and the accuracy with which they perceived their child's actual weight status in either of the cohorts (kindergarten $p=0.109$, second grade $p=0.920$ ).

\section{Kindergarten Cohort}

In the kindergarten cohort, a significant relationship between accurate parental perceptions of their child's weight status and the child's actual weight status $(p<0.001)$ was

found. In the groups of the kindergarten children perceived by their parents to be about the right weight or less, $78.2 \%$ of kindergarten children were actually under or normal weight. Of the kindergarten children perceived by their parents to be about the right weight or less, $21.8 \%$ of the children were actually overweight and obese. Of the kindergarten children perceived by their parents to be slightly overweight and overweight, $7.5 \%$ of those children were actually underweight or normal weight and $92.5 \%$ were overweight/obese (Table 4).

\section{Cohort Second Grade}

In the second grade cohort, a significant relationship was noted between parental perception of the child's weight status and the child's actual weight status $(p<0.001)$. Of the second grade children perceived by their parents to be about the right weight or less, $80.6 \%$ were under/normal weight. However, $19.4 \%$ of the children perceived as under/normal weight were actually overweight/obese. Of the second grade children perceived to be slightly overweight and 
overweight, 9.3\% were under or normal weight children and 90.7\% were overweight/obese (Table 4).

\section{Fifth Grade Cohort}

Parents of children in the fifth grade cohort also demonstrated a significant relationship between perception of their child's weight status and their actual weight status $(p=0.002)$. In the fifth grade cohort, $44.1 \%$ of children perceived by their parents to be about the right weight or less were under/normal weight. In the same group, 55.9\% were actually overweight/obese. Of the fifth grade group perceived to be slightly overweight and overweight, $24.1 \%$ were under/normal weight and 75.9\% were overweight/obese (Table 4).

Table 4: Parental Perception and Actual BMI Status

\begin{tabular}{|c|c|c|c|c|c|}
\hline Cohort & Perception & Under/Normal & Overweight/Obese & & \\
\hline & & $\mathrm{BMI}$ & $\mathrm{BMI}$ & $\chi^{2}$ & $p$ \\
\hline Kindergarten & & $(n=615)$ & $(n=244)$ & 178.202 & $<.001$ \\
\hline & $\begin{array}{l}\text { About } \\
\text { rioht/under }\end{array}$ & $78.2 \% *$ & $21.8 \%$ & & \\
\hline & Slightly Overweight/ & & & & \\
\hline & Overweight & $7.5 \%$ & $92.5 \% *$ & & \\
\hline Second Grade & & $(n=624)$ & $(n=239)$ & 204.738 & $<.001$ \\
\hline & $\begin{array}{l}\text { About } \\
\text { right/under }\end{array}$ & $80.6 \% *$ & $19.4 \%$ & & \\
\hline & Slightly Overweight/ & & & & \\
\hline & Overweight & $9.3 \%$ & $90.7 \% *$ & & \\
\hline Fifth Grade & & $(n=111)$ & $(n=179)$ & 9.926 & .002 \\
\hline & $\begin{array}{l}\text { About } \\
\text { right/under }\end{array}$ & $44.1 \% *$ & $55.9 \%$ & & \\
\hline & Slightly Overweight/ & & & & \\
\hline & Overweight & $24.1 \%$ & $75.9 \% *$ & & \\
\hline
\end{tabular}

*Indicates accurate parental perception 
RQ2: Are there relationships between selected demographics of parents who accurately perceive their child's weight status and parents who inaccurately perceive their child's weight status? To determine the possible impact of demographics between parents who accurately and inaccurately perceive their child's weight status, chi-square analyses were performed. Demographic variables consisted of: gender, race, poverty level, rural status, parent's BMI category, child's BMI category and mother's education. This question did not require recoding of child's BMI category. Results are seen in table five.

\section{Kindergarten Cohort}

For the parents of children in kindergarten, there was a statistically significant relationship between whether or not the parent was accurate in the perception of the child's weight status and the child's gender $(\mathrm{p}<0.001)$. In parents with daughters, $45.7 \%$ were inaccurate and $54.3 \%$ were accurate in their perception of the child's weight status. Of the parents with sons, $49.1 \%$ were inaccurate while $50.9 \%$ were accurate in weight perception of their child. There was also a statistically significant relationship between whether or not the parent was accurate in the perception of the child's weight status and the child's BMI category (p $<0.001)$. In groups of parents of children with BMIs categorized as underweight, $68.6 \%$ were inaccurate and $31.4 \%$ were accurate in perceiving their child's weight status. In parents of normal weight BMIs children, $22.0 \%$ were inaccurate and $78.0 \%$ were accurate. Parents with children having BMIs in the overweight category were $95.8 \%$ inaccurate and $4.2 \%$ accurate. In parents with children in BMI groups considered obese, $92.9 \%$ were inaccurate and $7.1 \%$ were accurate in weight perception (tables 5,6 ). No relationship was found between race, poverty level, rural status, parent BMI category, or mother's education and accurate parental perception of their child's weight status. 
Table 5: Kindergarten Cohort: Gender as Related to Parental Accuracy

\begin{tabular}{lcccc}
\hline & $\begin{array}{c}\text { Females } \\
(n=441)\end{array}$ & $\begin{array}{c}\text { Males } \\
(n=468)\end{array}$ & $\chi^{2}$ & $\mathrm{P}$ \\
\hline Parental Perception & & & 5.839 & $<.001$ \\
Accurate & $54.3 \%$ & $50.9 \%$ & & \\
Inaccurate & $45.7 \%$ & $49.1 \%$ & & \\
& & & & \\
\hline
\end{tabular}

Table 6: Kindergarten Cohort: Child's BMI Category as Related to Parental Accuracy

\begin{tabular}{lllllll}
\hline $\begin{array}{l}\text { Child's BMI } \\
\text { category }\end{array}$ & $\begin{array}{l}\text { Underweight } \\
(n=35)\end{array}$ & $\begin{array}{l}\text { Normal weight } \\
(n=590)\end{array}$ & $\begin{array}{l}\text { Overweight } \\
(n=120)\end{array}$ & $\begin{array}{l}\text { Obese } \\
(n=127)\end{array}$ & $\chi 2$ & $\mathrm{P}$ \\
\hline $\begin{array}{l}\text { Parental } \\
\text { Perception }\end{array}$ & & & & & 377.544 & $<.001$ \\
Accurate & $31.4 \%$ & $78.0 \%$ & $21.8 \%$ & $7.1 \%$ & & \\
Inaccurate & $68.6 \%$ & $22.0 \%$ & $95.8 \%$ & $92.9 \%$ & & \\
\hline
\end{tabular}

\section{Second Grade Cohort}

No relationship was found between gender, poverty level, rural designation, or mother's education and accurate parental perception of their child's weight status. However, a significant relationship between whether or not the parent was accurate or inaccurate in the perception of their child's weight status as related to race $(p=0.002)$, child BMI categories $(p<0.001)$, and parent BMI category $(p=0.010)$ was noted. Parents of Caucasian children demonstrated $52.3 \%$ inaccuracy and $47.7 \%$ accuracy in weight status perception. Parents of children categorized as "all other races" had inaccurate perception of $24.2 \%$ and accurate perception of $75.8 \%$ of their child's weight status. 
In groups of parents whose child's BMI was categorized as underweight, $35.3 \%$ were inaccurate and $64.7 \%$ were accurate in perceiving their child's weight status. In parents of children with BMIs categorized as normal, $33.2 \%$ were inaccurate and $66.8 \%$ were accurate. Parents with children having BMIs in the overweight category were $77.8 \%$ inaccurate and 22.2\% accurate. Parents with children in BMI groups considered obese were $89.8 \%$ inaccurate and $10.2 \%$ accurate in weight perception. In parents whose BMI category was designated as underweight, $56.0 \%$ were not accurate and $44.0 \%$ were accurate in perceiving their child's weight. Parents in the normal weight category demonstrated $46.1 \%$ inaccuracy and $53.9 \%$ accuracy. Parents that were categorized as overweight had $43.6 \%$ inaccuracy and $56.4 \%$ accuracy levels while obese parents noted $60.8 \%$ inaccuracy and $39.2 \%$ accuracy in perception of their child's weight (Tables 7, 8, 9).

Table 7: Second Grade Cohort: Race as Related to Parental Accuracy

\begin{tabular}{|c|c|c|c|c|}
\hline \multirow[t]{2}{*}{ Race } & Caucasian & \multicolumn{3}{|c|}{ Non-Caucasian } \\
\hline & $(n=570)$ & $(n=33)$ & $\chi^{2}$ & $\mathrm{P}$ \\
\hline Parental Perception & & & 9.811 & .002 \\
\hline Accurate & $47.7 \%$ & $75.8 \%$ & & \\
\hline Inaccurate & $52.3 \%$ & $24.2 \%$ & & \\
\hline
\end{tabular}


Table 8: Second Grade Cohort: Child's BMI Category as Related to Parental Accuracy

\begin{tabular}{|c|c|c|c|c|c|c|}
\hline $\begin{array}{l}\text { Child's BMI } \\
\text { category }\end{array}$ & $\begin{array}{l}\text { Underweight } \\
(n=17)\end{array}$ & $\begin{array}{l}\text { Normal weight } \\
(n=386)\end{array}$ & $\begin{array}{l}\text { Overweight } \\
(n=90)\end{array}$ & $\begin{array}{l}\text { Obese } \\
(n=108)\end{array}$ & $\chi^{2}$ & $\mathrm{P}$ \\
\hline Parental & & & & & 141.511 & $<.001$ \\
\hline \multicolumn{7}{|l|}{ Perception } \\
\hline Accurate & $64.7 \%$ & $66.8 \%$ & $22.2 \%$ & $10.2 \%$ & & \\
\hline Inaccurate & $35.3 \%$ & $33.2 \%$ & $77.8 \%$ & $89.8 \%$ & & \\
\hline
\end{tabular}

Table 9: Second Grade Cohort Parents' BMI Category as Related to Parental Accuracy

\begin{tabular}{|c|c|c|c|c|c|c|}
\hline $\begin{array}{l}\text { Parents' BMI } \\
\text { category }\end{array}$ & $\begin{array}{l}\text { Underweight } \\
(n=25)\end{array}$ & $\begin{array}{l}\text { Normal weight } \\
(n=256)\end{array}$ & $\begin{array}{l}\text { Overweight } \\
(n=140)\end{array}$ & $\begin{array}{l}\text { Obese } \\
(n=153)\end{array}$ & $\chi^{2}$ & $P$ \\
\hline Parental & & & & & 11.348 & .010 \\
\hline \multicolumn{7}{|l|}{ Perception } \\
\hline Accurate & $44.0 \%$ & $53.9 \%$ & $56.4 \%$ & $39.2 \%$ & & \\
\hline Inaccurate & $56.0 \%$ & $46.1 \%$ & $43.6 \%$ & $60.8 \%$ & & \\
\hline
\end{tabular}

\section{Fifth Grade Cohort}

In the $5^{\text {th }}$ grade cohort there was a significant relationship between whether or not the parent was accurate in the perception of the child's weight status $(p<0.001)$ and the child's gender $(\mathrm{p}<0.001)$. In parents with daughters, $38.2 \%$ were inaccurate and $61.8 \%$ were accurate 
in their perception of the child's weight status. Of the parents with sons, $61.0 \%$ were inaccurate while $39.0 \%$ were accurate in their weight perception of their child.

In cases where the child's BMI was categorized as underweight, $100.0 \%$ were accurate in perceiving their child's weight status. In parents whose children had BMIs in the normal weight category, 26.4\% were inaccurate and 73.6\% were accurate. Parents with children having BMIs in the overweight category were $61.1 \%$ inaccurate and $38.9 \%$ accurate. In parents with children in BMI groups considered obese, $86.8 \%$ were inaccurate and $13.2 \%$ were accurate in weight perception (see Tables 10). No relationship was found between race, poverty level, rural designation, parent BMI category, or mother's education and accurate parental perception of their child's weight status.

Table 10: Fifth Grade Cohort: Gender and Child's BMI Category as Related to Parental Accuracy

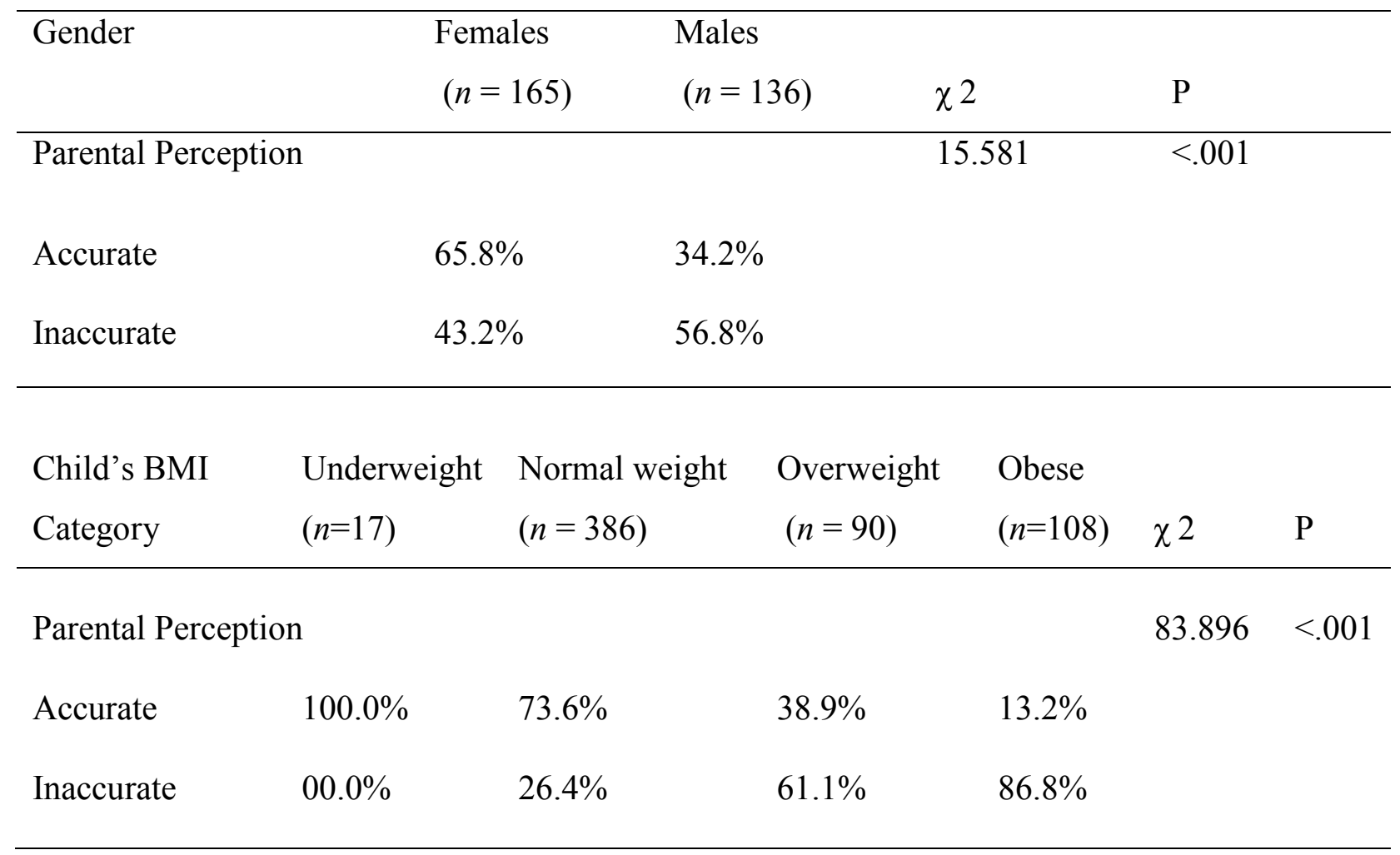


RQ3: Is there a relationship between self-perceived weight status of parents and their actual weight status as determined by CDC guidelines?

\section{Recoding of Variables}

For this question, one variable required recoding. Parent BMI categories required recoding into three categories: a) underweight/normal, b) overweight, and c) obese. This corresponded with the parental perception variables of "about right, overweight, and obese".

Parents of each cohort were evaluated to investigate relationships between their actual weight status and perception of their weight status. All cohorts demonstrated a significant relationship between accuracy in self-perceived weight status of the parent and the parent's actual weight status as determined by their reported weight designated into CDC categories.

\section{Kindergarten Cohort}

Accuracy for self-perceived weight status was less than one-half in parents of kindergarten children in the under/normal weight and overweight group. In the group of parents with BMIs in the obese category, less than one-third were accurate in self-perceived weight status. More than one-half of the parents who were in the under/normal weight BMI category perceived themselves as overweight or obese (Table 11).

Table 11: Kindergarten Cohort: Parental Accuracy of Their Own BMI Category

\begin{tabular}{llllll}
\hline $\begin{array}{l}\text { Parent's BMI } \\
\text { category }\end{array}$ & $\begin{array}{l}\text { Underweight/Normal } \\
\text { BMI }(n=502)\end{array}$ & $\begin{array}{l}\text { Overweight } \\
(n=105)\end{array}$ & $\begin{array}{l}\text { Obese } \\
(n=102)\end{array}$ & $\chi 2$ & $\mathrm{P}$ \\
\hline $\begin{array}{l}\text { Parental } \\
\text { Perception }\end{array}$ & & & & 16.535 & .002 \\
About Right & $43.4 \% *$ & $34.3 \%$ & $25.5 \%$ & & \\
Overweight & $39.4 \%$ & $45.7 \% *$ & $44.1 \%$ & & \\
Obese & $17.2 \%$ & $20.0 \%$ & $30.4 \% *$ & & \\
\hline
\end{tabular}

*indicates accurate perception of parent's weight status 


\section{Second Grade Cohort}

In the second grade cohort, nearly one-half of parents in the under/normal weight category were accurate in self-perceived weight status. Less parents in the overweight category were accurate $(35.6 \%)$ and parents in the obese category demonstrated the lowest accuracy (22.1\%). Slightly more than one-half of the parents in the under/normal weight BMI category group perceived themselves as overweight or obese (Table 12).

Table 12: Second Grade Cohort: Parental Accuracy of their Own BMI Category

\begin{tabular}{llllll}
\hline $\begin{array}{l}\text { Parent's BMI } \\
\text { category }\end{array}$ & $\begin{array}{l}\text { Underweight/Normal } \\
\text { BMI }(n=395)\end{array}$ & $\begin{array}{l}\text { Overweight } \\
(n=87)\end{array}$ & $\begin{array}{l}\text { Obese } \\
(n=104)\end{array}$ & $\chi 2$ & $\mathrm{p}$ \\
\hline Parental & & & & 115.631 & .004 \\
Perception & & & & \\
About Right & $48.4 \% *$ & $40.2 \%$ & $34.6 \%$ & & \\
Overweight & $40.0 \%$ & $35.6 \% *$ & $43.3 \%$ & & \\
Obese & $11.6 \%$ & $24.2 \%$ & $22.1 \% *$ & & \\
\hline
\end{tabular}

*indicates indicates accurate perception of parent's weight status

\section{Fifth Grade Cohort}

Parents with children in the $5^{\text {th }}$ grade cohort had the highest level of accuracy in selfperceived weight status in the under/normal weight BMI category. In this group, 77.3\% accurately perceived themselves as under/normal weight. In the overweight BMI category, $76.9 \%$ perceived themselves to be overweight. In the obese BMI category, slightly more than one-half of the parents were accurate in self-perceived weight status (Table 13). 
Table 13: Fifth Grade Cohort: Parental Accuracy of their Own BMI Category

\begin{tabular}{llllll}
\hline $\begin{array}{l}\text { Parent's BMI } \\
\text { category }\end{array}$ & $\begin{array}{l}\text { Underweight/Normal } \\
\text { BMI }(n=110)\end{array}$ & $\begin{array}{l}\text { Overweight } \\
(n=78)\end{array}$ & $\begin{array}{l}\text { Obese } \\
(n=99)\end{array}$ & $\chi^{2}$ & $\mathrm{p}$ \\
\hline $\begin{array}{l}\text { Parental } \\
\text { Perception }\end{array}$ & & & & 188.467 & $<.001$ \\
About Right & $77.3 \%^{*}$ & $12.8 \%$ & $8.1 \%$ & & \\
Overweight & $20.0 \%$ & $76.9 \% *$ & $38.4 \%$ & & \\
Obese & $2.7 \%$ & $10.3 \%$ & $53.5 \% *$ & & \\
\hline
\end{tabular}

*indicates indicates accurate perception of parent's weight status

RQ4: Are there differences in food provision patterns between parents who accurately perceive their child's weight status as overweight, parents who accurately perceive their child's weight status as under/normal weight, parents who inaccurately perceive their child's weight status as overweight, and parents who inaccurately perceive their child's weight status as under/normal weight?

\section{Variables Measuring Food Provision and Eating Patterns}

Food provision and eating patterns differed between parents who were accurate and inaccurate in perceiving their child's weight status in only one cohort. Seven questions describing present food provision patterns were evaluated. Responses differed in two questions from the second grade cohort.

\section{Recoding of Responses}

To meet the assumption of chi-square analyses, responses to the questions required collapsing and recoding in to similar categories. All of the questions that allowed 5 responses required recoding from 5 responses to 3 due to lack of responses in categories of "never", "rarely" and "sometimes". These three answers were collapsed together as one category of "never, rarely and sometimes." The responses "most often" and "always" were maintained. 
Combining the variables met the assumptions for chi-square and analyses were performed (see Table 14).

Responses were insufficient to calculate the question in four separate groupings of (1) accurate perception in under or normal weight children, (2) accurate perception in overweight children, (3) inaccurate perception in under or normal weight children, and (4) inaccurate perception in overweight children as proposed. Groups of accurate perception and inaccurate perception at any weight status were used with this question related to food provision. This recoding met the assumptions for chi-square analysis. 
Table 14: Food Provision and Eating Patterns Questions and Responses

\begin{tabular}{|c|c|c|c|}
\hline Question & Cohort & $\begin{array}{l}\text { Original Possible } \\
\text { Responses }\end{array}$ & Recoded Responses \\
\hline $\begin{array}{l}\text { How often in the last two } \\
\text { months have you } \\
\text { established regular meal } \\
\text { times? }\end{array}$ & All & $\begin{array}{l}\text { Never } \\
\text { Rarely } \\
\text { Sometimes } \\
\text { Most Often } \\
\text { Regularly }\end{array}$ & $\begin{array}{l}\text { Response 1: } \\
\text { Never, rarely, sometimes, } \\
\text { Response 2: } \\
\text { Most often } \\
\text { Response 3: } \\
\text { Always }\end{array}$ \\
\hline $\begin{array}{l}\text { How often in the last two } \\
\text { months have you required } \\
\text { the family to eat as a } \\
\text { group? }\end{array}$ & All & $\begin{array}{l}\text { Never } \\
\text { Rarely } \\
\text { Sometimes } \\
\text { Most Often } \\
\text { Regularly }\end{array}$ & $\begin{array}{l}\text { Response 1: } \\
\text { Never, rarely, sometimes, } \\
\text { Response 2: } \\
\text { Most often } \\
\text { Response 3: } \\
\text { Always }\end{array}$ \\
\hline $\begin{array}{l}\text { How often in the last two } \\
\text { months have you talked } \\
\text { to your child about } \\
\text { his/her eating habits }\end{array}$ & All & $\begin{array}{l}\text { Never } \\
\text { Rarely } \\
\text { Sometimes } \\
\text { Most Often } \\
\text { Regularly }\end{array}$ & $\begin{array}{l}\text { Response 1: } \\
\text { Never, rarely, sometimes, } \\
\text { Response 2: } \\
\text { Most often } \\
\text { Response 3: } \\
\text { Always }\end{array}$ \\
\hline $\begin{array}{l}\text { To what extent can you } \\
\text { child independently } \\
\text { decide what to eat at } \\
\text { home }\end{array}$ & All & $\begin{array}{l}\text { Never } \\
\text { Rarely } \\
\text { Sometimes } \\
\text { Most Often } \\
\text { Regularly }\end{array}$ & $\begin{array}{l}\text { Response 1: } \\
\text { Never, rarely, sometimes, } \\
\text { Response 2: } \\
\text { Most often } \\
\text { Response 3: } \\
\text { Always }\end{array}$ \\
\hline $\begin{array}{l}\text { To what extent can your } \\
\text { child independently } \\
\text { decide what to eat outside } \\
\text { the home }\end{array}$ & All & $\begin{array}{l}\text { Never } \\
\text { Rarely } \\
\text { Sometimes } \\
\text { Most Often } \\
\text { Regularly }\end{array}$ & $\begin{array}{l}\text { Response 1: } \\
\text { Never, rarely, sometimes, } \\
\text { Response 2: } \\
\text { Most often } \\
\text { Response 3: } \\
\text { Always }\end{array}$ \\
\hline $\begin{array}{l}\text { Do you encourage your } \\
\text { child to eat healthier? }\end{array}$ & Kindergarten & $\begin{array}{l}\text { Never } \\
\text { Rarely } \\
\text { Sometimes } \\
\text { Most Often } \\
\text { Regularly }\end{array}$ & $\begin{array}{l}\text { Response 1: } \\
\text { Never, rarely, sometimes, } \\
\text { Response 2: } \\
\text { Most often } \\
\text { Response 3: } \\
\text { Always }\end{array}$ \\
\hline $\begin{array}{l}\text { Do you use sweets as a } \\
\text { reward? }\end{array}$ & Kindergarten & $\begin{array}{l}\text { Never } \\
\text { Rarely } \\
\text { Sometimes } \\
\text { Most Often } \\
\text { Regularly }\end{array}$ & $\begin{array}{l}\text { Response 1: } \\
\text { Never, rarely, sometimes, } \\
\text { Response 2: } \\
\text { Most often } \\
\text { Response 3: } \\
\text { Always }\end{array}$ \\
\hline $\begin{array}{l}\text { Do you encourage your } \\
\text { child to eat healthier? }\end{array}$ & $\begin{array}{l}\text { Second Grade } \\
\text { Cohort }\end{array}$ & $\begin{array}{l}\text { Yes } \\
\text { No }\end{array}$ & $\begin{array}{l}\text { Yes } \\
\text { No }\end{array}$ \\
\hline $\begin{array}{l}\text { Do you use sweets as a } \\
\text { reward? }\end{array}$ & $\begin{array}{l}\text { Fifth Grade } \\
\text { Cohort }\end{array}$ & $\begin{array}{l}\text { Yes } \\
\text { No }\end{array}$ & $\begin{array}{l}\text { Yes } \\
\text { No }\end{array}$ \\
\hline
\end{tabular}




\section{Parental Accuracy and Food Provision Patterns.}

No significant relationships were found in the group of parents of kindergarten or fifth grade children that accurately or inaccurately perceived their child's weight status and food provision patterns. Significant relationships were found in second grade (see Tables 15, 16) between the groups that accurately and inaccurately perceived their child's weight status when asked: "In the past 2 months, how often have you done the following: Talked to your child about his/her eating habits?" $(p=0.044)$ and "To what extent can your child independently decide what to eat at home?" $(p=0.015)$.

\section{Second Grade Parents}

\section{Discussion of Eating Habits}

In second grade parents who inaccurately perceived their child's weight status, $35.7 \%$ responded that they "Never, rarely, or sometimes" talked to their child about their eating habits. In the same group, "Most often" was noted $41.4 \%$, and "Always" 22.9\%. In second grade parents who accurately perceived their child's weight status, $47.4 \%$ responded that they "Never, rarely, or sometimes" talked to their child about their eating habits. In the same group, "Most often" was noted $31.3 \%$, and "Always" 21.3\%.

\section{Independence of Child in Food Decision}

In the group that inaccurately perceived their child's weight status, $53.2 \%$ responded that they "Never, rarely, or sometimes" thought that their child could independently decide what to eat while at home. When asked about their child's eating habits, "Most often" was given in $39.3 \%$ of that group, and "Always" $7.5 \%$. In the group of parents that accurately perceived their child's weight status, $61.1 \%$ responded that they "Never, rarely, or sometimes" thought that their child could independently decide what to eat while at home. "Most often" was given in $28.4 \%$ 
of the parents who accurately perceived their child's weight status and $10.5 \%$ responded that they "Always" thought their child could independently decide what to eat at home (Tables 15 and 16).

Table 15: Second Grade Cohort: Talked to Child About Eating Habits

\begin{tabular}{lllll}
\hline $\begin{array}{l}\text { Perception of Child's weight } \\
\text { Status }\end{array}$ & $\begin{array}{l}\text { Accurate } \\
(n=303)\end{array}$ & $\begin{array}{c}\text { Inaccurate } \\
(n=319)\end{array}$ & $\chi^{2}$ & $\mathrm{P}$ \\
\hline Responses & $47.4 \%$ & $35.7 \%$ & & \\
Never, Rarely, Sometimes* & $31.3 \%$ & $41.4 \%$ & \\
Most Often & & & \\
& $21.3 \%$ & $22.9 \%$ & \\
Always & & & \\
\hline
\end{tabular}

*Combined responses

Table 16: Second Grade Cohort: Decide What to Eat at Home

\begin{tabular}{lllll}
\hline $\begin{array}{l}\text { Perception of Child's weight } \\
\text { Status }\end{array}$ & $\begin{array}{c}\text { Accurate } \\
(n=296)\end{array}$ & $\begin{array}{c}\text { Inaccurate } \\
(n=295)\end{array}$ & $\chi 2$ & $\mathrm{P}$ \\
\hline Responses & & & 8.351 & .015 \\
Never, Rarely, Sometimes* & $61.1 \%$ & $53.2 \%$ & & \\
Most Often & $28.4 \%$ & $39.3 \%$ & \\
Always & $10.5 \%$ & $7.5 \%$ & \\
\hline
\end{tabular}

RQ5: Is there a relationship between accuracy in weight status perception for parents and accuracy for their child?

Parent's accuracy in self-perception of their own weight status was compared to accurate or inaccurate perception for their child's weight status. Chi-square assumptions were met. There were no significant relationships in parents of kindergarten or fifth grade cohorts regarding accuracy of parental weight status for themselves and for their children. A significant 
relationship $(p=0.038)$ was found in the second grade cohort between perception of parent's own weight status and perception of their child's weight status.

Parents of children in the second grade cohort, who were not accurate in perceiving their own weight status, were typically not accurate for their child (56.5\%). In the group of parents from the second grade cohort who were accurate in their own weight status perception, $47.6 \%$ were not accurate in perceiving their child's weight status (see Table 17).

Table 17: Accuracy in Weight Status Perception for Parents and Accuracy for Their Child

\begin{tabular}{lllll}
\hline $\begin{array}{l}\text { Perception of Child's } \\
\text { Weight Status }\end{array}$ & $\begin{array}{l}\text { Accurate } \\
(n=296)\end{array}$ & $\begin{array}{c}\text { Inaccurate } \\
(n=295)\end{array}$ & $\chi^{2}$ & $\mathrm{P}$ \\
\hline $\begin{array}{l}\text { Parental Self- } \\
\text { accuracy }\end{array}$ & & 4.288 & .038 \\
Accurate for Self & $52.4 \%$ & $47.6 \%$ & & \\
Inaccurate for Self & $43.5 \%$ & $56.5 \%$ & & \\
\hline
\end{tabular}

RQ6: What are the significant predictors of accuracy in parental perception of their child's weight status?

Determining the predictors for accurate and inaccurate perception was performed using binary logistic regression. Before conducting the regression analyses, the set of predictor variables was evaluated for multicollinearity by computing collinearity diagnostics in SPSS. For each cohort the corresponding set of predictor variables was tested for tolerance and VIF (variance inflation factor). A tolerance of less than 0.10 or a VIF value of above 10.0 indicates multicollinearity (Munro, 2005). The lowest value for tolerance in the data was 0.958 and the highest value for VIF was 1.044. A casewise listing of residuals was requested along with the logistic regression output in SPSS in each cohort. Extreme residuals were used to identify outliers. Cases listed as outliers were identified. They were then removed from each cohort and 68 
regression was again performed. Within each cohort, predictor variables maintained similar levels of significance as in the original logistic testing results.

For each cohort, the dependent variable, "parental accuracy for their child's weight status" was tested with demographic variables and food provision questions that were found to be statistically significant in univariate analysis. In the kindergarten cohort, independent variables included in the regression analysis were gender and child's BMI category. The independent variables in second grade cohort were: food provision questions "talked to your child about his/her eating habits", "independently decide what to eat at home", race, child's BMI category and parent BMI category. In the cohort of fifth graders, independent variables were gender and child's BMI category.

\section{Kindergarten Cohort}

Of the two variables considered for predictors of parental accuracy, only one was significant. In the kindergarten cohort, gender was not a significant predictor of accuracy. However, child's BMI category was a significant predictor of accurate parental perception of their child's weight status $(p<0.001)$. Compared to the parents of children in the under/normal weight group, the parents of children in the overweight category $(p<0.001)$ noted a $98.70 \%$ decrease in odds of being accurate. The odds of being accurate decreased by $97.7 \%$ for the parents of obese children $(p<0.001)$ compared to the parents of under/normal weight children (Table 18).

\section{Second Grade Cohort}

Two predictors of accuracy were found in the second grade cohort. In parents of the second grader cohort, BMI category was a significant predictor of accurate parental perception of their child's weight status $(p<0.001)$. Compared to the parents of children in the under/normal 
weight group, parents of children in the overweight category $(p<0.001)$ noted an $87.4 \%$ odds decrease of being accurate. The odds of being accurate decreased by $93.0 \%$ for parents of obese children $(p<0.001)$ compared to under/normal weight children. Race was observed as a significant predictor of parental accuracy $(p=0.006)$. The odds of being accurate for the parents of non-Caucasian children are 6.754 times the odds of being accurate for parents of Caucasian children. That is a $575.4 \%$ increase in odds of being accurate (Table 19).

\section{Fifth Grade Cohort}

Again, child's BMI category was a significant predictor of parental accuracy in the fifth grade cohort $(p<0.001)$. Compared to the parents of the under/normal weight group, the parents of children in the overweight category $(p<0.001)$ demonstrated a $77.9 \%$ odds decrease of being accurate. The odds of being accurate decreased by $95.8 \%$ for parents of obese children ( $p$ $<0.001$ ) compared to parents of under/normal weight children (Table 20). 
Table 18: Kindergarten Association Between Accurate Prediction of Child's Weight Status and BMI Category

95\% C.I.for

Variable

EXP(B)

B S.E. Wald df Sig. $\quad$ Exp(B) Lower Upper

BMI Category

Under/normal*

$184.3972 \quad .000$

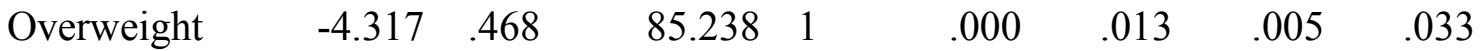

$\begin{array}{lllllllll}\text { Obese } & -3.756 & .359 & 109.351 & 1 & .000 & .023 & .012 & .047\end{array}$

*Reference Category

Table 19: Second Grade Association Between Accurate Prediction of Child's Weight Status,

Race, and BMI Category

\begin{tabular}{|c|c|c|c|c|c|c|c|c|}
\hline Variables & B & S.E. & Wald & $\mathrm{df}$ & Sig. & $\operatorname{Exp}(B)$ & $\begin{array}{c}95 \% \\
\text { C.I.for } \\
\text { EXP(B) }\end{array}$ & \\
\hline & & & & & & & Lower & Upper \\
\hline \multicolumn{9}{|c|}{ BMI Category } \\
\hline \multicolumn{9}{|c|}{ Under/normal* } \\
\hline & & & 53.872 & 2 & .000 & & & \\
\hline Overweight & -2.075 & .416 & 24.869 & 1 & .000 & .126 & .056 & .284 \\
\hline Obese & -2.666 & .459 & 33.735 & 1 & .000 & .070 & .028 & .171 \\
\hline Race ** & 1.910 & .689 & 7.677 & 1 & .006 & 6.754 & 1.749 & 26.082 \\
\hline
\end{tabular}

*Reference Category **Non-Caucasian as compared to Caucasian. 
Table 20: Fifth Grade Association Between Accurate Prediction of Child's Weight Status and BMI Category

\begin{tabular}{|c|c|c|c|c|c|c|c|c|}
\hline Variables & B & S.E. & Wald & $\mathrm{df}$ & Sig. & $\operatorname{Exp}(B)$ & $\begin{array}{l}95 \% \\
\text { C.I.for } \\
\operatorname{EXP(B)}\end{array}$ & \\
\hline BMI Category & & & & & & & Lower & Upper \\
\hline Under/Normal* & & & 66.972 & 2 & .000 & & & \\
\hline Overweight & -1.511 & .331 & 20.901 & 1 & .000 & .221 & .115 & .422 \\
\hline Obese & -3.169 & .414 & 58.578 & 1 & .000 & .042 & .019 & .095 \\
\hline
\end{tabular}

*Reference Category 


\section{Chapter 5: Discussion}

This chapter presents a discussion of the findings of the study. Limitations of secondary data analyses are discussed. Findings of the study are reviewed and then related to current knowledge in the field. This chapter will conclude with a discussion of implications of the findings of this study for nursing practice and future research recommendations.

The sensitizing framework for this study was the Health Belief Model. This chapter will discuss individual perceptions as reflected in parental perception of their child's weight status. Evaluations of modifying factors of parental perception will be discussed as well as likelihood of actions which is described as food provision and eating factors. In addition, an analysis of the utility of the Health Belief Model in supporting this study will be presented.

\section{Limitations of Secondary Data}

This study utilized secondary data to answer the research questions. While secondary data are a valuable resource, use of such data presents certain limitations. The data were collected for defined purposes, not specifically for the aims of this study. Therefore, data analysis required redefining variables and re-categorizing of data elements to meet the objectives of this study. These changes resulted in decreased variability of the data potentially impacting the results. Re-categorizing the data was performed with vigilance to preserve the original definition of the variables while balancing the need to have adequate responses in each category. Categories that required collapsing due to insufficient responses in each cell were: parental perception of the child's weight status, child's BMI category, parent's BMI category, parent's educational level, RUCA codes, child's race, and food provision responses.

Parental perception of their child's weight status and parental perception of their own weight status were collapsed to perform statistical analyses. Too few responses were given in 
two of the four categories of perception (underweight and obese) in both parent's perceiving their child's weight status and perceiving their own weight status. After combining four perception categories into two, BMI status had to be adjusted from four categories into two (under/normal and overweight/obese) to match the perception categories for both the parent and child. Combining BMI categories from four specific categories into two reduces the variability of the data. Self-reporting of height and weight by the parents could have been over or under estimated, further distorting the actual BMI category of the parents.

This study aimed to describe perception of the child's weight status by parents. However, most of the forms in the original study were completed by mothers with an insignificant number of questionnaires completed by fathers or other family members in the kindergarten and second grade cohort. The fifth grade cohort did not contain information regarding who completed the questionnaire. This suggests that for two cohorts, the study is primarily evaluating the mother's perception of the child's weight status. Lack of information in the fifth grade cohort as to who completed the form makes it difficult to identify which parent actually perceived the weight status and makes comparison with other studies challenging.

Parental perception of their child's weight status was assessed using questions from the study that asked parents to evaluate their child's appearance to other children of the same age and gender. Considering the rate of obesity in the general population of children in West Virginia (Neal et al., 2006) $\{\{\}\}$, this method of questioning and comparison could be limiting. In this study, it could not be determined if the parent was comparing their child to another child in the normal weight category. If comparison of the child's weight status was to children who were overweight or obese, parental accuracy would naturally be distorted. 
The use of secondary data presents risks that variables may be operationalized during data collection in a way that is inconsistent with the conceptual definitions adopted for this study. Food provision and eating patterns were evaluated in this study by seven questions related to the child's dietary intake. Data elements from the available data set were not comprehensive in capturing the child's food provision and eating patterns, therefore limiting the ability to fully measure the variables as conceptualized.

The secondary data used in this study did not adequately represent the population of West Virginia as related to educational status. A higher level of education was noted in the respondents than in the general population of West Virginia (West Virginia Quick Facts from the US Census Bureau). The higher education of the sample, than in the general population, may have impacted the respondent's perceptions, as education may be linked to understanding of the implications of overweight and obesity.

Another limitation of this study was the need to use a proxy measure of socioeconomic status of respondents for analyses. Income levels were not collected in the original study, so family socioeconomic level was determined by the mean income of the county where the families resided. This method is not reflective of the individual family. Using county level socioeconomic status to classify family socioeconomic status can lead to inaccurate estimation of actual socioeconomic status. The actual relationships of socioeconomic status on parental perception of their child's weight status could be distorted.

Limitations were noted with respect to geographic location in this study. RUCA codes were used to classify rural or urban dwelling of the family. Lack of representation of every county in the state in the original data set allowed only certain RUCA codes to be represented. Several of the RUCA areas contained too few respondents and had to be combined with similar 
RUCA code areas. The lack of representation from all RUCA codes may have prevented the true impact of rural dwelling on the outcome of the study. The location of the original data collection sites in the Appalachian area suggests a prevalence of Appalachian culture in the respondents. However, this study does not account for residents living in the area who would not self-identify as a member of the Appalachian cultures by virtue of in-migration or other factors. Lack of self-identified ethnic information prevents comparison of this study with other Appalachian studies.

\section{Individual Perceptions/Parental Perception of Child's Weight Status}

\section{Perceived Susceptibility and Perceived Severity}

According to the Health Belief Model, perceived severity of a disease process and how vulnerable the person is to that process determines the likelihood of taking action to prevent the disease process. Perception of severity involves understanding the potential outcomes of a particular disease process. Perceived susceptibility involves acknowledging the present state of health as well as the tendency of the present state of health to incur illness (Glanz, Lewis, \& Rimer, 1990; Hochbaum, 1958; Rosenstock, 1960; Rosenstock, 1974). Individual perceptions, in this study, correspond to the measured variable of parental perception of their child's weight status.

\section{Individual Perceptions/Parental Perception}

Parental perception of their child's weight status was often accurate as compared to the child's actual BMI category in this sample. Accurate parental perception of their child's weight status was highest among kindergarten children and declined to its lowest rate in parents of fifth grade children. This is in direct contrast to other studies of parental recognition of their child's weight status. The perceptions of the parents in this study, as compared to other studies, were 
more accurate than those of parents reported in the literature (Baughcum et al., 2000; Myers \& Vargas 2000; National Center for Health Statistics, 2000; Hackie \& Bowles, 2007; Jeffery, Voss, Metcalf, Alba, \& Wilkin, 2005;West et al., 2008; Cottrell et al., 2007). The contrast in results could be explained by the larger sample of children in this study than noted in previous studies, as well as the similarity of ages in each of the cohorts in this study. Higher educational level of the parents may have influenced perception of the parents regarding their child's weight status in this study. Also, the time lapse since the previous studies were completed could account for the difference, since education on children's obesity has been initiated in the media (Baughcum et al., 2000; Myers \& Vargas 2000; National Center for Health Statistics, 2000; Hackie \& Bowles, 2007; Jeffery et al., 2005; West et al., 2008; Cottrell et al., 2007).

Parental perception of their child's weight status related to the child's BMI category. To further investigate aspects of accurate and inaccurate parental perception of their child's weight status, BMI categories were re-expanded into the four original categories (underweight, normal weight, overweight, and obese) and then compared only to established accurate and inaccurate parental perception. When accurate parental perception of their child's weight status was compared to BMI categories, differences in parental accuracy of their child's weight status at each BMI category were identified. There was a major decrease in parental accuracy at the obese category in all cohorts. The major decrease in parental accuracy in the obese category is difficult to explain. Perhaps the line between overweight and obesity is not clear to parents. Few studies have specifically linked BMI categories to accurate parental perception of their child's weight status and under/normal weight children were not always included in the studies. One previous study did evaluate parental perception of their child's weight status and included categories other than overweight and obese. West et al (2008) noted less than one-half of parents with children 
having BMIs in the underweight category were accurate in weight perception. Other studies were conducted primarily with overweight children without a distinction between overweight and obese, and BMI categories were not always used for comparison to parental perception of their child's weight (Baughcum et al., 2000; Myers \& Vargas 2000; National Center for Health Statistics, 2000; Hackie \& Bowles, 2007).

Differences in accurate parental perception related to the age of the child in this study varied from the literature. Accurate parental perception of their child's weight status declined as the child got older in this study. Other studies in the literature demonstrated lower accuracy in children younger than 6 years of age (West et al., 2008) and higher accuracy in children older than 6 years of age (Eckstein et al., 2006; Maynard, Galuska, Blanck, \& Serdula, 2003; Wald et al., 2007).

The influence of Appalachian culture and beliefs may be responsible for the discrepancy in agreement of parental perception of their child's weight status with the literature. Appalachian culture holds the belief that heavier children are stronger and better equipped for sports. As the child ages, parents may perceive that the size of the child demonstrates sustenance and hardiness. Thin, or even normal weight children are often seen as disadvantaged with less ability to withstand illness and other adverse situations. Parent's beliefs that they have performed well in nurturing their child by feeding them adequately are reinforced through having a child who is heavier (Cochran, 2005; Cochran, 2008; Trombini et al., 2003). However, lack of knowledge as to whether the sample would self-identify as an Appalachian remains a limitation.

\section{Parental Perception of Their Own Weight Status}

Parents of $5^{\text {th }}$ grade children demonstrated the highest level of accuracy in perceiving their own weight status. Interestingly, more than half of the parents of children in kindergarten 
and second grade cohort that were under/normal weight thought that they were overweight or obese. Inaccurate perception by parents of their own weight status has been noted in other studies. Chang (2003) noted inaccurate parental perception of their own weight status in women from both normal weight and overweight categories. However, other studies found that mothers were correct in assessing their own weight status (Crouch, O'Dea, \& Battisti, 2007) and in general women were more accurate than men in self-perceived weight status (Dorsey, Eberhardt, \& Ogden, 2010). Other factors that could potentially influence parental perception of their own weight status were not measured in this study. Young postpartum mothers or breastfeeding mothers, while not overweight or obese by standard criteria, could be at a different weight than their perceived normal weight. Inaccurate perception in this study could also be reflective of the culture of Appalachia and the overall acceptance of overweight and obesity as signs of health and hardiness (Brown \& May, 2005).

\section{Parental Self-Accuracy Compared to Accuracy for Their Child}

Parents who were accurate in perceiving their own weight status were not consistently accurate in perceiving their child's weight status. Only the results from parents of second grade children demonstrated a relationship between accurately perceiving their own weight status and accurately perceiving their child's weight status. The inconsistencies between parents who accurately perceived their own weight status, as well as their child's weight status in this study, concur with previous literature. One study noted that mothers underestimated their own weight status as well as their child's weight status (Harrison et al., 2007). In comparison, other studies found that mothers correctly assessed their own obesity, but did not correctly assess their child's obesity (Crouch et al., 2007). Similar studies by West et al (2008) and Jeffery et al (2005) noted that parental weight status was not associated with accurate perception of their child's 
weight status. Multiple factors could influence the lack of relationship between parental accuracy for their own weight status and accuracy for the weight status of their child. Age of the child could be a factor. Age of the mother as well as changes occurring to her body during pregnancy could influence perception of her weight status. Another factor that may contribute to the difference in parental perception of their own weight status and perception of their child's weight status is the strong Appalachian belief that heredity controls the size of their body and that larger body size represents hardiness and strength rather than a disease process (Cochran, 2005; Cochran, 2008).

\section{Perception Summary}

The Health Belief Model depicts individual perceptions, or in this study, parental perceptions of their child's weight status, as a process leading to perceived threat of illness. Accurate parental perception includes knowledge of the implications of the size of their child as correlated with the health benefits and risks that the size imposes upon the child. How susceptible the child is to obesity, as well as the severity of diabetes and hypertension, influences accurate parental perception of their child's weight status. However, this study's findings did not measure the meaning of BMI category to the parent. Without the measurement of perceived threat, individual perception cannot be evaluated. According to the HBM, parents will not consider perceived benefits of taking action until they realize that their overweight/obese child is unhealthy. Likelihood of action will not occur until the perceived benefits of taking action are realized.

\section{Modifying Factors}

According to the Health Belief Model, individual perceptions are influenced by multiple factors. Personal experience with illness may modify perception of the severity of a disease 
process. Demographic influences of culture, gender, socioeconomic status, and knowledge alter perception as well as the perceived threat of an illness. Cues to action offer substantial impact on perception, especially from respected sources. The impact of modifying factors and cues to actions upon individual perception creates a perceived threat of the illness (Glanz et al., 1990; Hochbaum, 1958; Rosenstock, 1960; Rosenstock, 1974). This study measured gender, rurality, socio-economic status, race, education, and child's BMI status as potential modifiers of the severity of obesity.

\section{Demographic Factors}

In this study, gender of the child was related to accurate parental perception of their child's weight status in parents of kindergarten and fifth grade children. Parents of younger children were more accurate in perceiving their daughter's weight status than their son's. This finding is consistent with previous studies that found parental accuracy in perception of their child's weight status more consistently in daughters than sons (Crouch et al., 2007; Maynard et al., 2003; Wald et al., 2007). Society's generalized acceptance of larger males, while females are expected to be smaller, may explain these findings (Cafri \& Thompson, 2004; McCreary, 2002).

Other modifying factors for accurate parental perception varied among the cohorts. Modifying factors of race, education, poverty and rural designation had limited to no impact on accurate parental perception of their child's weight in all cohorts. Race was found to only be a modifier in the cohort of second grade children in "all other races", and due to small numbers of children in these categories, is considered to be a coincidental finding. Previous studies found high levels of inaccurate perception in WIC populations which included homogeneous respondents from lower socioeconomic status and lower educational levels groups (Etelson et al., 2003; Myers \& Vargas, 2000; Jain et al., 2001; Baughcum et al., 2000; Baughcum et al., 
1998). Baughcum et al. (2000) identified lower educational status of the mother as an associated factor of inaccurate parental perception of their child's weight status. These studies, however, were conducted primarily with lower income families (income at or below $185 \%$ of the U.S. Poverty Income Guidelines), making the impact of income versus education is difficult to ascertain. Myers and Vargas (2000) noted low levels of accurate parental perception of their child's weight status among Hispanic families. The homogenous nature of this sample most likely prevented the impact of race, education, and income on the results.

The dissimilarity of previous literature with this study may be multi-factorial. The discrepancy may be explained by noting that the majority of the children in this study were Caucasian, and other races were not well represented. Also, the higher than average educational status of the parents, as well as the determination of the socioeconomic status of the families determined by proxy in this study, could explain the differences in findings in this study and those studies reported in previous literature.

\section{Perceived Threat}

Perceived threat of illness is the catalyst for likelihood of action in the Health Belief Model. The realization of the perceived threat of the illness motivates likelihood of change within the individual (Glanz et al., 1990; Hochbaum, 1958; Rosenstock, 1960; Rosenstock, 1974). This study did not address parental recognition of perceived threat associated with the child's weight status. However, it has been addressed in previous literature. Myers and Vargas (2000) used direct visualization of overweight children aged 2-5. Parents did acknowledge health risks, especially cardiac risks, of their child being overweight. However, parents did not perceive their child as overweight/obese. Wake et al. (2002) reported that parents were not aware of their child's obesity and therefore did not perceive the association between health risks 
and obesity for their child. Another study noted that parents of normal weight and overweight children did not differ in the concerns of excess weight as a health indicator (Etelson et al., 2003). Quantifying the perceived threat of their child's BMI category is crucial to the process of the Health Belief Model. Individual perceptions change as perceived threats are realized.

\section{Modifying Factors Summary}

The relationship of modifying factors to parental perception of their child's weight status and likelihood of action did not support the HBM overall. The only modifying factor related to parental perception of their child's weight status was the child's gender. Other demographic factors did not show relationship in groups that were accurate and inaccurate in perceiving their child's weight status.

\section{Actions/Likelihood of Change}

According to the Health Belief Model, perceived benefits of the health related behavioral change minus perceived barriers to change results in the likelihood that the behavioral change will occur (Glanz et al., 1990; Hochbaum, 1958; Rosenstock, 1960; Rosenstock, 1974). Benefits of providing a healthy diet for their child, minus the barriers of changing their child's food provisions patterns dictate the likelihood that the parent will take action. In order for parents to indentify perceived benefits and barriers to change, they must first accurately perceive their child's weight status. This study evaluated the relationship between parental perception of their child's weight status and actions, defined as food provision and consumption patterns.

\section{Food Provision Patterns}

Significant relationships between food provision and consumption patterns in families with parents who were accurate and inaccurate in perceiving their child's weight status were found in only one cohort. In second grade children, parents who were inaccurate in perceiving 
their child's weight status were more likely to respond affirmatively that they talked to their child about their eating habits. This result is not easily explained. The lack of relationship between food provision and consumption patterns in this cohort might be due to the concern that parents perceived their normal weight child as underweight and therefore needed additional nutrition or that quantity, rather than quality, was emphasized.

Conversely, parents who were accurate in their perception of their child's weight status were more likely to respond that they seldom, if ever, talked to their child about the child's eating habits. As might be predicted by the Health Belief Model, Appalachian beliefs that heavy people are hardy may contribute to the lack of intervention by parents related to food consumption and eating patterns. Appalachian people often are fatalistic and therefore feel powerless to change (Cochran, 2005). Also, lack of a relationship between parents who accurately perceived their child's weight status and food provision and consumption patterns may represent perceived inadequacies in parenting compensated by nutritional control regardless of the child's perceived weight status (Cochran, 2008; Trombini et al., 2003). It is difficult to substantiate the influence of Appalachian culture without self-identified ethnic information.

The lack of parental awareness of self-regulating mechanisms in the child's consumption patterns is confirmed in the literature. Studies suggest that mothers have an inherent need to control the food provision of their child. Trombini et al. (2003) noted that mothers of overweight or obese children had an insistent requirement of idealization in their own role as a parent and required frequent reinforcement that their care was sufficient. Investigators have suggested that overfeeding meets this need. Previous studies suggest that mothers who overfeed their child have lessened the self-control of the child's eating patterns (Laessle et al., 2001). 
In this study, parental recognition of their child's BMI status does not relate to action. The lack of significant relationship between parents who were accurate/inaccurate in perceiving their child's weight status and to questions about food provision and consumption patterns could indicate that parents did not perceive the threat of their child's weight status and associated health risks. Association of hardiness, health, and stability associated with large body size has historically been a facet of Appalachian culture (Cochran, 2005; Cochran, 2008). The results of this study may be been impacted by the use of questions that do not accurately represent food provision and consumption patterns.

\section{Likelihood of Action Summary}

In this study, food provision and consumption patterns were used to measure likelihood of action as described in the HBM. However, food provision patterns were not related to accurate and inaccurate parental perception of their child's weight status in this study. Perceived threat of illness must be evaluated to adequately test the model and determine the likelihood of action.

\section{Utility of the Health Belief Model as a Framework for this Study}

Although the Health Belief Model has been shown to be helpful predicting action in many populations, this study documents that the HBM's utility is limited when applied to situations in which participants do not perceive a health threat, even though the threat does in fact exist. In this study, individual perception was defined as parental assessment of their child's BMI categories. Findings demonstrated that parents in this sample were likely to correctly identify their children's weight status as defined by current standards. While perception was accurate in many cases, it does not seem to have led to action for change in food consumption patterns, nor do any of the modifying factors, except gender, help to predict accuracy. It is not 
known if parents perceived a threat related to their child's abnormal weight status. Therefore, the HBM has limited utility in predicting actions in this study. However, if gaps in the model were bridged and measured; and if additional model elements, such as perceived threat and cues to action were measured, utility would be increased. Utility of the HMB could also be increased by restructuring food provision and consumption patterns questions and decreasing the limitations of the sample.

Partially related to the use of secondary data, gaps in the available data for this study to measure all components of the HBM prevented adequate testing of the theory.

Acknowledgement of the child's accurate BMI status by their parents is imperative; however, the health threat imposed by BMI status on the child must also be measured. Whether parents accurately perceive the weight status of their child is secondary to the relationship of overweight or obesity to the health of their children. Health promotion actions will only occur when parents accurately associate the threat of health risks to the BMI category (see figure 3). 
Figure 3: Parental Perception and Perceived Threat

\begin{tabular}{|l|l|l|}
\hline \begin{tabular}{|l|l|} 
Individual \\
Perceptions
\end{tabular} & $\begin{array}{l}\text { Likelihood of } \\
\text { Action }\end{array}$ \\
\hline $\begin{array}{l}\text { Parental } \\
\text { Perception of their } \\
\text { Child's } \\
\text { Weight Status: } \\
\text { Accurate/Inaccurat } \\
\text { - Pactors }\end{array}$ & $\begin{array}{l}\text { Socio-economic } \\
\text { status } \\
\text { Education } \\
\text { Rurality } \\
\text { Parental Weight } \\
\text { Status } \\
\text { Race/Ethnicity }\end{array}$ \\
\hline
\end{tabular}

Adapted from Becker, M. H., Drachman, R. H., \& Kirscht, J. R. (1974). A new approach to explaining sick-role behavior in low income populations. American Journal of Public Health, 64, 205-216. (Fig 1, p. 206).

\section{Implications for Practice}

Implications for nursing practice are identified. Nurses have great potential for interactions with mothers of school age children. Nurses are involved in weight and measurement of children through primary care centers, WIC programs, and within schools. The 
brief interactions in these sites provide nurses excellent opportunities for educating parents and their children about proper nutrition, appropriate weight status for their children, and health risks of obesity.

Educating parents to adequately care for their children begins at birth and continues throughout childhood. Nurses can assist parents in perceiving normal weight status for their infant and reinforce that an overweight baby does not imply a "healthy" baby. Nurses can teach parents about the risks of developing obesity at a young age and the health risks associated with overweight and obese children. Nurses can assist in teaching feeding patterns at birth when the infant begins to consume nutrition. Understanding the infant's nutritional self-regulation and hunger cues can be taught and reinforced. Information regarding transitional feeding patterns can be instituted as the child develops and returns to primary care providers for well-child care. Educating parents regarding appropriate nutritional methods early in the life of the child could prevent future improper food provision and consumption patterns.

For children with a BMI status that is overweight or obese, nurses must understand that the literature describes parental perception of their child as personal and subjective. Informing a parent that their child is not "normal" requires communication skills and supportive actions that do not cause the parent guilt or embarrassment or make them feel as if their parenting skills are less than adequate. Identifying children that have a BMI in the overweight or obese category presents the nurse with a population of parents who are at high-risk for inaccurate perception of their child's weight status. Nurses have the ability and the position to interact with the parent to shift parental perceptions toward accuracy in a positive manner. The increase of obesity between second and fifth grade in this sample demonstrates a need for nursing interventions early, preferably during and after second grade. Interventions should be targeted in these age groups, 
especially for parents of male children. Programs that emphasize athletes with normal BMIs could serve as cues to action in promoting likelihood of change for parents of overweight or obese children.

Nurses can educate parents about health risks associated with obesity. As parents accurately understand their child's weight status, the health benefits and risks of that particular BMI category can be explained to the parents. The benefit of a normal BMI for their child can potentially be a motivating factor for change.

Parents of underweight and normal weight children may also demonstrate inaccuracy in perceiving their child's weight status. Nurses can emphasize to parents that their child is normal weight and encourage feeding practices that maintain a healthy weight status. Children who are considered underweight also require specialized nutritional counseling.

In primary care, the school systems, and in WIC, nurses can target children with demographic characteristics, such as gender, whose parents are more likely to be inaccurate in their perception of their child's weight status. Methods can be initiated to assist parents of male children in understanding and accurately perceiving their child's weight status. For parents of pre-adolescent males, programs to promote parental accuracy of weight status and the difference in being muscular and being obese can be demonstrated. Also, noting that a significant number of parents in each cohort perceived themselves as overweight when they were in the normal BMI category suggests that programs demonstrating differences between normal BMI status and underweight BMI categories should be implemented.

Programs, or cues to action, which improve perception and understanding of the health risks associated with obesity will have a greater likelihood of spurring parental action than mass screening. Recommended testing of lipids and glucose in obese children (Daniels \& Greer, 
2008) will not be effective unless abnormal values are used to educate the parents of the unhealthy weight status of the child and the perceived threat of the illness is understood. Parental perception and understanding of health risks precede actions to improve health status. Interventions should be aimed at parents who are designated as accurate and inaccurate in not only perceiving their child's weight status, but understanding the associated health risk of the BMI category. Motivation to change will be improved as the parents grow toward accurate perception. As motivation emerges, the nurses will provide support and education to reconstruct parental food provision and eating patterns. This, in turn, will help the child develop a normal BMI status. Parents can relate the patterns of food provision and eating patterns that promote healthy BMIs. Parents with accurate perception of their child's normal BMI will receive reinforcement of healthy food provision and eating patterns.

In clinical situations, nurses have the skills to not only take weights and measurements of the child, but also to identify families that have inaccurate perception of their child's weight status. Nurses have the ability to inform parents about how the child's weight status is impairing health and growth processes for their child. Families of overweight and obese children should receive information on the association of BMI category with hypertension, diabetes, and long term organ failure. More emphasis should be placed on threat and harm caused by comorbidities of obesity.

Mothers can alter feeding practices without major changes in food choices if proper information is provided. Nurses can collaborate with outside agencies to provide recipes for working mothers that are healthy and suitable for children. Nurses can assist mothers in evaluating true hunger cues and replacing unhealthy food rewards with healthier choices. 
Changes to health care policy to impact childhood obesity can be initiated by nurses on multiple levels. Within school systems, school nurses can advocate for more physical education time in the school day and encourage more cardiovascular activities. Nurses can provide information to county and state school boards on obesity and the co-morbid conditions that impair the health of the child and therefore facilitate change in nutritional components and activity requirements for the schools.

Changes in policy involving reimbursement for medical care to children with obesity can be initiated and reinforced by nursing. New available immunizations for fifth grade children (Vaccines: Recs/Schedules/Child schedule) can be used to encourage resumption of well visits in this age group, providing a regular opportunity for child and parental counseling about weight issues. Since obesity in children is not a "billable" diagnosis in primary care, repeat visits for this diagnosis may not occur. Nurses can lobby to create changes in billing practices to include the diagnosis of obesity for children as well as the associated diagnosis of hypertension and metabolic syndrome, thereby facilitating closer primary care follow-up of these problems for children.

\section{Opportunities for Further Study}

The Health Belief Model should continue to provide a sensitizing framework for future research opportunities related to accurate parental perception of their child's weight status. Accurate parental perception of their child's weight status can take on new meaning when perceived threat of the illness is understood. Further studies evaluating perceived health threat of the child's BMI category should be initiated.

Replication of this study in geographic areas that contain a larger population of racially diverse families should be considered. Measures should be taken to include a more normal 
distribution of educational and socioeconomic levels in future studies. Other age groups of children should be included in the study to evaluate the impact of physical development on parental perception of their child's weight status. Perception of weight status and associated health risks should be expanded and studied in children as well.

Further evaluation of parental perception of their child's weight status should be considered using the term "healthy" weight status as opposed to accurate weight status. Research questions including the concept of "healthy" weight will provide understanding about how the parents see the child's weight in relationship to their health rather than just related to size recognition. Perceived threat of the weight status can be assessed using this terminology and likelihood of change will be better understood.

Significant results in this study need further evaluation. Further investigation should be focused on identifying modifying factors that impact the decline of accurate parental perception of their child's weight status as the child ages. Demographic factors, such as race and gender should be studied in larger, more diverse populations. Influence of Appalachian culture should be evaluated in future studies that promote self-identification of ethnic status. Also, longitudinal studies should be performed to assess perception through the child's developmental progress to discover influences of cues to action and the child's physical development on parental perception of their child's weight status.

While the secondary data used in this study provides insight to the general attitudes of accurate or inaccurate parental perception of their child's weight status, the data do not provide more specific information related to meanings of the child's perceived BMI category. Future works should study parental perception by identifying the meaning of accurate or inaccurate 
parental perception. Qualitative methods for future research could identify similar meanings that parents associate with perception associated with their child's weight status.

More studies are needed to comprehensively evaluate food provision and consumption patterns. Reliable and valid tools for evaluation of food provision and consumption should be created and implemented. Methods such as gathering computerized grocery store receipts through WIC, food stamps, or online food diaries for the parent to complete could be considered to evaluate food provision and consumption patterns. To evaluate change, baseline food consumption and eating patterns must be established.

\section{Conclusion}

It is necessary for a parent to accurately perceive their child's weight in order for them to take action related to food provision and consumption patterns. Some groups may be at a greater risk for inaccurate perception. Association of obesity and health risks must be evaluated to determine the meaning of accurate parental perception of their child's weight status. Future research should support the development of childhood obesity tools, parental and family intervention strategies and methods of evaluating change in food provision and consumption patterns in children. Nurses have the opportunity to identify those parents who are at risk of inaccurately perceiving their child's weight status and to intervene to improve perception.

Nurses also have the opportunity to help accurate perceiving parents understand the risk of child hood obesity, and assist with the development of appropriate patterns of food provision and consumption, thereby improving long term health for children and families. 


\section{References}

Adams, A. K., Quinn, R. A., \& Prince, R. J. (2005). Low recognition of childhood overweight and disease risk among native-American caregivers. Obesity Research, 13(1), 146-152. Retrieved from http://search.ebscohost.com/login.aspx?direct=true $\& \mathrm{db}=\mathrm{cmedm} \& \mathrm{AN}=15761174 \&$ site $=$ ehos $\underline{\mathrm{t}-\text { live }}$

Appalachian Regional Commission. (2007). ARC: Maps. Retrieved 3/5/2009, 2009, from http://www.arc.gov/index.do?nodeId=938

Appalachian Regional Commission. (2009). ARC | development and progress of the Appalachian higher education network. Retrieved 10/3/2009, 2009, from http://www.arc.gov/index.do?nodeId=2215

ARC $\mid$ development and progress of the Appalachian higher education network Retrieved 9/17/2009, 2009, from http://www.arc.gov/index.do?nodeId=2215

Baldaro, B., Rossi, N., Caterina, R., Codispoti, M., Balsamo, A., \& Trombini, G. (2003). Deficit in the discrimination of nonverbal emotions in children with obesity and their mothers. International Journal Obesity Related Metabolic Disorders, 27(0307-0565; 2), 191-195. Retrieved from PM:12586998

Baughcum, A. E., Burklow, K. A., Deeks, C. M., Powers, S. W., \& Whitaker, R. C. (1998). Maternal feeding practices and childhood obesity: A focus group study of low-income 
mothers. Archives Pediatric Adolescent Medicine, 152(1072-4710; 10), 1010-1014. Retrieved from PM:9790612

Baughcum, A. E., Chamberlin, L. A., Deeks, C. M., Powers, S. W., \& Whitaker, R. C. (2000). Maternal perceptions of overweight preschool children. Pediatrics, 106(1098-4275; 6), 1380-1386. Retrieved from PM:11099592

Becker, M. H. (1974). The health belief model and personal health behavior. Health Education Monographs, 2, entire issue.

Becker, M. H., Drachman, R. H., \& Kirscht, J. R. (1974). A new approach to explaining sick-role behavior in low income populations. American Journal of Public Health, 64, 205-216. Retrieved from http://search.ebscohost.com/login.aspx?direct=true\&db=fyh\&AN=MRB$\underline{\text { WRI0061829\&site }=\text { ehost-live }}$

Benton, D. (2004). Role of parents in the determination of the food preferences of children and the development of obesity. Internal Journal of Obesity Related Metabolic Disorders, 28(0307-0565; 7), 858-869. Retrieved from PM:15170463

Ben-Tovim, D. I., Gilchrist, P. N., \& Walker, M. K. (2001). Evolving evidence and continuing uncertainties for eating disorders 1. The Medical Journal of Australia, 175 (0025-729; 5), 238-239. Retrieved from PM:11587250

Birch, L. L., \& Fisher, J. O. (1998). Development of eating behaviors among children and adolescents. Pediatrics, 101(1098-4275; 3), 539-549. Retrieved from PM:12224660 
Blumberg, S. J., Halfon, N., \& Olson, L. M. (2004). The national survey of early childhood health. Pediatrics, 113(6 Suppl), 1899-1906.

Brown, J. W., \& May, B. A. (2005). Rural older Appalachian women's formal patterns of care. Southern Online Journal of Nursing Research, 6(2), 21p. Retrieved from http://search.ebscohost.com/login.aspx?direct=true \&db=c8h\&AN=2005106712\&site=ehost$\underline{\text { live }}$

Cafri, G., \& Thompson, J. K. (2004). Measuring male body image: A review of the current methodology. Psychology of Men \& Masculinity, 5(1), 18-29. doi:10.1037/1524-9220.5.1.18

Carnell, S., Edwards, C., Croker, H., Boniface, D., \& Wardle, J. (2005). Parental perceptions of overweight in 3-5 y olds. International Journal of Obesity, 29(4), 353-355. doi:10.1038/sj.ijo.0802889

Cash, T. F., \& Deagle, E. A.,III. (1997). The nature and extent of body-image disturbances in anorexia nervosa and bulimia nervosa: A meta-analysis 1. The International Journal of Eating Disorders, 22(0276-3478; 2), 107-125. Retrieved from PM:9261648

Center for Disease Control. (2007). Obesity and overweight: Defining overweight and obesity.

Center for Disease Control. (2009). Obesity and overweight for professionals: Childhood: Data: Low-income, preschool-aged children. Retrieved 12/6/2009, 2009, from http://www.cdc.gov/obesity/childhood/lowincome.html

Cochran, J. (2008). Empowerment in adolescent obesity: State of the science. Online Journal of Rural Nursing \& Health Care, 8(1), 63-73. Retrieved from 
$\underline{\text { http://search.ebscohost.com/login.aspx?direct=true } \& \mathrm{db}=\mathrm{c} 8 \mathrm{~h} \& \mathrm{AN}=2010054348 \& \text { site }=\text { ehost- }}$ $\underline{\text { live }}$

Cochran, J. (2005). Appalachian culture: Bringin' it home: Appalachian culture. Paper presented at the In Rural Culture: West Virginia's Legacy. West Virginia Geriatric Association.

Cottrell, L. A., Minor, V., Murphy, E., Ward, A., Elliott, E., Tillis, G., . . Neal, W. A. (2007). Comparisons of parent cardiovascular knowledge, attitudes, and behaviors based on screening and perceived child risks. Journal of Community Health Nursing, 24(2), 87-99. doi:10.1080/07370010701316213

Crouch, P., O'Dea, J. A., \& Battisti, R. (2007). Child feeding practices and perceptions of childhood overweight and childhood obesity risk among mothers of preschool children. Nutrition \& Dietetics, 64(3), 151-158. doi:10.1111/j.1747-0080.2007.00180.x

Daniels, S. R., \& Greer, F. R. (2008). Lipid screening and cardiovascular health in childhood. Pediatrics, 122(1), 198-208. doi:10.1542/peds.2008-1349

de Ferranti, S. D., Gauvreau, K., Ludwig, D. S., Neufeld, E. J., Newburger, J. W., \& Rifai, N. (2004). Prevalence of the metabolic syndrome in American adolescents: Findings from the third national health and nutrition examination survey. Circulation, 110 (1524-4539; 16), 2494-2497. Retrieved from PM:15477412

Demerath, E., Muratova, V., Spangler, E., Li, J. R., Minor, V. E., \& Neal, W. A. (2003). Schoolbased obesity screening in rural Appalachia. (0091-7435) Retrieved from http://search.epnet.com/login.aspx?direct=true $\& \mathrm{db}=1 \mathrm{bh} \& \mathrm{an}=20033208147$ 
Dorsey, R. R., Eberhardt, M. S., \& Ogden, C. L. (2010). Racial and ethnic differences in weight management behavior by weight perception status. Ethnicity \& Disease, 20 (3), 244-250. Retrieved from $\underline{\text { http://search.ebscohost.com/login.aspx? direct }=\text { true } \& \mathrm{db}=\mathrm{cmedm} \& \mathrm{AN}=20828097 \& \text { site }=\text { ehos }}$ $\underline{\text { t-live }}$

Eckstein, K. C., Mikhail, L. M., Ariza, A. J., Thomson, J. S., Millard, S. C., \& Binns, H. J. (2006). Parents' perceptions of their child's weight and health. Pediatrics, 117(3), 681-690. doi:10.1542/peds.2005-0910

ERS/USDA data - 1990 rural-urban commuting area code. Retrieved 5/8/2009, 2009, from http://www.ers.usda.gov/Data/RuralUrbanCommutingAreaCodes/

ERS/USDA data - rural definitions: Data documentation and methods Retrieved 11/14/2010, 2010, from http://www.ers.usda.gov/data/ruraldefinitions/documentation.htm

Etelson, D., Brand, D. A., Patrick, P. A., \& Shirali, A. (2003). Childhood obesity: Do parents recognize this health risk? Obesity Research, 11(1071-7323;11), 1362-1368. Retrieved from PM:14627757

Finkelstein, E. A., Fiebelkorn, I. C., \& Wang, G. (2004). State-level estimates of annual medical expenditures attributable to obesity. Obesity Research, 12(1), 18-24.

doi:10.1038/oby.2004.4 
Finkelstein, E. A., Fiebelkorn, I. C., \& Wang, G. (2003). National medical spending attributable to overweight and obesity: How much, and who's paying? Health Aff, doi:10.1377/hlthaff.w3.219

Franzese, A., Valerio, G., Argenziano, A., Esposito-del, P. A., Iannucci, M. P., Caputo, G., Rubino, A. (1998). Onset of obesity in children through the recall of parents: Relationship to parental obesity and life events. Journal of Pediatric Endocrinology and Metabolism, 11(0334-018; 1), 63-67. Retrieved from PM:9642631

Genovesi, S., Giussani, M., Faini, A., Vigorita, F., Pieruzzi, F., Strepparava, M. G., Valsecchi, M. G. (2005). Maternal perception of excess weight in children: A survey conducted by paediatricians in the province of Milan. Acta Paediatrica, 94(6), 747-752. Retrieved from http://search.ebscohost.com/login.aspx?direct=true\&db=boh\&AN=BACD200510112283\&s $\underline{\text { ite }=\text { ehost-live }}$

Glanz, K., Lewis, F. M., \& Rimer, B. K. (1990). Health behavior and health education: Theory, research, and practice. San Francisco: Jossey-Bass Publishers.

Golan, M., Fainaru, M., \& Weizman, A. (1998). Role of behaviour modification in the treatment of childhood obesity with the parents as the exclusive agents of change. International Journal of Obesity, 22(0307-0565; 12), 1217-1224. Retrieved from PM:9877257 1

Golan, M. (2006). Parents as agents of change in childhood obesity - from research to practice. International Journal of Pediatric Obesity, 1(2), 66-76. Retrieved from ISI:000245083900001 
Goodman, E., Hinden, B. R., \& Khandelwal, S. (2000). Accuracy of teen and parental reports of obesity and body mass index 1. Pediatrics, 106(0031-4005; 1), 52-58. Retrieved from PM:10878149

Goodman, E., Daniels, S. R., Morrison, J. A., Huang, B., \& Dolan, L. M. (2004). Contrasting prevalence of and demographic disparities in the world health organization and national cholesterol education program adult treatment panel III definitions of metabolic syndrome among adolescents. The Journal of Pediatrics, 145(4), 445-451. Retrieved from http://www.sciencedirect.com/science/article/B6WKR-4DHW54B$\underline{\text { W/2/d93480bdca7b8d3978f77ea216d76786 }}$

Hackie, M., \& Bowles, C. L. (2007). Maternal perception of their overweight children. Public Health Nursing, 24(6), 538-546. doi:10.1111/j.1525-1446.2007.00666.x

Hammer, L. D., Kraemer, H. C., Wilson, D. M., Ritter, P. L., \& Dornbusch, S. M. (1991). Standardized percentile curves of body-mass index for children and adolescents. American Journal of Diseases of Children (1960), 145(3), 259-263.

Harrison, G. G., Jenks, E., Whaley, S., Gomez, J., McGregor, S., \& Ramirez, A. (2007). Mothers of preschool children underestimate their own and their children's weight status. FASEB Journal, 21(5), A160-A160. Retrieved from $\underline{\text { http: } / / \text { search.ebscohost.com/login.aspx? direct=true } \& \mathrm{db}=\mathrm{a} 9 \mathrm{~h} \& \mathrm{AN}=25632278 \& \text { site }=\text { ehost- }}$ $\underline{\text { live }}$

Hochbaum, G. M. (1958). Public participation in a medical screening program: A sociopsychological study. No. 572). Washington, DC: Government Printing Office. 
Intagliata, V., Ip, E. H., Gesell, S. B., \& Barkin, S. L. (2008). Accuracy of self- and parental perception of overweight among Latino preadolescents. North Carolina Medical Journal, 69(2), 88-91. Retrieved from $\underline{\text { http://search.ebscohost.com/login.aspx? direct }=\text { true } \& \mathrm{db}=\mathrm{cmedm} \& \mathrm{AN}=18605154 \& \text { site }=\text { ehos }}$ $\underline{\text { t-live }}$

Jackson, D., Mannix, J., Faga, P., \& McDonald, G. (2005). Overweight and obese children: Mothers' strategies. Journal of Advanced Nursing, 52(1), 6-13. Retrieved from ISI:000231566200002 a

Jain, A., Sherman, S. N., Chamberlin, L. A., Carter, Y., Powers, S. W., \& Whitaker, R. C. (2001). Why don't low-income mothers worry about their preschoolers being overweight? Pediatrics, 107(1098-4275; 5), 1138-1146. Retrieved from PM:11331699

Jeffery, A. N., Voss, L. D., Metcalf, B. S., Alba, S., \& Wilkin, T. J. (2005). Parents' awareness of overweight in themselves and their children: Cross sectional study within a cohort (EarlyBird 21). British Medical Journal (Clinical Research Edition), 330(7481), 23-24. Retrieved from $\underline{\text { http://search.ebscohost.com/login.aspx?direct=true } \& \mathrm{db}=\mathrm{lbh} \& \mathrm{AN}=20053000859 \& \text { site }=\text { ehost }}$ $\underline{\text {-live }}$

Kirchhoff, K. T., Sylwestrak, M. L., Chenelly, S., \& McLane, C. Evaluation of adherence to policy and procedures..planning inservice offerings. clinical skills. Nursing Management (NURS MANAGE), 1988 Jan; 19 (1): 51-4 (10 Ref), 
Klohe-Lehman, D. M., Freeland-Graves, J., Anderson, E. R., McDowell, T., Clarke, K. K., Hanss-Nuss, H., Milani, T. J. (2006). Nutrition knowledge is associated with greater weight loss in obese and overweight low-income mothers. Journal American Dietetic Association, 106(0002-8223; 1), 65-75. Retrieved from PM:16390668

Kostanski, M., \& Gullone, E. (1999). Dieting and body image in the child's world: Conceptualization and behavior. Journal of Genetic Psychology, 160(4), 488. Retrieved from http://search.ebscohost.com.www.libproxy.wvu.edu/login.aspx?direct=true $\& d b=f 5 h \& A N=2$ $559005 \&$ site $=$ ehost-live

Koivisto, U. K., Fellenius, J., \& Sjoden, P. O. (1994). Relations between parental mealtime practices and children's food intake. Appetite, 22(0195-6663; 3), 245-257. Retrieved from PM:7979342

Kuczmarski, R. J., Ogden, C. L., Grummer-Strawn, L. M., Flegal, K. M., Guo, S. S., Wei, R., Johnson, C. L. (2000). CDC growth charts: United states. Advanced Data, (0147-3956; 314), 1-27. Retrieved from PM:11183293

Laessle, R. G., Uh1, H., Lindel, B., \& Muller, A. (2001). Parental influences on laboratory eating behavior in obese and non-obese children. Internal Journal of Obesity Related Metabolic Disorders, 25 Suppl 1(0307-0565), S60-S62. Retrieved from PM:11466591

Lewin, K., Dembo, T., Fester, L., \& and Sears, P. (1944). Level of aspiration. In J. Hunt (Ed.), Personality and behavior disorders. New York: The Ronald press company. 
Lewin, K., Adams, D. K., Zener, K. E., \& Joint Tr. (1935). A dynamic theory of personality; selected papers (1st ed.). New York: London, McGraw-Hill Book Co.

Lissau, I., \& Sorensen, T. I. (1994). Parental neglect during childhood and increased risk of obesity in young adulthood. Lancet, 343(0140-6736; 8893), 324-327. Retrieved from PM:7905145

Liu, J., Bennett, K., Harun, N., Zheng, X., Probst, J., \& Pate, R. (2007). Overweight and physical inactivity among rural children aged 10-17: A national and state portrait 11. Columbia, SC: South Carolina Rural Health Research Center. Retrieved from http://rhr.sph.sc.edu.

Mamun, A. A., McDermott, B. M., O'Callaghan, M. J., Najman, J. M., \& Williams, G. M. (2008). Predictors of maternal misclassifications of their offspring's weight status: A longitudinal study. International Journal of Obesity, 32(1), 48-54. Retrieved from http://www.nature.com/ijo/; http://search.ebscohost.com/login.aspx?direct=true\&db=lbh\&AN=20083039072\&site=ehost -live

Maynard, L. M., Galuska, D. A., Blanck, H. M., \& Serdula, M. K. (2003). Maternal perceptions of weight status of children. Pediatrics, 111(5), 1226-1231. Retrieved from $\underline{\text { http://search.ebscohost.com/login.aspx } ? \text { direct=true } \& d b=1 b h \& A N=20033101375 \& \text { site }=\text { ehost }}$ -live

McCreary, D. R. (2002). Gender and age differences in the relationship between body mass index and perceived weight: Exploring the paradox. International Journal of Men's Health, 1(1), 31-42. Retrieved from 
ttp://search.ebscohost.com/login.aspx?direct=true \&db=1bh\&AN=20033187694\&site=ehostlive

Munro, B. H. (2005). Statistical methods for health care research. Philadelphia: Lippincott Williams \& Wilkins.

Murtagh, J., Dixey, R., \& Rudolf, M. (2006). A qualitative investigation into the levers and barriers to weight loss in children: Opinions of obese children. Archives of Diseases in Children, 91(1468-2044; 11), 920-923. Retrieved from PM:16820388

Myers, S., \& Vargas, Z. (2000a). Parental perceptions of the preschool obese child. Pediatric Nursing, 26(0097-9805; 1), 23-30. Retrieved from PM:12026313

Myers, S., \& Vargas, Z. (2000b). Parental perceptions of the preschool obese child. Pediatric Nursing, 26(0097-9805; 1), 23-30. Retrieved from PM:12026313

Myers, S., \& Vargas, Z. (2000c). Parental perceptions of the preschool obese child. Pediatric Nursing, 26(1), 23. Retrieved from http://search.ebscohost.com/login.aspx?direct=true $\& d b=a 9 h \& A N=2896966 \&$ site=ehost-live

National Center for Chronic Disease Prevention and Health Promotion. (2006). Epidemology of type 1 and type 2 diabetes mellitus among north American children and adolescents.

National Center for Chronic Disease Prevention and Health Promotion, \& Diabetes Public Health Resource. (2005). SEARCH for diabetes in youth; fact sheet. Hyattsville, MD: U.S. Department of Health and Human services, Center for Disease Control. Retrieved from www.cdc.gov/diabetes/pubs/factsheets 
National Center for Health Statistics. (2000). Center for disease control growth charts: Untied states.

Neal, W., Minor, V., Elliott, E., Cotterell, L., Tillis, G., Nicloloson, P. \& Murphy, S. (2006). CARDIAC project. www.cardiacwv.org.

Ogden, C. L., Carroll, M. D., Curtin, L. R., McDowell, M. A., Tabak, C. J., \& Flegal, K. M. (2006). Prevalence of overweight and obesity in the united states, 1999-2004 1. JAMA: The Journal of the American Medical Association, 295(1538-3598; 13), 1549-1555. Retrieved from PM:16595758

Ogden, C. L., Carroll, M. D., \& Flegal, K. M. (2008). High body mass index for age among US children and adolescents, 2003-2006. JAMA, 299(20), 2401-2405. doi:10.1001/jama.299.20.2401

Ogden, C. L., Carroll, M. D., Curtin, L. R., Lamb, M. M., \& Flegal, K. M. (2010). Prevalence of high body mass index in US children and adolescents, 2007-2008. JAMA: Journal of the American Medical Association, 303(3), 242-249. Retrieved from http://search.ebscohost.com.www.libproxy.wvu.edu/login.aspx?direct=true $\& d b=a 9 h \& A N=$ $\underline{47600275 \& \text { site }=\text { ehost-live }}$

Ohring, R., Graber, J. A., \& Brooks-Gunn, J. (2002). Girls' recurrent and concurrent body dissatisfaction: Correlates and consequences over 8 years. International Journal of Eating Disorders, 31(4), 404-415. Retrieved from http://search.ebscohost.com.www.libproxy.wvu.edu/login.aspx?direct=true \&db=agr\&AN=I $\underline{\text { ND23337640+\&site }=\text { ehost-live }}$ 
Olvera-Ezzell, N., Power, T. G., \& Cousins, J. H. (1990). Maternal socialization of children's eating habits: Strategies used by obese Mexican-American mothers. Child Development, 61(0009-3920; 2), 395-400. Retrieved from PM:2344777

Olvera, N., Remy, R., Power, T. G., Bellamy, C., \& Hays, J. (2001). Observed maternal strategies and children's health locus of control in low-income Mexican American families

Olvera-Ezzell, N., Power, T. G., \& Cousins, J. H. (1990). Maternal socialization of children's eating habits: Strategies used by obese Mexican-American mothers. Child Development, 61(0009-3920; 2), 395-400. Retrieved from PM:2344777

Omar, M. A., Coleman, G., \& Hoerr, S. (2001). Healthy eating for rural low-income toddlers: Caregivers' perceptions. Journal of Community Health Nursing, 18(0737-0016; 2), 93-106. Retrieved from PM:11407183

Perception as a process Retrieved 12/5/2009, 2009, from http://novaonline.nvcc.edu/eli/spd110td/interper/listen/percept1.html

Pietrobelli, A., Faith, M. S., Allison, D. B., Gallagher, D., Chiumello, G., \& Heymsfield, S. B. (1998). Body mass index as a measure of adiposity among children and adolescents: A validation study. The Journal of Pediatrics, 132(2), 204-210.

Posner, M. I. (1977). Review of 'human information processing: An introduction to psychology. 2nd ed'. PsycCRITIQUES, 22(9), 726-726. doi:10.1037/016321

Probst, M., Vandereycken, W., Vanderlinden, J., \& Van, C. H. (1998). The significance of body size estimation in eating disorders: Its relationship with clinical and psychological variables 
11. The International Journal of Eating Disorders, 24(0276-3478; 2), 167-174. Retrieved from PM:9697015

Rolls, B. J., Engell, D., \& Birch, L. L. (2000). Serving portion size influences 5-year-old but not 3-year-old children's food intakes. Journal American Dietetic Association, 100(0002-8223; 2), 232-234. Retrieved from PM:10670398

Rosenbloom, A. L., Joe, J. R., Young, R. S., \& Winter, W. E. (1999). Emerging epidemic of type 2 diabetes in youth emerging epidemic of type 2 diabetes in youth. Diabetes Care, 22(2), 345-354. Retrieved from Publisher URL: www.cinahl.com/cgibin/refsvc?jid=1029\&accno=1999025478; http://search.epnet.com/login.aspx?direct=true\&d $\underline{\mathrm{b}=\mathrm{cin} 20 \& \mathrm{an}=1999025478}$

Rosenstock, I. M. (1960). What research in motivation suggests for public health. American Journal of Public Health, 50, 295.

Rosenstock, I. M. (1974). Historical orgins of the health belief model. Health Education Monographs, (2), 328.

Sands, R. (2000). Reconceptualization of body image and drive for thinness 1. The International Journal of Eating Disorders, 28(0276-3478; 4), 397-407. Retrieved from PM:11054786

Satter, E. (1990). The feeding relationship: Problems and interventions. Journal of Pediatrics, 117(0022-3476; 2), S181-S189. Retrieved from PM:2199651 
Satter, E. M. (1996). Internal regulation and the evolution of normal growth as the basis for prevention of obesity in children. Journal American Dietetic Association, 96(0002-8223; 9), 860-864. Retrieved from PM:8784329

Schur, E. A., Sanders, M., \& Steiner, H. (2000). Body dissatisfaction and dieting in young children 1. The International Journal of Eating Disorders, 27(0276-3478; 1), 74-82. Retrieved from PM:10590451

Seca - seca sensa 804. Retrieved 4/5/2009, 2009, from https://www.seca-online.com/seca-sensa804.secasensa804.0.html? \&L $=1 \& \mathrm{C}=\mathrm{us}$

Skinner, B. F. (1938). The behavior of human organisms. Englewood, NJ: Appleton-CenturyCrofts.

Slade, P. D. (1994). What is body image? 2. Behaviour Research and Therapy, 32(0005-7967; 5), 497-502. Retrieved from PM:8042960

Stolley, M. R., \& Fitzgibbon, M. L. (1997). Effects of an obesity prevention program on the eating behavior of African American mothers and daughters. Health Education \& Behaviors, 24(1090-1981; 2), 152-164. Retrieved from PM:9079575

Temple, J. L., Wrotniak, B. H., Paluch, R. A., Roemmich, J. N., \& Epstein, L. H. (2006). Relationship between sex of parent and child on weight loss and maintenance in a familybased obesity treatment program. International Journal of Obesity, 30(8), 1260-1264. Retrieved from ISI:000239309300015 
Thorndike, E. L. (1998). Animal intelligence : Experimental studies. Bristol \{England\}; Tokyo, Japan: Thoemmes Press; Maruzen.

Tolman, E. C. (1932). Purposive behavior in animals and men. New York: Appleton-CenturyCrofts.

Trombini, E., Baldaro, B., Bertaccini, R., Mattei, C., Montebarocci, O., \& Rossi, N. (2003). Maternal attitudes and attachment styles in mothers of obese children. Perceptual \& Motor Skills, 97(0031-5125; 2), 613-620. Retrieved from PM:14620250

U.S. Department of Health and Human Services. (2007). Obesity and overweight: Economic consequences. Retrieved 2/5/2009, 2009, from http://www.cdc.gov.www.NCCDPHP/DNPA/obesity/economic consequences.htm

U.S. Department of Health and Human Services. (2009). Overweight and obesity: Health consequences. Retrieved 3/7/2009, 2009, from http://www.surgeongeneral.gov/topics/obesity/calltoaction/fact_consequences.html

U.S. Surgeon General. (2001). The surgeon general's call to action to prevent and decrease overweight and obesity. U.S. Department Of Health and Human Services. Retrieved from http://www.surgeongeneral.gov/topics/obesity/calltoaction/CalltoAction.pdf

U.S. Census Bureau. (2001). U.S. census 2000. Retrieved from www.census.gov

U.S. Census Bureau. (2007). Poverty in Appalachia relative to the nation. 
U.S. Department of Health and Human Services. (2006). CDC table for body mass index values for selected helghts and weights for ages 2 to 20 years.

United States Department of Agriculture. Women, infants, and children: Income eligibility guidelines. Retrieved 3/26/2009, 2009, from http://www.fns.usda.gov/wic/howtoapply/incomeguidelines.htm

Vaccines: Recs/Schedules/Child schedule main page Retrieved 4/9/2011, 2011, from http://www.cdc.gov/vaccines/recs/schedules/child-schedule.htm\#parentsteen

Wake, M., Salmon, L., Waters, E., Wright, M., \& Hesketh, K. (2002). Parent-reported health status of overweight and obese Australian primary school children: A cross-sectional population survey. Internal Journal of Obesity Related Metabolic Disorders, 26(0307-0565; 5), 717-724. Retrieved from PM:12032758

Wald, E. R., Ewing, L. J., Cluss, P., Goldstrohm, S., Cipriani, L., Colborn, D. K., \& Weissfeld, L. (2007). Parental perception of children's weight in a paediatric primary care setting. Child: Care, Health \& Development, 33(6), 738-743. doi:10.1111/j.13652214.2007.00753.x

Watson, J. B. (1930). Behaviorism (Rev. ed.). Chicago: University of Chicago Press.

West Virginia Quick Facts from the US census bureau Retrieved 12/5/2010, 2010, from http://quickfacts.census.gov/qfd/states/54000.html

West, D., Raczynski, M., Phillips, M., Bursac, Z., Gauss, C., \& Montgomery, B. (2008). Parental recognition of overweight in school-age children. Obesity, 16 (3), 630. 
Wu, F. L., Yu, S., Wei, I. L., \& Yin, T. J. (2003). Weight-control behavior among obese children: Association with family-related factors. Journal of Nursing Research, 11(16823141; 1), 19-30. Retrieved from PM:12695976 


\section{Appendix A: Cardiac Demographic Form}

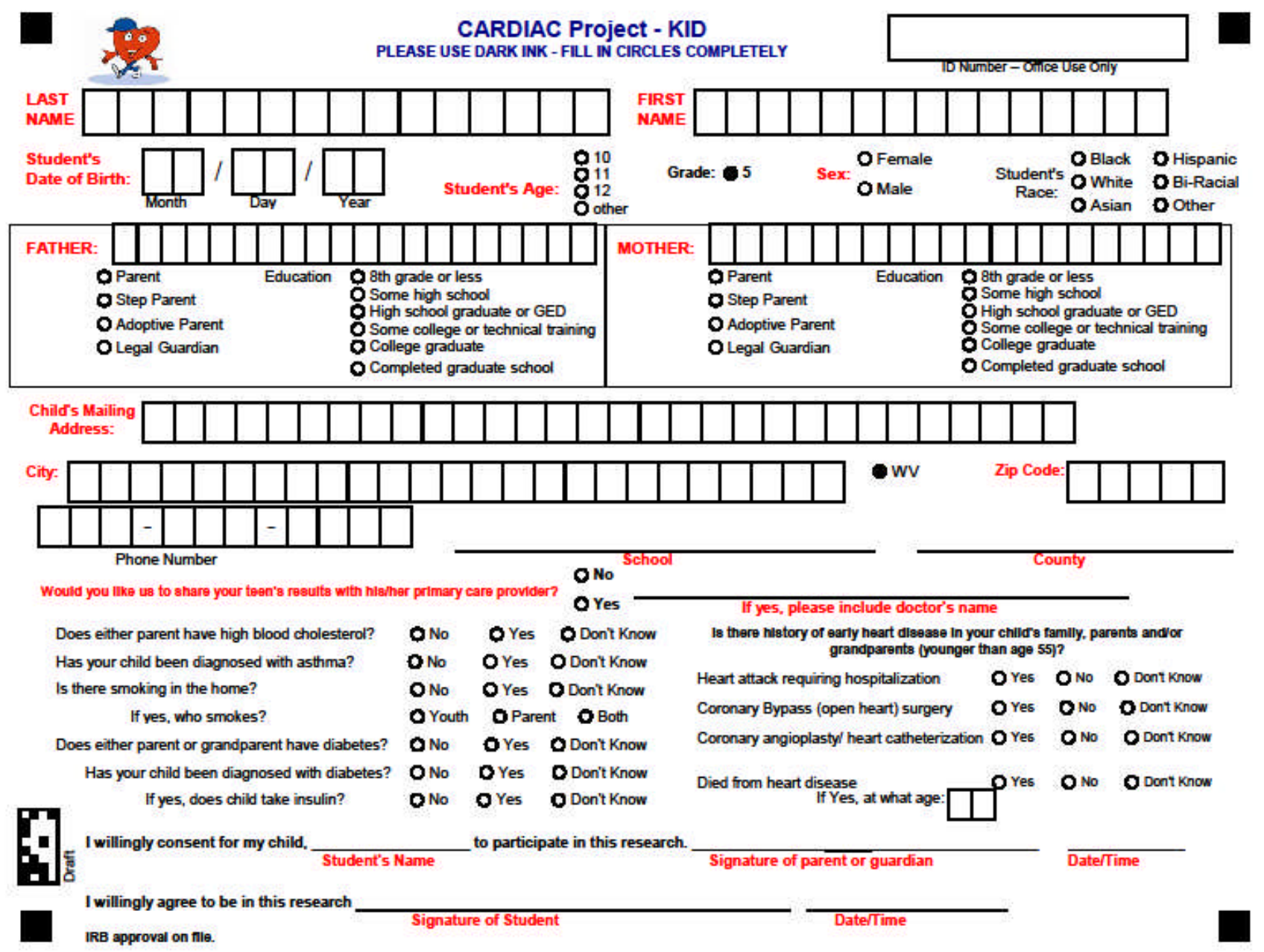




\title{
Appendix B: Cardiac Questionnaire 2005-2006
} \\ Parent Post-A8sesament \\ Environmental Determinants of Physical Activity \\ in Children \& Teens \\ -Please fill in entire answer circle-
}

DATE:

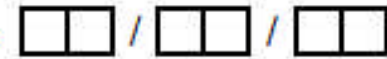

ID:

Q-1. Does your child have any medical conditions or disabilities that limit his or her physical activity?

No $\quad$ Yes, please specify:

Q-2. Compared to other children of the same age and gender, how would you describe your child's level of physical activity? (circle one number)

O Much less than others

O Somewhat less than others

About the same

O Somewhat more than others

Much more than others

Q-3. In your opinion, does your child generally get more than enough, about the right amount, or not enough physical activity?

Q More than enough

O About the right amount

Not enough

Q-4. Compared to other children the same age and gender, how would you describe your child's level of athletic coordination?

Much less coordinated

- Somewhat less coordinated

About the same

Somewhat more coordinated

- Much more coordinated

Q-5. How much does your child enjoy physical activity?

- Physical activity is not enjoyable at all

- Physical activity is a little enjoyable

O Neutral

O Physical activity is somewhat enjoyable

O Physical activity is very enjoyable

Q-6. What does your child usually do when he or she has a choice about how to spend their free time?

O Almost always chooses sedentary activities, such as watching TV. playing video games, or reading

O Usually chooses sedentary activties, such as watching TV. playing video games, or reading.

O Just as likely to choose physically active play as inactive recreation.

Usually chooses physically active play.

O Almost always chooses physically active play. 
Q-7. On an average WEEK day (Monday-Friday), how many hours does your child watch TV or play video games?
O Less than 1 hour per day
O Between 1 and 2 hours per day
$O$ Between 2 and 3 hours per day
O Between 3 and 4 hours per day
O Between 4 and 5 hours per day
O More than 5 hours per day

Q-8. On an average WEEKEND day (Saturday and Sunday), how many hours does your child watch TV or play video games?
O Less than 1 hour per day
O Between 1 and 2 hours per day
O Between 2 and 3 hours per day
O Between 3 and 4 hours per day
O Between 4 and 5 hours per day
O More than 5 hours per day

Q-9. Which items do you have in your home, yard, or apartment complex?
O Basketball hoop
O Tricycle/Bicycle
O Big yard, empty lot, field
O Exercise video tapes
O Frisbee
O Sandbox
O Swings
O Hula Hoop
O Jump Rope
O Jungle Gym
O Rowing machine
O Skateboard
O Skates (roller, in line, or ice)
O Sports equipment (bats, balls, rackets)
O Stair climber
O Step aerobics, slide aerobics
O Stationary bicycle
O Swiming pool
O Trampoline
O Treadmill
Weight lifting equipment
O Other, please specify

Q-10. How far from your home is the nearest public park where your child can be physically active or play sports:
O Less than 1 mile
O 1 - 2 miles
O 2 - 5 miles
O 5 - 10 miles
O More than 10 miles

Q-11. The nearest park has a reputation of being:

$$
\begin{aligned}
& \text { O Very unsafe } \\
& \text { O Somewhat unsafe } \\
& \text { O Neutral } \\
& \text { O Somewhat safe } \\
& \text { O very safe }
\end{aligned}
$$

Q-12. How often do you take your child to this park?

O Never

O 1-2 times per month

O 3-7 times per month

O 8-14 times per month

O 14 or more times per month 
DURING A TYPICAL WEEK HOW OFTEN DOES A MEMBER OF YOUR HOUSEHOLD:

Q-13. Encourage your child to do physical activity or play outside?

$\begin{array}{ccccc}\text { Never } & \text { Once } & \text { Sometimes } & \begin{array}{c}\text { Almost } \\ \text { Daily }\end{array} & \text { Daily } \\ \text { (1) } & 0 & 0 & 0 & 0 \\ \text { (1) } & 0 & 0 & 0 & 0 \\ 0 & 0 & 0 & 0 & 0\end{array}$

Q-14. Play outside or do physical activity with your child?

$\begin{array}{llllll}\text { Myself } & 0 & 0 & 0 & 0 & 0 \\ \text { Other adult - male } & 0 & 0 & 0 & 0 & 0 \\ \text { Other adult - female } & 0 & 0 & 0 & 0 & 0\end{array}$

Q-15. Provide transportation to a place where he or she can do physical activity or play?

$\begin{array}{llllll}\text { Myself } & 0 & 0 & 0 & 0 & 0 \\ \text { Other adult - male } & 0 & 0 & 0 & 0 & 0 \\ \text { Other adult - female } & 0 & 0 & 0 & 0 & 0\end{array}$

Q-16. Watch your child participate in physical activities or outdoor games?

$\begin{array}{llllll}\text { Myself } & 0 & 0 & 0 & \odot & 0 \\ \text { Other adult - male } & 0 & 0 & 0 & \odot & 0 \\ \text { Other adult - female } & 0 & 0 & 0 & \odot & 0\end{array}$

Q-17. Tell your child that physical activity is good for his or her health?

\begin{tabular}{|c|c|c|c|c|}
\hline Myself & (1) & (2) & (3) & () \\
\hline Other adult - male & (1) & (2) & (3) & (4) \\
\hline Other adult - female & (1) & (2) & (3) & (4) \\
\hline
\end{tabular}

Q-18 How important is it to the adults in your household that your child is good at sports and physical activities?

\begin{tabular}{|c|c|c|c|c|c|}
\hline \multirow[t]{2}{*}{ ities? } & \multicolumn{2}{|c|}{ Unimportant } & \multirow[b]{2}{*}{ Neutral } & \multicolumn{2}{|c|}{ Important } \\
\hline & Very & Somewhat & & Somewhat & Very \\
\hline Myself & (1) & (2) & (3) & () & (?) \\
\hline Other adult - male & (1) & (2) & (3) & (4) & (?) \\
\hline Other adult - female & (1) & (2) & (3) & (4) & (?) \\
\hline
\end{tabular}

Q-19 How much do the adults in your family enjoy participating in sports or exercise?

\begin{tabular}{lccccc} 
& \multicolumn{2}{c}{ Unimportant } & & \multicolumn{2}{c}{ Important } \\
Myself & Very & Somewhat & Neutral & Somewhat & Very \\
Other adult - male & 0 & 0 & 0 & 0 & 0 \\
Other adult - female & 0 & 0 & 0 & 0 & 0 \\
& 0 & 0 & 0 & 0 & 0
\end{tabular}




\section{THE FOLLOWING QUESTIONS ASK ABOUT YOUR OWN PHYSICAL ACTIVITY.}

Q-20. On how many of the past 7 days did YOU exercise or participate in sports activities for at least 20 minutes that made you sweat and breathe hard - such as basketball, soccer, running, swimming, laps, fast bicycling, fast dancing, or similar aerobic activites?
O 0 days
O 4 days
O 1 day
O 5 days
O 2 days
O 6 days
O 3 days
O 7 days

Q-21. On how many of the past 7 days did YOU participate in physical activity for at least $\mathbf{3 0}$ minutes that did NOT make you sweat or breathe hard - such as fast walking, slow bicycling, skating, pushing a lawn mower, or mopping floors?
O 0 days
O 4 days
O 1 day
O 5 days
O 2 days
O 6 days
O 3 days
O 7 days

Q-22. On how many of the past 7 days did YOU do exercises to strengthen or tone your muscles, such as push-ups, sit-ups, or weight lifting?

$\begin{array}{ll}\text { O } 0 \text { days } & 04 \text { days } \\ 01 \text { day } & 05 \text { days } \\ 02 \text { days } & 06 \text { days } \\ 03 \text { days } & 07 \text { days }\end{array}$

Q-23. Please rate your OWN phypsical activity level using a scale of 0 to 10. A 10 means "You are in such good shape, you could be training for the Olympics", and 0 means "You hardly get off the couch."
O 0
O 1
O 2
O $3 \quad 04$
O 5
O 6
O 7
$08 \quad 09$
O 10

Q-24. How do you describe YOUR OWN weight?
$O$ Very underweight
O Slightly underweight
O About the right weight
O Slightly overweight
O Very overweight

Q-25. What is YOUR height?

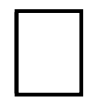

feet

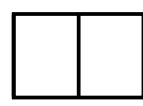

inches
Q-26 What is YOUR weight?

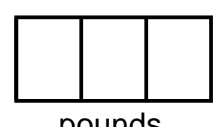


THE FOLLOWING QUESTIONS ASK ABOUT YOUR SPOUSE'S PHYSICAL ACTIVITY LEVEL. IF YOU DO NOT HAVE A SPOUSE PLEASE GO DIRECTLY TO QUESTION Q-38.

Q-27. On how many of the past 7 days did your spouse (or the other adult who lives in your house) exercise or participate in sports activities for at least $\mathbf{2 0}$ minutes that made him/her sweat and breathe hard - such as basketball, soccer, running, swimming laps, fast bicycling, fast dancing, or similar aerobic activites?
O 0 days
O 4 days
O 1 day
O 5 days
O 2 days
O 6 days
O 3 days
O 7 days

Q-28. On how many of the past 7 days did your spouse (or the other adult who lives in your house) participate in physical activity for at least $\mathbf{3 0}$ minutes that did NOT make him/her sweat or breathe hard - such as fast walking, slow bicycling, skating, pushing a lawn mower, or mapping floors?
O 0 days
O 4 days
O 1 day
O 5 days
O 2 days
O 6 days
O 3 days
O days

Q-29. On how many of the past 7 days did your spouse (or the other adult who lives in your house) do exercises to strengthen or tone his/her muscles - such as push-ups, sit-ups, or weight lifting?
O 0 days
O 4 days
O 1 day
O 5 days
O 2 days
O 6 days
O 3 days
O 7 days

Q-30. Please rate your spouse's (or other adult who lives in your house) physical activity level using a scale of 0-10. A 10 means "He/She is in such good shape helshe could be training for the Olympics", and 0 means "He/She hardly get off the couch."
O 0
O 1
O 2
O 3
O 4
O 5
O 6
07
O 8
O9 910

Q-31 How do you describe your spouse's weight?
$\mathrm{O}$ Very underweight
O Slightly underweight
O About the right weight
O Slightly overweight
$O$ Very overweight

Q-32. What is your spouse's height?

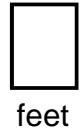

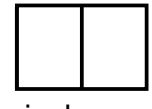

inches
Q-33 What is your spouse's weight?

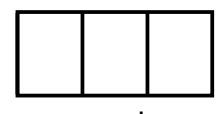

pounds 
Q-34 Which of the following categories includes the age of yourself and other adults in the household.

\begin{tabular}{|c|c|c|c|c|c|c|c|}
\hline Myself & Onder 25 & O 25-34 & O 35-44 & O 45-54 & O 55-64 & O 65-74 & O 75 or over \\
\hline Other Adult Male & Under 25 & O 25-34 & O 35-44 & O 45-54 & 55-64 & O 65-74 & O 75 or over \\
\hline Other Adult Female & Under 25 & O 25-34 & O 35-44 & O 45-54 & O 55-64 & O 65-74 & O 75 or over \\
\hline
\end{tabular}

Q-35. My current residence is best described as:

O Single family house

O Apartment

O Duplex

O Condominium/Townhouse

Q-36. Who is the main person completing this form?
O Mother
O Other adult female
O Father
O Other adult male

Q-37 In the past 4 months, how often have you done the following:

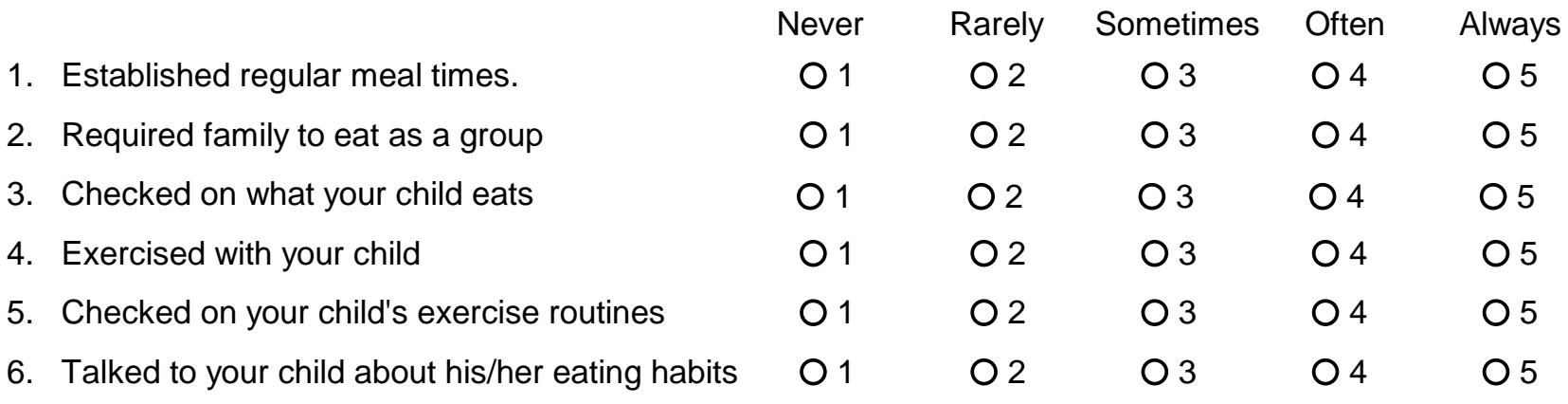

Q-38 In the next 4 months, do you think your child will do the following:

$\begin{array}{lccc} & \text { Yes } & \text { No } & \text { Don't Know } \\ \text { 1. Eat unhealthy foods or not enough healthy foods } & \text { O } & \text { O } 2 & \text { O } 3\end{array}$

2. Have limited opportunity to engage in vigorous exercise $\quad 01 \quad 003$ while at home

3. Have limited opportunity to engage in moderate exercise $\quad 01 \quad 03$ while at home

4. Have limited opportunity to engage in vigorous exercise $\quad 01 \quad 02$ while outside of home

5. Have limited opportunity to engage in moderate exercise $\quad 01 \quad 02$ 
Q-39 To what extent do you think your child can independently decide:

Never Rarely Sometimes $\begin{array}{ll}\text { Most } & \text { Often Always }\end{array}$
1. What to eat while at home
01
O 2
03
O 4
05
2. What to eat while outside of home
01
02
03
$\bigcirc 4$
05
3. How active to be while at home
O 1
03
O 4
05
4. How active to be while outside of home
01
02
03
$\bigcirc 4$
05
5. What activities to do while at home
01
O 2
03
O 4
05
6. What activities to do while outside of home
$01 \quad 02$
03
O 4
O 5

\section{Q-40 How much does each of the following fit your style of parenting?}

1. I always tell my child what to do

2. I make rules without asking my child

3. I am too busy to talk to my child

4. I listen to what my child has to say

5. I make my child feel better when he/she is upset

6. I like my child just the way he/she is

7. I tell my child when he/she does a good job on things

8. I want to hear about my child's problems

9. I am pleased with how my child behaves

10. I have rules that my child must follow

11. I tell my child what time he/she must come home

12. I make my child tell me where he/she is going

13. I make sure that my child goes to bed on time

14. I ask my child what he/she does with friends

15. I know where my child is after school

16. I check to see if my child did his/her homework

$\begin{array}{cc}\text { Just like } & \text { A lot like } \\ \text { mine } & \text { mine }\end{array}$

O 1

O 2

O 2

○ 2

O 2

O 2

03

O 4

01

O 2

03

O 4

01

O 2

03

O 4

01

O 2

03

O 4

O 1

O 2

03

04

O 1

O 2

O 3

04

01

O 2

03

04

01

O 2

O 3

04

01

O 2

O 3

O 4

01

O 2

03

04

O 1

O 2

03

O 4

01

O 2

03

O 4 
Q-41. Directions: Make a verticle line at the point where you make the decisions in your home.

EXAMPLE: $\quad$ Who makes the decisions about what your child wears.

$\begin{array}{lc}\text { Decision based completely } & \text { Decision based completely } \\ \text { by parents } & \text { by you }\end{array}$

1. Decisions about what your child eats while at home.

Decision based completely by parents

2. Decisions about what your child eats while away from home.

\section{Decision based completely} by parents
Decision based completely by you
For office use only

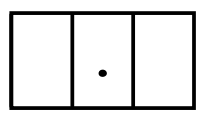

Decision based completely by you

3. Decisions about the type of physical activities your child engages in while at home.

Decision based completely by parents
Decision based completely by you

4. Decisions about the type of physical activities your child engages in while away from home.

Decision based completely

by parents
Decision based completely by you

5. Decisions about how much activity your child does while at home.

Decision based completely

by parents
Decision based completely by you

6. Decisions about how much activity your child has while away from home.

Decision based completely by parents
Decision based completely by you

7. Decisions about what foods are bought for meals at home.

Decision based completely

by parents
Decision based completely by you
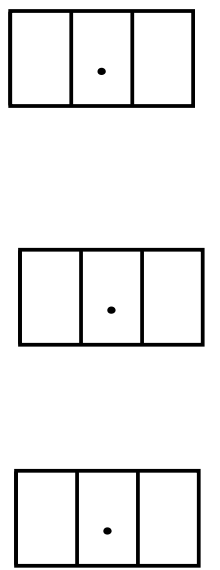
8. Decisions to modify meal plans.

$\begin{array}{lc}\text { Decision based completely } & \text { Decision based completely } \\ \text { by parents } & \text { by you }\end{array}$

9. Decisions to eat out.

Decision based completely by parents
Decision based completely by you

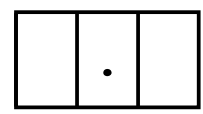

Q - 42 Compared to other children the same age and gender, how would you describe your child's weight (fill in only one):

$$
\begin{aligned}
& \text { O very underweight } \\
& \text { O slightly underweight } \\
& \text { O about the right weight } \\
& \text { O slightly overweight } \\
& \text { O very overweight }
\end{aligned}
$$

Please complete each question based on activities that have happened since you began the program.

\begin{tabular}{|c|c|c|c|}
\hline O never & O rarely & O sometimes & Often \\
\hline O ne & O rarely & O sometimes & O often \\
\hline
\end{tabular}

\section{Q - 43 Physical Activity}

On average, how often does your child do these activities in a day?

$\begin{array}{llllll}\text { Walking } & \text { O never } & \text { O rarely } & \text { O sometimes } & \text { O often } & \text { O always } \\ \text { Running } & \text { O never } & \text { O rarely } & \text { O sometimes } & \text { O often } & \text { O always } \\ \text { Skipping } & \text { O never } & \text { O rarely } & \text { O sometimes } & \text { O often } & \text { O always } \\ \text { Jumping } & \text { O never } & \text { O rarely } & \text { O sometimes } & \text { O often } & \text { O always } \\ \text { Dancing } & \text { O never } & \text { O rarely } & \text { O sometimes } & \text { O often } & \text { O always } \\ \text { Climbing } & \text { O never } & \text { O rarely } & \text { O sometimes } & \text { O often } & \text { O always }\end{array}$

Other Outdoor Activities:

\section{Q - 44 Diet \& Nutrition}

Food Item Average Number

Eaten Each Day

$\begin{array}{lllllll}\text { Fruits } & \downarrow & \text { O never } & \text { O rarely } & \text { O sometimes } & \text { O often } & \text { O always } \\ \text { Vegetables } & & \text { O never } & \text { O rarely } & \text { O sometimes } & \text { O often } & \text { O always } \\ \text { Meats } & \text { O never } & \text { O rarely } & \text { O sometimes } & \text { O often } & \text { O always } \\ \text { Breads } & \text { O never } & \text { O rarely } & \text { O sometimes } & \text { O often } & \text { O always } \\ \text { Sweets } & \text { O never } & \text { O rarely } & \text { O sometimes } & \text { O often } & \text { O always }\end{array}$




\section{Dr.}

11497

\section{Q-45 Please check the one answer that best fits your experience}

1. Body mass index $(\mathrm{BMI})$ is:

2. What BMI percentage is considered at risk for overweight?

3. What is a pedometer?
O the proportion between an individual's weight and height $O$ a measure of the amount of physical activity $O$ a measure of muscle mass

$0<50$ th percentile

$O>85$ th percentile

$O$ between the 3rd and 5th percentile

O tool used to measure an individual's BMI

$O$ tool used to measure an individual's muscle mass

O tool used to measure the number of steps an individual takes

4. Did you know how to use a pedometer before you started this program?

O yes $\quad$ no

5. How much time, on average, do you set aside each day to participate in physical activity with your family?

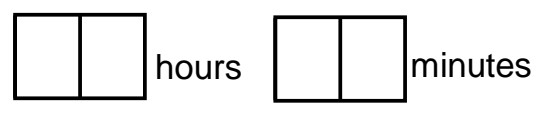

6. Did you help your child set goals to reach in terms of increased physical activity?

O yes O no

7. Did you encourage your child to be more physically active?

O yes O no

8. Did you encourage your child to eat healthier?

O yes O no

9. Did you use sweets as a reward?

O yes O no

10. Did you think about ways to cut your child's calories?

O yes $\quad$ no

11. Did you think about ways to increase steps in a day?

O yes O no

12. Did you see an increase in physical activity/steps while your child was wearing a pedometer?

O yes O no

13. Looking over the completed daily step log, were you concerned with the amount of physical activity your child is getting?

O yes $\quad$ no

14. Since participating, have your child's nutrition habits improved?

O yes O no

15. Did you feel wearing a pedometer motivated your child to participate in more $\quad$ yes $\bigcirc$ no physical activity?

16. Is your child still wearing his/her pedometer?

O yes $\quad$ no 
Q-45. Does your child currently have a regular dental provider (i.e., dentist)?

OYES ONO

\section{Q-46. Has your child ever received care from a dentist?}

Please check the one statement that best describes your child's dental experience.

O YES

My child needed emergency dental care.

O I wanted my child to meet our dentist and get used to visits.

My physician recommended that we arranage a dental visit for my child.

I wanted my child to see the dentist to protect against cavities and other problems.

Other
$\mathrm{ONO}$

It is too early to take my child to the dentist. $\mathrm{O}$ I don't have a dentist in my area. It costs too much to go to the dentist. My child is scared of the dentist or dentist's office. I don't have time to take my child to the dentist. O I don't have a way to get to the dentist. $\mathrm{O}$ I don't know how to find a dentist.

Q-47. On average, how many times per day does your child do the following:

O Brush his/her teeth

\# of times per day

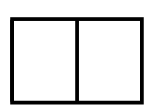

O Floss his/her teeth

\# of times per day

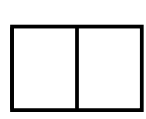

Q-48. My child's teeth affect his/her overall health.
O Strongly disagree
O Disagree
O Agree
O Strongly agree

Q-49. It is important to have my child's teeth checked by the dentist at least once a year.
O Strongly disagree
O Disagree
O Agree
O Strongly agree

Q-50. I would be able to take my child to the dentist if I needed to.

O Strongly disagree

O Disagree

O Agree

O Strongly agree
Q-51. Over the next 4 months, I plan to take my child to see the dentist.

O Strongly disagree

O Disagree

O Agree

O Strongly agree 


\section{Appendix C: Cardiac Questionnaire 2006-2007}

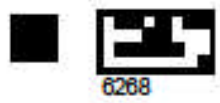

DATE:

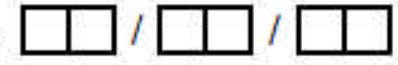

Q-1. Does your child have any medical conditions or disabilities that limit his or her physical activity?

2006-2007 Parent Post-Assessment

O No OYes, please specify:

Q-2. Compared to other children of the same age and gender, how would you describe your child's level of physical activity? (circle one number)

O Much less than others

- Somewhat less than others

O About the same

O Somewhat more than others

- Much more than others

Q-3. In your opinion, does your child generally get more than enough, about the right amount, or not enough physical activity?

C More than enough

O About the right amount

Not enough

Q-4. Compared to other children the same age and gender, how would you describe your child"s level of athletic coordination?

Much less coordinated

Somewhat less coordinated

- About the same

Somewhat more coordinated

Much more coordinated

Q-5. How much does your child enjoy physical activity?

O Physical activity is not enjoyable at all

Physical activity is a little enjoyable

O Neutral

O Physical activity is somewhat enjoyable

O Physical activity is very enjoyable

Q-6. What does your child usually do when he or she has a choice about how to spend their free time?

A Almost always chooses sedentary activities, such as watching TV, playing video games, or reading

O Usually chooses sedentary activties, such as watching TV. playing video games, or reading.

O Just as likely to choose physically active play as inactive recreation.

Usually chooses physically active play.

O Almost always chooses physically active play. 
Q-7. On an average WEEK day (Monday-Friday), how many hours does your child watch TV or play video games?
O Less than 1 hour per day
O Between 1 and 2 hours per day
$O$ Between 2 and 3 hours per day
O Between 3 and 4 hours per day
O Between 4 and 5 hours per day
O More than 5 hours per day

Q-8. On an average WEEKEND day (Saturday and Sunday), how many hours does your child watch TV or play video games?
O Less than 1 hour per day
O Between 1 and 2 hours per day
O Between 2 and 3 hours per day
O Between 3 and 4 hours per day
O Between 4 and 5 hours per day
$O$ More than 5 hours per day

Q-9. Which items do you have in your home, yard, or apartment complex?
O Basketball hoop
O Tricycle/Bicycle
Big yard, empty lot, field
Oxercise video tapes
O Frisbee
O Sandbox
O Swings
O Hula Hoop
O Jump Rope
O Jungle Gym
O Rowing machine
O Skateboard
O Skates (roller, in line, or ice)
O Sports equipment (bats, balls, rackets)
O Stair climber
O Step aerobics, slide aerobics
O Stationary bicycle
O Swiming pool
O Trampoline
O Treadmill
Weight lifting equipment
O Other, please specify

Q-10. How far from your home is the nearest public park where your child can be physically active or play sports:
O Less than 1 mile
O 1 - 2 miles
O 2 - 5 miles
O 5 - 10 miles
O More than 10 miles

Q-11. The nearest park has a reputation of being:

$$
\begin{aligned}
& \text { O Very unsafe } \\
& \text { O Somewhat unsafe } \\
& \text { O Neutral } \\
& \text { O Somewhat safe } \\
& \text { O Very safe }
\end{aligned}
$$

Q-12. How often do you take your child to this park?

O Never

1-2 times per month

O 3-7 times per month

O 8-14 times per month

O 14 or more times per month 
DURING A TYPICAL WEEK HOW OFTEN DOES A MEMBER OF YOUR HOUSEHOLD:

Q-13. Encourage your child to do physical activity or play outside?

$\begin{array}{ccccc}\text { Never } & \text { Once } & \text { Sometimes } & \begin{array}{c}\text { Almost } \\ \text { Daily }\end{array} & \text { Daily } \\ 0 & 0 & 0 & 0 & 0 \\ 0 & 0 & 0 & \odot & 0 \\ 0 & 0 & 0 & 0 & 0\end{array}$

Q-14. Play outside or do physical activity with your child?

$\begin{array}{llllll}\text { Myself } & 0 & 0 & 0 & 0 & 0 \\ \text { Other adult - male } & 0 & \odot & 0 & \odot & 0 \\ \text { Other adult - female } & 0 & 0 & 0 & 0 & 0\end{array}$

Q-15. Provide transportation to a place where he or she can do physical activity or play?

\begin{tabular}{|c|c|c|c|c|}
\hline Myself & ○ & (2) & (3) & ๑) \\
\hline Other adult - male & (1) & (2) & (3) & (๑) \\
\hline Other adult - female & (1) & (2) & (3) & () \\
\hline
\end{tabular}

Q-16. Watch your child participate in physical activities or outdoor games?

\begin{tabular}{|c|c|c|c|c|}
\hline Myself & ○ & (2) & (3) & ๑ \\
\hline Other adult - male & (1) & (2) & (3) & (4) \\
\hline Other adult - female & (1) & (2) & (3) & () \\
\hline
\end{tabular}

Q-17. Tell your child that physical activity is good for his or her health?

$\begin{array}{llllll}\text { Myself } & \odot & \odot & 0 & \odot & \odot \\ \text { Other adult - male } & \odot & \odot & \odot & \odot & \odot \\ \text { Other adult - female } & \odot & \odot & \odot & \odot & \odot\end{array}$

Q-18 How important is it to the adults in your household that your child is good at sports and physical activities?

\begin{tabular}{lccccc} 
& \multicolumn{2}{c}{ Unimportant } & \multicolumn{2}{c}{ Important } \\
Myself & Very & Somewhat & Neutral & Somewhat & Very \\
Other adult - male & 0 & 0 & 0 & 0 & 0 \\
Other adult - female & 0 & 0 & 0 & 0 & 0 \\
& 0 & 0 & 0 & 0 & 0
\end{tabular}

Q-19 How much do the adults in your family enjoy participating in sports or exercise?

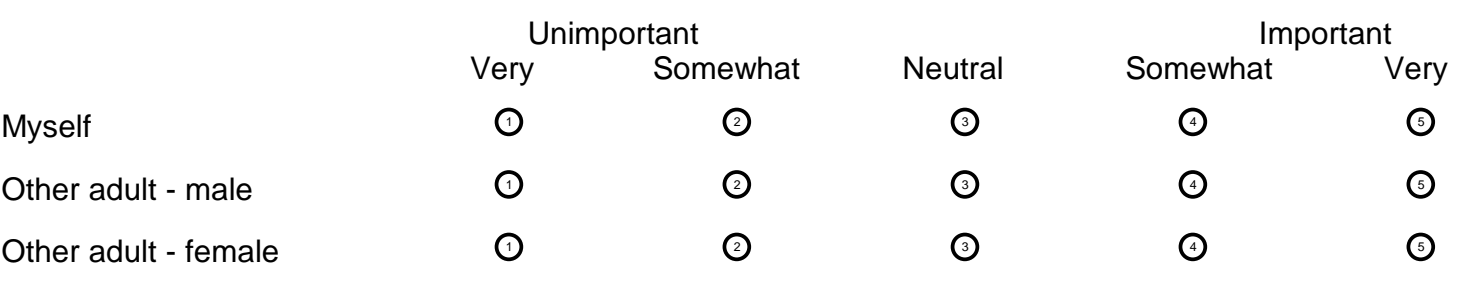




\section{THE FOLLOWING QUESTIONS ASK ABOUT YOUR OWN PHYSICAL ACTIVITY.}

Q-20. On how many of the past 7 days did YOU exercise or participate in sports activities for at least 20 minutes that made you sweat and breathe hard - such as basketball, soccer, running, swimming, laps, fast bicycling, fast dancing, or similar aerobic activites?
O 0 days
O 4 days
O 1 day
O 5 days
O 2 days
O 6 days
O 3 days
O 7 days

Q-21. On how many of the past 7 days did YOU participate in physical activity for at least $\mathbf{3 0}$ minutes that did NOT make you sweat or breathe hard - such as fast walking, slow bicycling, skating, pushing a lawn mower, or mopping floors?
O 0 days
O 4 days
O 1 day
O 5 days
O 2 days
O 6 days
O 3 days
O 7 days

Q-22. On how many of the past 7 days did YOU do exercises to strengthen or tone your muscles, such as push-ups, sit-ups, or weight lifting?
O 0 days
O 4 days
O 1 day
O days
O 2 days
O 6 days
O 3 days
O 7 days

Q-23. Please rate your OWN phypsical activity level using a scale of 0 to 10. A 10 means "You are in such good shape, you could be training for the Olympics", and 0 means "You hardly get off the couch."
○ 0
01
O 2
O 304
○ 5
O 6
O 7
$08 \quad 09$
O 10

Q-24. How do you describe YOUR OWN weight?
$O$ Very underweight
O Slightly underweight
O About the right weight
O Slightly overweight
O Very overweight

Q-25. What is YOUR height?

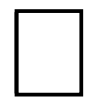

feet

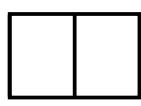

inches
Q-26 What is YOUR weight?

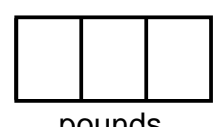




\section{THE FOLLOWING QUESTIONS ASK ABOUT YOUR SPOUSE'S PHYSICAL ACTIVITY LEVEL.} IF YOU DO NOT HAVE A SPOUSE PLEASE GO DIRECTLY TO QUESTION Q-38.

Q-27. On how many of the past 7 days did your spouse (or the other adult who lives in your house) exercise or participate in sports activities for at least $\mathbf{2 0}$ minutes that made him/her sweat and breathe hard - such as basketball, soccer, running, swimming laps, fast bicycling, fast dancing, or similar aerobic activites?
O 0 days
O 4 days
O 1 day
O 5 days
O 2 days
O 6 days
O 3 days
O 7 days

Q-28. On how many of the past 7 days did your spouse (or the other adult who lives in your house) participate in physical activity for at least $\mathbf{3 0}$ minutes that did NOT make him/her sweat or breathe hard - such as fast walking, slow bicycling, skating, pushing a lawn mower, or mapping floors?
O 0 days
O 4 days
O 1 day
O 5 days
O 2 days
O 6 days
O 3 days
O 7 days

Q-29. On how many of the past 7 days did your spouse (or the other adult who lives in your house) do exercises to strengthen or tone his/her muscles - such as push-ups, sit-ups, or weight lifting?
O 0 days
O 4 days
O 1 day
O 5 days
O 2 days
O 6 days
O 3 days
O 7 days

Q-30. Please rate your spouse's (or other adult who lives in your house) physical activity level using a scale of 0-10. A 10 means "He/She is in such good shape helshe could be training for the Olympics", and 0 means "He/She hardly get off the couch."
O 0
O 1
O 2
$\mathrm{O} 3$
O 4
O 5
O 6
O 7
O 8
O $9 \quad 010$

Q-31 How do you describe your spouse's weight?
$\mathrm{O}$ Very underweight
O Slightly underweight
O About the right weight
O Slightly overweight
$O$ Very overweight

Q-32. What is your spouse's height?

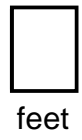

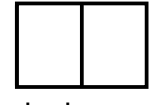

inches
Q-33 What is your spouse's weight?

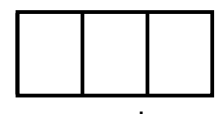


Q-34 Which of the following categories includes the age of yourself and other adults in the household.

\begin{tabular}{|c|c|c|c|c|c|c|c|}
\hline Myself & O Under 25 & O 25-34 & O $35-44$ & O 45-54 & O 55-64 & O $65-74$ & O 75 or over \\
\hline Other Adult Male & Under 25 & O 25-34 & O 35-44 & O 45-54 & O 55-64 & O 65-74 & O 75 \\
\hline Other Adult Female & Under 25 & O 25-34 & O $35-44$ & O $45-54$ & O 55-64 & O 65-74 & r \\
\hline
\end{tabular}

Q-35. My current residence is best described as:

O Single family house

O Apartment

O Duplex

O Condominium/Townhouse

Q-36. Who is the main person completing this form?
O Mother
O Other adult female
O Father
O Other adult male

Q-37 In the past 4 months, how often have you done the following:

Most

Never Rarely Sometimes Often Always

1. Established regular meal times.

O 1 O 2

O 3

O $4 \quad 05$

2. Required family to eat as a group

$01 \quad 02$

03

O 4

O 5

3. Checked on what your child eats

$01 \quad 02$

O 3

O 4

O 5

4. Exercised with your child

01

O 2

03

O 4

05

5. Checked on your child's exercise routines

01

O 2

O 3

O 4

05

6. Talked to your child about his/her eating habits

O 1

O 2

03

O 4

05

Q-38 In the next 4 months, do you think your child will do the following:

1. Eat unhealthy foods or not enough healthy foods

Yes No

Don't Know

O 1

O 2

O 3

2. Have limited opportunity to engage in vigorous exercise while at home

$01 \quad 02$

O 3

3. Have limited opportunity to engage in moderate exercise

O 1

O 2

O 3 while at home

4. Have limited opportunity to engage in vigorous exercise

01

O 2

03 while outside of home

5. Have limited opportunity to engage in moderate exercise while outside of home

01

O 2

03 
Q-39 To what extent do you think your child can independently decide:

Never Rarely Sometimes Often Always

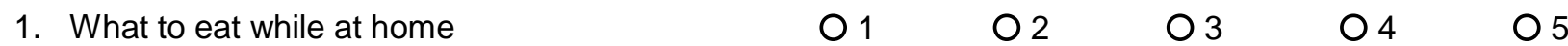

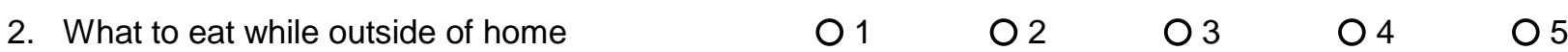

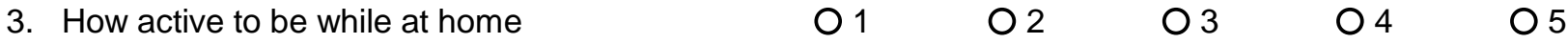

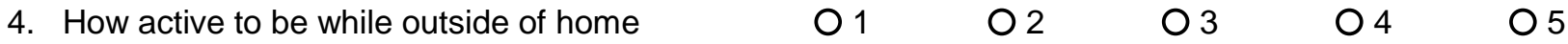

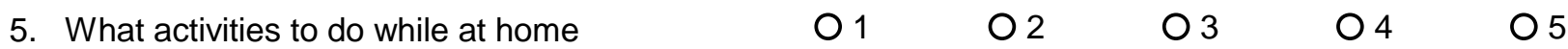

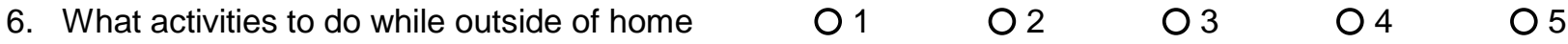

\section{Q-40 How much does each of the following fit your style of parenting?}

1. I always tell my child what to do

2. I make rules without asking my child

3. I am too busy to talk to my child

4. I listen to what my child has to say

5. I make my child feel better when he/she is upset

6. I like my child just the way he/she is

7. I tell my child when he/she does a good job on things

8. I want to hear about my child's problems

9. I am pleased with how my child behaves

10. I have rules that my child must follow

11. I tell my child what time he/she must come home

12. I make my child tell me where he/she is going

13. I make sure that my child goes to bed on time

14. I ask my child what he/she does with friends

15. I know where my child is after school

16. I check to see if my child did his/her homework

$\begin{array}{cc}\text { Just like } & \text { A lot like } \\ \text { mine } & \text { mine }\end{array}$

01

O 2

O 2

O 2

O 2

$\mathrm{O} 2$

O 3

03

03

O 4

01

O 2

O 3

O 4

01

O 2

O 3

O 4

01

O 2

O 3

O 4

01

O 2

03

O 4

01

O 2

O 3

O 4

01

O 2

O 3

O 4

01

O 2

O 3

O 4

01

O 2

O 3

O 4

01

O 2

O 3 
Q-41. Directions: Make a verticle line at the point where you make the decisions in your home.

EXAMPLE: $\quad$ Who makes the decisions about what your child wears.

\begin{tabular}{|c|c|}
\hline $\begin{array}{l}\text { Decision based completely } \\
\text { by parents }\end{array}$ & $\begin{array}{c}\text { Decision based completely } \\
\text { by you }\end{array}$ \\
\hline
\end{tabular}

1. Decisions about what your child eats while at home.

Decision based completely by parents

2. Decisions about what your child eats while away from home.

\section{Decision based completely} by parents

3. Decisions about the type of physical activities your child engages in while at home.

Decision based completely by parents

4. Decisions about the type of physical activities your child engages in while away from home.

\section{Decision based completely}

by parents

5. Decisions about how much activity your child does while at home.

Decision based completely

by parents
Decision based completely by you
For office use only

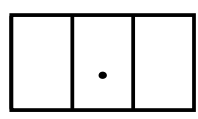

by you

Decision based completely

Decision based completely by you
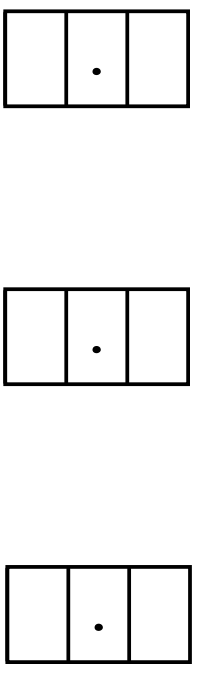

Decision based completely by you

6. Decisions about how much activity your child has while away from home.

Decision based completely by parents

Decision based completely by you
Decision based completely by you

7. Decisions about what foods are bought for meals at home.

Decision based completely

by parents

Decision based completely
by you
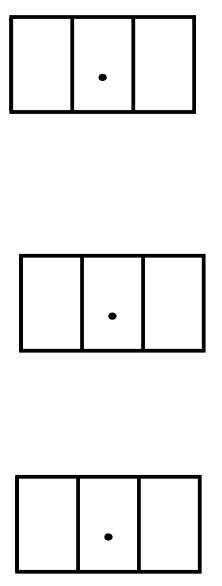
8. Decisions to modify meal plans.

$\begin{array}{lc}\text { Decision based completely } & \text { Decision based completely } \\ \text { by parents } & \text { by you }\end{array}$

9. Decisions to eat out.

Decision based completely by parents
Decision based completely by you

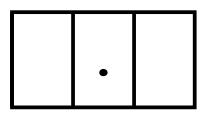

Q - 42 Compared to other children the same age and gender, how would you describe your child's weight (fill in only one):

$$
\begin{aligned}
& \text { O very underweight } \\
& \text { O slightly underweight } \\
& \text { O about the right weight } \\
& \text { O slightly overweight } \\
& \text { O very overweight }
\end{aligned}
$$

Please complete each question based on activities that have happened since you began the program.

\begin{tabular}{|c|c|c|c|}
\hline O never & O rarely & O sometimes & O often \\
\hline O ne & O rarely & O sometimes & O often \\
\hline
\end{tabular}

\section{Q - 43 Physical Activity}

On average, how often does your child do these activities in a day?

$\begin{array}{llllll}\text { Walking } & \text { O never } & \text { O rarely } & \text { O sometimes } & \text { O often } & \text { O always } \\ \text { Running } & \text { O never } & \text { O rarely } & \text { O sometimes } & \text { O often } & \text { O always } \\ \text { Skipping } & \text { O never } & \text { O rarely } & \text { O sometimes } & \text { O often } & \text { O always } \\ \text { Jumping } & \text { O never } & \text { O rarely } & \text { O sometimes } & \text { O often } & \text { O always } \\ \text { Dancing } & \text { O never } & \text { O rarely } & \text { O sometimes } & \text { O often } & \text { O always } \\ \text { Climbing } & \text { O never } & \text { O rarely } & \text { O sometimes } & \text { O often } & \text { O always }\end{array}$

Other Outdoor Activities:

Q - 44 Diet \& Nutrition

Food Item Average Number

Eaten Each Day

$\begin{array}{lllllll}\text { Fruits } & \text { O never } & \text { O rarely } & \text { O sometimes } & \text { O often } & \text { O always } \\ \text { Vegetables } & L & \text { O never } & \text { O rarely } & \text { O sometimes } & \text { O often } & \text { O always } \\ \text { Meats } & \text { O never } & \text { O rarely } & \text { O sometimes } & \text { O often } & \text { O always } \\ \text { Breads } & \text { O never } & \text { O rarely } & \text { O sometimes } & \text { O often } & \text { O always } \\ \text { Sweets } & \text { O never } & \text { O rarely } & \text { O sometimes } & \text { O often } & \text { O always }\end{array}$




\section{- E: \\ 6268}

\section{Q-45 Please check the one answer that best fits your experience}

1. Body mass index $(\mathrm{BMI})$ is:

2. What BMI percentage is considered at risk for overweight?

3. What is a pedometer?
O the proportion between an individual's weight and height $O$ a measure of the amount of physical activity $O$ a measure of muscle mass
$0<50$ th percentile

$O>85$ th percentile

O between the 3rd and 5th percentile

O tool used to measure an individual's BMI

$O$ tool used to measure an individual's muscle mass

$O$ tool used to measure the number of steps an individual takes

4. Did you know how to use a pedometer before you started this program?

O yes Ono

5. How much time, on average, do you set aside each day to participate in physical activity with your family?

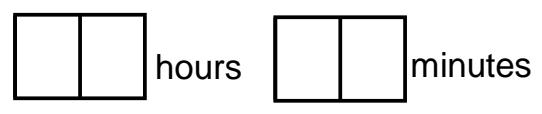

6. Did you help your child set goals to reach in terms of increased physical activity?

O yes $\quad$ no

7. Did you encourage your child to be more physically active?

O yes $\quad$ no

8. Did you encourage your child to eat healthier?

O yes O no

9. Did you use sweets as a reward?

O yes $\quad O$ no

10. Did you think about ways to cut your child's calories?

O yes $\quad$ no

11. Did you think about ways to increase steps in a day?

O yes $\quad$ no

12. Did you see an increase in physical activity/steps while your child was wearing a pedometer?

O yes $\quad$ no

13. Looking over the completed daily step log, were you concerned with the amount of physical activity your child is getting?

O yes $\quad$ no

14. Since participating, have your child's nutrition habits improved?

O yes O no

15. Did you feel wearing a pedometer motivated your child to participate in more $\quad$ yes $\quad$ no physical activity?

16. Is your child still wearing his/her pedometer?

O yes $\quad$ no 
Q-45. Does your child currently have a regular dental provider (i.e., dentist)?

OYES ONO

\section{Q-46. Has your child ever received care from a dentist?}

Please check the one statement that best describes your child's dental experience.

O YES

My child needed emergency dental care.

O I wanted my child to meet our dentist and get used to visits.

My physician recommended that we arranage a dental visit for my child.

I wanted my child to see the dentist to protect against cavities and other problems.

Other
ONO

It is too early to take my child to the dentist.

$\mathrm{O}$ I don't have a dentist in my area.

It costs too much to go to the dentist.

My child is scared of the dentist or dentist's office.

I don't have time to take my child to the dentist.

I don't have a way to get to the dentist.

I don't know how to find a dentist.

Q-47. On average, how many times per day does your child do the following:

O Brush his/her teeth

\# of times per day

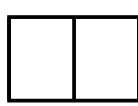

O Floss his/her teeth

\# of times per day

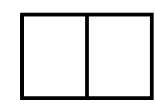

Q-48. My child's teeth affect his/her overall health.

O Strongly disagree

O Disagree

O Agree

O Strongly agree
Q-49. It is important to have my child's teeth checked by the dentist at least once a year.

O Strongly disagree

O Disagree

O Agree

O Strongly agree
Q-50. I would be able to take my child to the dentist if I needed to.

O Strongly disagree

O Disagree

O Agree

O Strongly agree
Q-51. Over the next 4 months, I plan to take my child to see the dentist.

O Strongly disagree

O Disagree

O Agree

O Strongly agree 


\section{Appendix D: Cardiac Questionnaire 2007-2008}

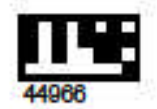

DATE:

\author{
2007-2008 Parent Post-Assessment \\ Environmental Determinants of Physical Activity in Children \\ -Please fill in entire answer circle-
}

Q-1. Does your child have any medical conditions or disabilities that limit his or her physical activity?

ONo OYes, please specify:

Q-2. Compared to other children of the same age and sex, how would you describe your child's level of physical activity? (circle one number)

O Much less than others

O Somewhat less than others

O About the same

Somewhat more than others

O Much more than others

Q-3. In your opinion, does your child generally get more than enough, about the right amount, or not enough physical activity?

O More than enough

A About the right amount

O Not enough

Q-4. Compared to other children the same age and sex, how would you describe your child's level of athletic coordination?

Much less coordinated

Somewhat less coordinated

O About the same

O Somewhat more coordinated

O Much more coordinated

Q-5. Please list your child's THREE favorite activities:

Q-5-b. How much does your child enjoy physical activity?

O Physical activity is not enjoyable at all

O Physical activity is a little enjoyable

O Neutral

Q Physical activity is somewhat enjoyable

- Physical activity is very enjoyable

Q-6. What does your child usually do when he or she has a choice about how to spend their free time?

O Almost always chooses sedentary activities, such as watching TV, playing video games, or reading

U Usually chooses sedentary activties, such as watching TV, playing video games, or reading.

O Just as likely to choose physically active play as inactive recreation.

Osually chooses physically active play.

O Almost always chooses physically active play. 
Q-7. On an average WEEK day (Monday-Friday), how many hours does your child watch TV or play video games?

O Less than 1 hour per day

O Between 1 and 2 hours per day

O Between 2 and 3 hours per day

$O$ Between 3 and 4 hours per day

Between 4 and 5 hours per day

O More than 5 hours per day

Q-8. On an average WEEKEND day (Saturday and Sunday), how many hours does your child watch TV or play video games?

$O$ Less than 1 hour per day

Between 1 and 2 hours per day

Between 2 and 3 hours per day

Between 3 and 4 hours per day

Between 4 and 5 hours per day

More than 5 hours per day

Q-9. Which items do you have in your home, yard, or apartment complex?

O Basketball hoop

O Tricycle/Bicycle

O Big yard, empty lot, field

O Exercise video tapes

O Frisbee

O Sandbox

O Swings

O Hula Hoop

O Jump Rope

O Jungle Gym

Rowing machine
O Skateboard

O Skates (roller, in line, or ice)

O Sports equipment (bats, balls, racquets)

O Stair climber

O Step aerobics, slide aerobics

O Stationary bicycle

O Swiming pool

O Trampoline

O Treadmill

O Weight lifting equipment

Other, please specify

Q-10. How far from your home is the nearest public park where your child can be physically active or play sports:

O Less than 1 mile

O 1 - 2 miles

O 2 - 5 miles

O 5 - 10 miles

More than 10 miles

Q-11. The nearest park has a reputation of being:

O Very unsafe

O Somewhat unsafe

O Neutral

O Somewhat safe

Very safe
Q-12. How often do you take your child to this park?

O Never

O 1-2 times per month

O 3-7 times per month

O 8-14 times per month

O 14 or more times per month 
DURING A TYPICAL WEEK HOW OFTEN DOES A MEMBER OF YOUR HOUSEHOLD:

Q-13. Encourage your child to do physical activity or play outside?

$\begin{array}{ccccc}\text { Never } & \text { Once } & \text { Sometimes } & \begin{array}{c}\text { Almost } \\ \text { Daily }\end{array} & \text { Daily } \\ 0 & 0 & 0 & \odot & 0 \\ 0 & 0 & 0 & \odot & 0 \\ 0 & 0 & 0 & \odot & 0\end{array}$

Q-14. Play out side or do physical activity with your child?

$\begin{array}{llllll}\text { Myself } & 0 & 0 & 0 & 0 & 0 \\ \text { Other adult - male } & 0 & \odot & 0 & \odot & 0 \\ \text { Other adult - female } & 0 & 0 & 0 & 0 & 0\end{array}$

Q-15. Provide transportation to a place where he or she can do physical activity or play?

\begin{tabular}{|c|c|c|c|c|}
\hline Myself & ○ & (2) & (3) & ๑) \\
\hline Other adult - male & (1) & (2) & (3) & (๑) \\
\hline Other adult - female & (1) & (2) & (3) & () \\
\hline
\end{tabular}

Q-16. Watch your child participate in physical activities or outdoor games?

\begin{tabular}{|c|c|c|c|c|}
\hline Myself & ○ & (2) & (3) & ๑ \\
\hline Other adult - male & (1) & (2) & (3) & (4) \\
\hline Other adult - female & (1) & (2) & (3) & () \\
\hline
\end{tabular}

Q-17. Tell your child that physical activity is good for his or her health?

$\begin{array}{llllll}\text { Myself } & \odot & 0 & \odot & \odot & 0 \\ \text { Other adult - male } & \odot & \odot & \odot & \odot & \odot \\ \text { Other adult - female } & \odot & \odot & \odot & \odot & 0\end{array}$

Q-18 How important is it to the adults in your household that your child is good at sports and physical activities?

\begin{tabular}{lccccc} 
& \multicolumn{2}{c}{ Unimportant } & \multicolumn{2}{c}{ Important } \\
Myself & Very & Somewhat & Neutral & Somewhat & Very \\
Other adult - male & 0 & 0 & 0 & $\odot$ & 0 \\
Other adult - female & 0 & 0 & 0 & 0 & 0 \\
& 0 & 0 & 0 & $\odot$ & 0
\end{tabular}

Q-19 How much do the adults in your family enjoy particpiating in sports or exercise?

\begin{tabular}{lccccc} 
& \multicolumn{2}{c}{ Unimportant } & \multicolumn{2}{c}{ Important } \\
& Very & Somewhat & Neutral & Somewhat & Very \\
Myself & 0 & 0 & 0 & $\odot$ & 0 \\
Other adult - male & 0 & 0 & 0 & 0 & 0 \\
Other adult - female & 0 & 0 & 0 & 0 & $\odot$
\end{tabular}


THE FOLLOWING QUESTIONS ASK ABOUT YOUR OWN PHYSICAL ACTIVITY.

Q-20. On how many of the past 7 days did YOU exercise or participate in sports activities for at least 20 minutes that made you sweat and breathe hard, such as basketball, soccer, running, swimming, laps, fast bicycling, fast dancing, or similar aerobic activites?
O 0 days
O 4 days
O 1 day
O 5 days
O 2 days
O 6 days
O 3 days
O 7 days

Q-21. On how many of the past 7 days did YOU participate in physical activity for at least $\mathbf{3 0}$ minutes that did NOT make you sweat or breathe hard, such as fast walking, slow bicycling, skating, pushing a lawn mower, or mopping floors?
O 0 days
O 4 days
O 1 day
O days
O 2 days
O 6 days
O 3 days
O 7 days

Q-22. On how many of the past 7 days did YOU do exercises to strengthen or tone your muscles, such as push-ups, sit-ups, or weight lifting?
O 0 days
O 4 days
O 1 day
O 5 days
O 2 days
O days
O 3 days
O 7 days

Q-23. Please rate your OWN phypsical activity level using a scale of 0 to 10 . A 10 means "You are in such good shape, you could be training for the Olympics", and 0 means "You hardly get off the couch."
$00 \quad 0$
$02 \quad 03$
$\bigcirc 4$
O 5
O 6
07
08
O9 O 10

Q-23-b. Please list your THREE favorite activities:

Q-24. How do you describe YOUR OWN weight?

O Very underweight

O Slightly underweight

O About the right weight

O Slightly overweight

$\mathrm{O}$ Very overweight

Q-25. What is YOUR height?
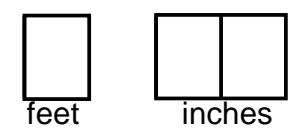

Q-26 What is YOUR weight?

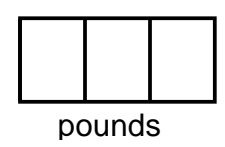




\section{THE FOLLOWING QUESTIONS ASK ABOUT YOUR SPOUSE'S PHYSICAL ACTIVITY LEVEL.} IF YOU DO NOT HAVE A SPOUSE PLEASE GO DIRECTLY TO QUESTION Q-38.

Q-27. On how many of the past 7 days did your spouse (or the other adult who lives in your house) exercise or participate in sports activities for at least $\mathbf{2 0}$ minutes that made you sweat and breathe hard, such as basketball, soccer, running, swimming laps, fast bicycling, fast dancing, or similar aerobic activites?
O 0 days
O 4 days
O 1 day
O 5 days
O 2 days
O 6 days
O 3 days
O 7 days

Q-28. On how many of the past 7 days did your spouse (or the other adult who lives in your house) participate in physical activity for at least $\mathbf{3 0}$ minutes that did NOT make you sweat or breathe hard, such as fast walking, slow bicycling, skating, pushing a lawn mower, or mapping floors?
O 0 days
O 4 days
O 1 day
O 5 days
O 2 days
O 6 days
O 3 days
O 7 days

Q-29. On how many of the past 7 days did your spouse (or the other adult who lives in your house) do exercises to strengthen or tone your muscles, such as push-ups, sit-ups, or weight lifting?
O 0 days
O 4 days
O 1 day
O 5 days
O 2 days
O 6 days
O 3 days
O 7 days

Q-30. Please rate your spouse's (or other adult who lives in your house) physical activity level using a scale of 0-10. A 10 means "You are in such good shape, you could be training for the Olympics", and 0 means "You hardly get off the couch."
O 0
O 1
O 203
O 4
O 5
O 6
$\bigcirc$
O 8
O9 O 10

Q-31 How do you describe your spouse's weight?
O Very underweight
O Slightly underweight
O About the right weight
O Slightly overweight
$O$ Very overweight

Q-32. What is your spouse's height?
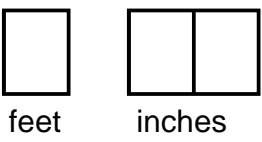

Q-33 What is your spouse's weight?

inches

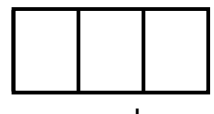

pounds 
Q-34 Which of the following categories includes the age of yourself and other adults in the household.

\begin{tabular}{|c|c|c|c|c|c|c|c|}
\hline Myself & O Under 25 & O 25-34 & O 35-44 & O 45-54 & 55-64 & O 65-74 & O 75 or over \\
\hline Other Adult Male & Under 25 & 25-34 & O $35-44$ & O $45-54$ & 55-64 & 65-74 & 75 or over \\
\hline Other Adult Female & Under 25 & O 25-34 & O $35-44$ & O 45-54 & 55-64 & O $65-74$ & O 75 \\
\hline
\end{tabular}

Q-35. My current residence is best described as:

O Single family house

O Apartment

O Duplex

O Condominium/Townhouse

Q-36. Who is the main person completing this form?
O Mother
O Other adult female
O Father
O Other adult male

Q-37 In the past 2 months, how often have you done the following:

\begin{tabular}{|c|c|c|c|c|}
\hline \multicolumn{2}{|l|}{ tn } & \multicolumn{3}{|c|}{ Most } \\
\hline Never & Rarely & Sometimes & Often & Always \\
\hline 01 & O 2 & 03 & $\bigcirc 4$ & O 5 \\
\hline O 1 & O 2 & O 3 & O 4 & O 5 \\
\hline 01 & 02 & 03 & O 4 & 05 \\
\hline 01 & 02 & 03 & 04 & 05 \\
\hline O 1 & O 2 & 03 & $\bigcirc 4$ & O 5 \\
\hline 01 & 02 & 03 & O 4 & 05 \\
\hline
\end{tabular}

Q-38 In the next 4 months, do you think your child will do the following:

1. Established regular meal times.

Yes No

Don't Know

1. Eat unhealthy foods or not enough healthy foods

O 1

O 2

O 3

2. Have limited opportunity to engage in vigorous exercise while at home

$01 \quad 02 \quad 03$

3. Have limited opportunity to engage in moderate exercise

01

O 2

03 while at home

4. Have limited opportunity to engage in vigorous exercise while outside of home

01

O 2

03

5. Have limited opportunity to engage in moderate exercise while outside of home

$01 \quad 02 \quad 03$ 
Q-39 To what extent do you think your child can independently decide:

Never Rarely Sometimes Often Always

$\begin{array}{llllll}\text { 1. What to eat while at home } & 01 & 02 & 03 & 04 & 05\end{array}$

2. What to eat while outside of home

$\begin{array}{lllll}01 & 02 & 03 & 04 & 05\end{array}$

3. How active to be while at home

$\begin{array}{lllll}01 & 02 & 03 & 04 & 05\end{array}$

4. How active to be while outside of home

O 4

05

5. What activities to do while at home

1

02

○ 3

O 4

05

6. What activities to do while outside of home

$01 \quad 02 \quad 03$

O 4

05

Q-40 How much does each of the following fit your style of parenting?

1. I always tell my child what to do

2. I make rules without asking my child

3. I am too busy to talk to my child

4. I listen to what my child has to say

5. I make my child feel better when he/she is upset

6. I like my child just the way he/she is

7. I tell my child when he/she does a good job on things

8. I want to hear about my child's problems

9. I am pleased with how my child behaves

10. I have rules that my child must follow

11. I tell my child what time he/she must come home

12. I make my child tell me where he/she is going

13. I make sure that my child goes to bed on time

14. I ask my child what he/she does with friends

15. I know where my child is after school

16. I check to see if my child did his/her homework

$\begin{array}{cc}\text { Just like } & \text { A lot like } \\ \text { mine } & \text { mine }\end{array}$

01

O 2

O 1

O 2

O 2

O 2

O 2

O 2

03

O 4

01

O 2

03

O 4

01

O 2

03

O 4

01

O 2

O 3

O 4

01

O 2

03

O 4

01

O 2

03

$\bigcirc 4$

01

O 2

O 3

O 4

01

O 2

03

O 4

01

O 2

03

O 4

01

O 2

03

O 4

01

O 2

03

O 4 
Q-41. Directions: Make a verticle line at the point where you make the decisions, in your home.

EXAMPLE: $\quad$ Who makes the decisions about what your child wears.

\begin{tabular}{l|c}
\hline $\begin{array}{l}\text { Decision based completely } \\
\text { by parents }\end{array}$ & $\begin{array}{c}\text { Decision based completely } \\
\text { by child }\end{array}$
\end{tabular}

1. Decisions about what your child eats while at home.

Decision based completely by parents
Decision based completely by child

2. Decisions about what your child eats while away from home.
Decision based completely
by parents
Decision based completely
by child

3. Decsisions about the type of physcial activities your child engages in while at home.

Decision based completely

by parents

Decision based completely

by child

4. Decisions about the type of physical activities your child engages in while away from home.

$\begin{array}{lc}\text { Decision based completely } & \begin{array}{c}\text { Decision based completely } \\ \text { by parents }\end{array}\end{array}$

5. Decisions about how much activity your child has while at home.

$\begin{array}{lc}\text { Decision based completely } & \text { Decision based completely } \\ \text { by parents } & \text { by child }\end{array}$

6. Decisions about how much activity your child has while away from home.

Decision based completely by parents

Decision based completely by child

7. Decisions about what foods are bought for meals at home.

Decision based completely

by parents
Decision based completely by child
For office
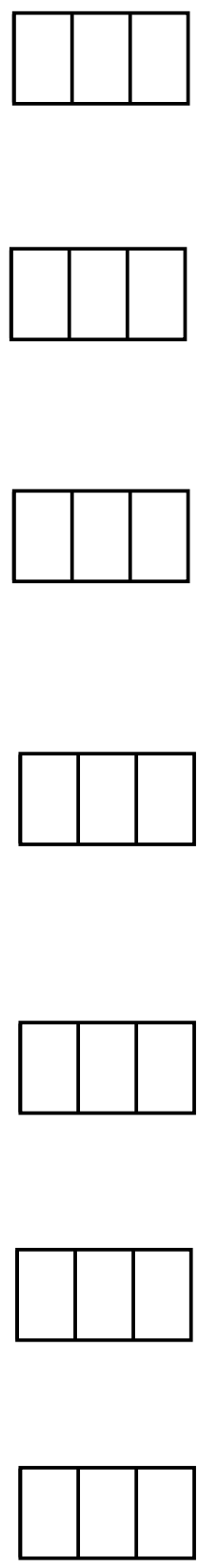
8. Decisions to modify meal plans.

$\begin{array}{lc}\text { Decision based completely } & \text { Decision based completely } \\ \text { by parents } & \text { by child }\end{array}$

9. Decisions to eat out.

Decision based completely

by parents

Decision based completely

by child

Q - 42 Compared to other children the same age and gender, how would you describe your child's weight (fill in only one):

$$
\begin{aligned}
& \text { O very underweight } \\
& \text { O slightly underweight } \\
& \text { Obout the right weight } \\
& \text { O slightly overweight } \\
& \text { O very overweight }
\end{aligned}
$$

\section{Q - 43 Physical Activity}

\begin{tabular}{|c|c|c|c|c|c|c|}
\hline Fruits & L & O never & O rarely & O sometimes & O often & O always \\
\hline Vegetables & 1 & O never & O rarely & O sometimes & O often & O always \\
\hline Meats & & O never & O rarely & O sometimes & O often & O always \\
\hline reads & $L$ & O never & O rarely & O sometimes & O often & O always \\
\hline Sweets & لـ & O never & O rarely & O sometimes & O often & O always \\
\hline
\end{tabular}

On average, how often does your child do these activities in a day?

$\begin{array}{llllll}\text { Walking } & \text { O never } & \text { O rarely } & \text { O sometimes } & \text { O often } & \text { O always } \\ \text { Running } & \text { O never } & \text { O rarely } & \text { O sometimes } & \text { O often } & \text { O always } \\ \text { Skipping } & \text { O never } & \text { O rarely } & \text { O sometimes } & \text { O often } & \text { O always } \\ \text { Jumping } & \text { O never } & \text { O rarely } & \text { O sometimes } & \text { O often } & \text { O always } \\ \text { Dancing } & \text { O never } & \text { O rarely } & \text { O sometimes } & \text { O often } & \text { O always } \\ \text { Climbing } & \text { O never } & \text { O rarely } & \text { O sometimes } & \text { O often } & \text { O always }\end{array}$

\section{Q - 44 Diet \& Nutrition}

$\begin{array}{ll}\text { Food Item } & \text { Average Number } \\ & \text { Eaten Each Day }\end{array}$




\section{口}

44966

\section{Q-45 Please check the one answer that best fits your experience}

1. Body mass index (BMI) is:

2. What BMI percentage is considered at risk for overweight?

3. What is a pedometer?
O the proportion between an individual's weight and height $O$ a measure of the amount of physical activity $\mathrm{O}$ a measure of muscle mass

$0<50$ th percentile

$O>85$ th percentile

O between the 3rd and 5th percentile

O tool used to measure an individual's BMI

O tool used to measure an individual's muscle mass

$O$ tool used to measure the number of steps an individual takes

4. Do you know how to use a pedometer? O Yes O No

5. How much time, on average, do you set aside each day to participate in physical activity with your family?

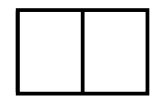
hours

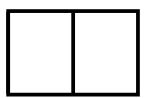
minutes

6. Do you help your child set goals to reach in terms of increased physical activity?

O yes O no

7. Do you encourage your child to be more physical active?

O yes O no

8. Do you encourage your child to eat healthier?

O yes O no

9. Do you use sweets as a reward?

O yes O no

10. Do you think about ways to cut your child's calories?

O yes O no

11. Do you think about ways to increase steps in a day?

O yes $\quad$ no

Q-46 Did the reminder system (phone call, email, etc) remind you to do more daily steps?

O No, the reminder did not make me want to do any more steps than I would normally do O Yes, the reminder made me want to do a little more steps than I would normally do O Yes, the reminder made me want to do some more steps than I would normally do O Yes, the reminder made me want to do a lot more steps than I would normally do O No, I did not participate in the reminder system

Q-47 Did wearing a pedometer (the thing that measured your daily steps) remind you to do more activity in your day than you normally would?
O NO
O YES

Q-48 Did you think a phone call each week was a good reminder to do more activity during the week?

O No, a phone call was not a good reminder to do more activity each week

O Yes, a phone call was an okay reminder to do more activity each week

O Yes, a phone call was a great reminder to do more activity each week 
Q-50 Is there something else that would be a better reminder to do as many steps as you can during the day?

Q-52. For each pair of activities listed below, please choose the one YOU most prefer:

$\begin{array}{lll}\text { O Watching TV } & \text { or } & \text { O Jogging/Walking } \\ \text { O Reading } & \text { or } & \text { O Riding bike } \\ \text { O Sports } & \text { or } & \text { O Watching TV } \\ \text { O Crafts } & \text { or } & \text { O Sports } \\ \text { O Watching TV } & \text { or } & \text { O Riding bike } \\ \text { O Crafts } & \text { or } & \text { O Jogging/Walking } \\ \text { O Reading } & \text { or } & \text { O Sports } \\ \text { O Jogging/Walking } & \text { or } & \text { O Reading } \\ \text { O Riding bike } & \text { or } & \text { O Crafts }\end{array}$

Q-53. For each pair of activities listed below, please choose the one your CHILD most prefers:
O Watching TV
or
O Jogging/Walking
O Reading
or
O Riding bike
O Sports
or
O Watching TV
O Crafts
or
O Sports
O Watching TV
or
O Riding bike
O Crafts
or
O Jogging/Walking
O Reading
or
O Sports
○ Jogging/Walking
or
○ Reading
o Riding bike
or
O Crafts 
Q-54 Does your child currently have a regular dental provider (i.e., dentist)?

OYES O NO

Q-55 Since you completed the last survey has your child received care from a dentist?

Please check the one statement that best describes your child's dental experience.

OYES

My child needed emergency dental care

I wanted my child to meet our dentist and get used to visits.

My physician recommended that we arrange a dental visit for my child

I I wanted my child to see the dentist to protect against cavities and other problems.

O Other
ONO

It is too early to take my child to the dentist.

O I don't have a dentist in my area.

It costs too much to go to the dentist.

My child is scared of the dentist or dentist's office.

O I don't have time to take my child to the dentist.

O I don't have a way to get to the dentist.

O I don't know how to find a dentist.

Q-56 On average, how many times per day does your child do the following:

O Brush his/her teeth

\# of times per day

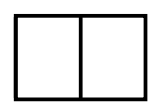

O Floss his/her teeth \# of times per day

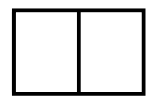

Q-58 It is important to have my child's teeth checked by the dentist at least once a year.
O Strongly disagree
O Disagree
O Agree
O Strongly agree

Q-60 Over the next 4 months, I plan to take my child to see the dentist. dentist if I needed to.
O Strongly disagree
O Disagree
O Agree
O Strongly agree

O Strongly disagree

O Disagree

O Agree

O Strongly agree 


\section{Appendix E: Components of Cardiac Questionnaire}

Components of CARDIAC Questionnaire Operationalized in Health Belief Model

\begin{tabular}{|c|c|c|}
\hline Individual Perceptions & Modifying factors & Actions \\
\hline Parental Perceptions & Demographic Factors & $\begin{array}{l}\text { Likelihood of Change in Food } \\
\text { provision and consumption } \\
\text { patterns }\end{array}$ \\
\hline $\begin{array}{l}\text { RQ1: Parental Perception of } \\
\text { their child's weight status: } \\
\text { Accurate/Inaccurate } \\
\text { Q42 } \\
\text { RQ3: Relationship of parental } \\
\text { perception of their Child's } \\
\text { weight status related to } \\
\text { parent's self-reported weight } \\
\text { status Q } 42 \text { related tp Q 24, } \\
\text { 25, 26. } \\
\text { RQ5: Accuracy of self- } \\
\text { perceived weight status on } \\
\text { parents as compared to their } \\
\text { own weight status. Q24: Q25, } \\
\text { Q26 } \\
\text { RQ6: Predictors of accuracy } \\
\text { in parental perception of their } \\
\text { child's weight status as } \\
\text { determined by relationship of } \\
\text { modifying demographic } \\
\text { factors to accurate/inaccurate } \\
\text { prediction }\end{array}$ & $\begin{array}{l}\text { RQ2: demographic } \\
\text { Socio-economic status } \\
\text { Questionnaire compared to US } \\
\text { census stats } \\
\text { Education Questionnaire } \\
\text { Rurality : Us Census maps } \\
\text { related to county of school } \\
\text { Parental Weight StatusQ24, } \\
\text { 25, } 26 \\
\text { Race/Ethnicity Questionnaire } \\
\text { Child's gender questionnaire }\end{array}$ & $\begin{array}{l}\text { Likelihood of Change in } \\
\text { Parental Food Provision and } \\
\text { Eating Behaviors. } \\
\text { Present Food provision and } \\
\text { consumption patterns } \\
\text { described as: RQ4: } \\
\text { Q: } 37 \text { : 1, established regular } \\
\text { meal times } \\
\text { 2. Required family to eat as a } \\
\text { group } \\
\text { 6. Talked to your child about } \\
\text { his/her eating habits } \\
\text { Q39: 1, What to eat while at } \\
\text { home } \\
\text { 2. What to eat while outside of } \\
\text { the home } \\
\text { Q45: } 8 \text {. Do you encourage } \\
\text { your child to eat healthier? } \\
\text { 9. Do you use sweets as a } \\
\text { reward? }\end{array}$ \\
\hline
\end{tabular}




\section{Appendix F: Components of Cardiac Questionnaire}

Rural-Urban Commuting Areas (RUCAs), 2000

1 Metropolitan area core: primary flow within an urbanized area (UA)

$1.0 \quad$ No additional code

1.1 Secondary flow $30 \%$ to $50 \%$ to a larger UA

2 Metropolitan area high commuting: primary flow $30 \%$ or more to a UA

2.0 No additional code

2.1 Secondary flow $30 \%$ to $50 \%$ to a larger UA

3 Metropolitan area low commuting: primary flow $5 \%$ to $30 \%$ to a UA

3.0 No additional code

4 Micropolitan area core: primary flow within an Urban Cluster of 10,000 to 49,999 (large UC)

4.0 No additional code

4.1 Secondary flow $30 \%$ to $50 \%$ to a UA

4.2 Secondary flow $10 \%$ to $30 \%$ to a UA

5 Micropolitan high commuting: primary flow $30 \%$ or more to a large UC

5.0 No additional code

5.1 Secondary flow $30 \%$ to $50 \%$ to a UA

5.2 Secondary flow $10 \%$ to $30 \%$ to a UA

6 Micropolitan low commuting: primary flow $10 \%$ to $30 \%$ to a large UC

6.0 No additional code

6.1 Secondary flow $10 \%$ to $30 \%$ to a UA

7 Small town core: primary flow within an Urban Cluster of 2,500 to 9,999 (small UC)

7.0 No additional code

7.1 Secondary flow $30 \%$ to $50 \%$ to a UA

7.2 Secondary flow $30 \%$ to $50 \%$ to a large UC

7.3 Secondary flow $10 \%$ to $30 \%$ to a UA

7.4 Secondary flow $10 \%$ to $30 \%$ to a large UC

8 Small town high commuting: primary flow $30 \%$ or more to a small UC

8.0 No additional code

8.1 Secondary flow $30 \%$ to $50 \%$ to a UA

8.2 Secondary flow $30 \%$ to $50 \%$ to a large UC

8.3 Secondary flow $10 \%$ to $30 \%$ to a UA

8.4 Secondary flow $10 \%$ to $30 \%$ to a large UC

9 Small town low commuting: primary flow $10 \%$ to $30 \%$ to a small UC 
9.0 No additional code

9.1 Secondary flow $10 \%$ to $30 \%$ to a UA

9.2 Secondary flow $10 \%$ to $30 \%$ to a large UC

10 Rural areas: primary flow to a tract outside a UA or UC

10.0 No additional code

10.1 Secondary flow $30 \%$ to $50 \%$ to a UA

10.2 Secondary flow $30 \%$ to $50 \%$ to a large UC

10.3 Secondary flow $30 \%$ to $50 \%$ to a small UC

10.4 Secondary flow $10 \%$ to $30 \%$ to a UA

10.5 Secondary flow $10 \%$ to $30 \%$ to a large UC

10.6 Secondary flow $10 \%$ to $30 \%$ to a small UC 


\section{Appendix G: HBM Permission}

Aith American Journal of Public Health

Publications Department

December 14, 2009

Jill D. Cochran, MSN, RN-BC, FNP

Robert C. Byrd Clinic

jicochran@suddenlink.net

Requested Material: Becker MH, Drachman RH, Kirsch JP. A new approach to explaining sick-role behavior in lowincome populations. Am J Public Health. 1974;64:205-216. (Fig. 1, p. 206)

Dear Ms. Cochran,

The American Public Health Association is pleased to grant you non-exclusive rights and non-transferable permission, limited to the format specified in this letter, and provided you meet our criteria. Such permission is for one-time print rights of the above figure to be included in your dissertation for West Virginia University. Unless otherwise specified, the permission does not cover future editions, revisions, additional printings, updates, ancillaries, customized forms, any electronic forms, Braille editions, translations, or promotional pieces unless otherwise specified. APHA must be contacted for permission each time such use is planned. This permission does not include the right to modify the material. Use of the material must not imply any endorsement by the copyright owner. CREDIT LINE(S) (author, title of article, title of Journal, volume and issue number, page range, year, publisher) must be published next to the figure.

Limitation of Liability and Disclaimer of Warranty

The American Public Health Association makes no warrantees with respect to the material presented here or the material for which permission is being granted; do not assume any expressly disclaim and liability for any loss or damage caused by errors or omissions whether such error or omissions result from negligence, accident or otherwise; and specifically disclaim any warranty of quality, performance, merchantability or fitness for a specific purpose. In no event will The American Public Health Association be liable for any direct, indirect, special, incidental or consequential damages, including without limitation any lost profits, lost savings, lost revenues, loss of data, or costs of recovery, arising out of the use of or inability to use the material, regardless of whether such losses are foreseeable or whether such damages are deemed to result from the failure or inadequacy of any exclusive or other remedy.

A full citation must be given, and the American Public Health Association acknowledged as the copyright holder. There is a fee of $\$ 55$ for use of the above figure. To secure this permission, please confirm with me via email and submit payment within 60 days along with a copy of this statement to: APHA; Accounting Department; 800 I Street, NW; Washington, DC 20001. You may also fax or mail the credit card form to my attention. APHA's Federal ID is 13-1628 688. Permission takes effect and is considered finalized once payment is received. Please indicate "Permissions Request" on check, as well as the reference \#: P3240 APHA AJPH 6431974 Becker Cochran.

Thank you for contacting the American Public Health Association. If I can be of further assistance, please don't hesitate to contact me.

Sincerely,

Maya Ribault, Permissions \& Licensing Coordinator

American Public Health Association

800 I Street, NW

Washington, DC 20001-3710

Tel. 202/777-2465 * Fax 202/777-2531

maya.ribault@apha.org 


\section{Appendix H: Permission for Cardiac Questionnaire}

\section{WEST VIRGINIA UNTVERSITY \\ SCHOOL OF MEDICINE}

April 14, 2011

Dr. Jill Cochran

Robert C. Byrd Clinic

400 North Jefferson

Lewisburg, WV 24901

Dear Dr. Cochran,

As the Director of the Coronary Artery Risk Detection in Appalachian Communities (CARDIAC) Project, 1 give you permission to reproduce the CARDIAC screening form with appropriate attributions within your approved dissertation document. I understand that giving you this permission allows you to illustrate the items you used in your dissertation project and feel this is an important element of presenting your findings.

Please do not hesitate to contact me about this permission or related qualifications at 304 293-2416 or wneal@hsc.wvu.edu.

Sincerely,

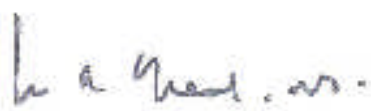

William A. Neal, MD

Director, CARDIAC Project

John $\mathrm{H}$.

Hagen
Digitally signed by John $\mathrm{H}$. Hagen DN: cn=John H. Hagen, o=West Virgin University Libraries, ou=Acquisitions
Department Department,
email=John.Hagen@mail.wvu.ed c=uls
Date: 2011.05.03 19:28:09 -04'00' 